\title{
Documentation of Short Stack and Button Cell Experiments Performed at INL and Ceramatec During FY 07
}

\author{
J. E. O'Brien \\ C. M. Stoots \\ J. J. Hartvigsen \\ J. S. Herring
}

September 2007

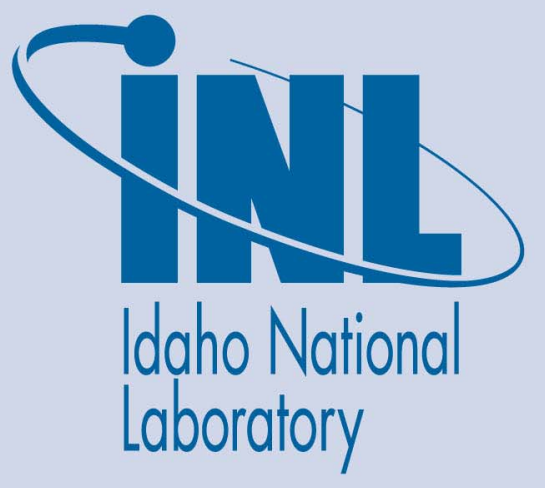

The INL is a U.S. Department of Energy National Laboratory operated by Battelle Energy Alliance 
INL/EXT-07-13574

\title{
Documentation of Short Stack and Button Cell Experiments Performed at INL and Ceramatec During FY 07
}

\author{
J. E. O'Brien \\ C. M. Stoots \\ J. J. Hartvigsen \\ J. S. Herring
}

September 2007

Idaho National Laboratory
Idaho Falls, Idaho 83415

Prepared for the

U.S. Department of Energy

Office of Nuclear Energy

Under DOE Idaho Operations Office

Contract DE-AC07-05ID14517 


\section{ABSTRACT}

This report provides documentation of experimental research activities performed at the Idaho National Laboratory and at Ceramatec, Inc. during FY07 under the DOE Nuclear Hydrogen Initiative, High Temperature Electrolysis Program. The activities discussed in this report include tests on single (button) cells, short planar stacks and tubular cells. The objectives of these small-scale tests are to evaluate advanced electrode, electrolyte, and interconnect materials, alternate modes of operation (e.g., coelectrolysis), and alternate cell geometries over a broad range of operating conditions, with the aim of identifying the most promising material set, cell and stack geometry, and operating conditions for the high-temperature electrolysis application. Cell performance is characterized in terms of initial area-specific resistance and long-term stability in the electrolysis mode. Some of the tests were run in the coelectrolysis mode. Research into coelectrolysis was funded by Laboratory Directed Research and Development (LDRD). Coelectrolysis simultaneously converts steam to hydrogen and carbon dioxide to carbon monoxide. This process is complicated by the reverse shift reaction. An equilibrium model was developed to predict outlet compositions of steam, hydrogen, carbon dioxide, and carbon monoxide resulting from coelectrolysis. Predicted compositions were compared to measurements obtained with a precision micro-channel gas chromatograph. 


\section{TABLE OF CONTENTS}

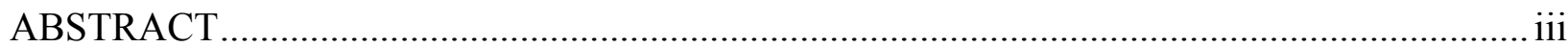

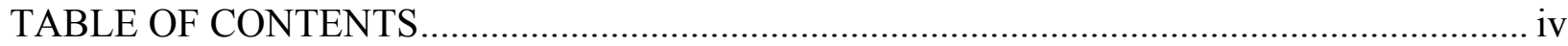

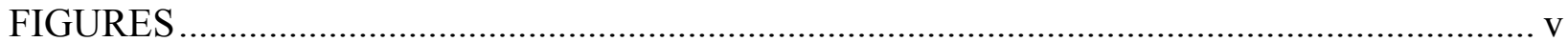

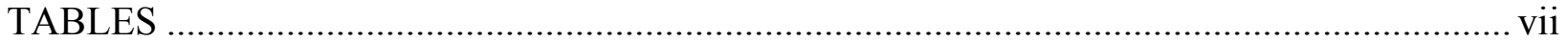

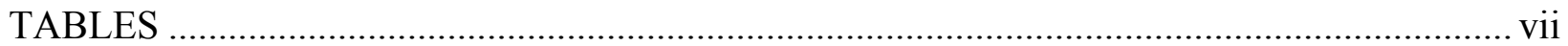

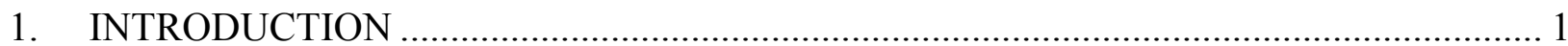

2. SINGLE CELL AND SHORT STACK TESTING AT CERAMATEC................................. 3

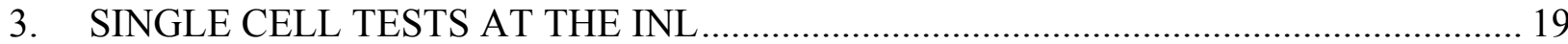

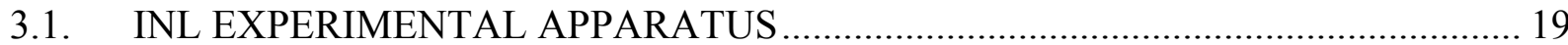

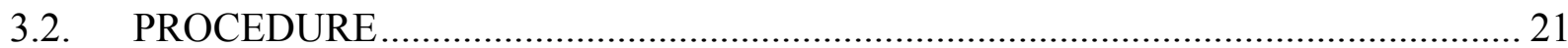

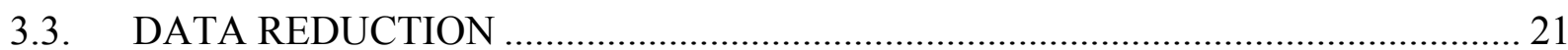

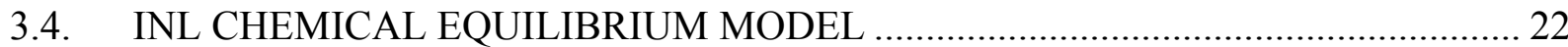

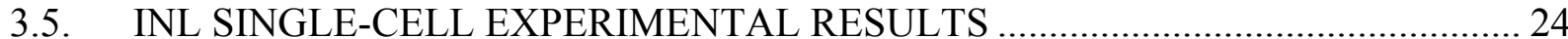

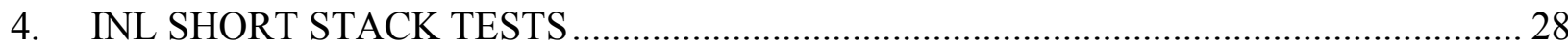

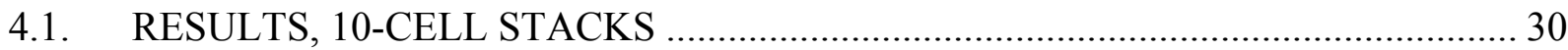

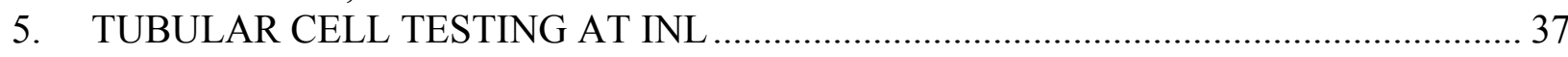

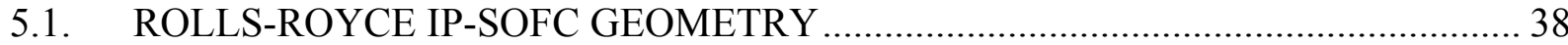

5.2. INL EXPERIMENTAL APPARATUS …………................................................ 40

5.3. REPRESENTATIVE RESULTS FROM FIRST BATCH OF IP-SOFCs ................... 42

5.4. REPRESENTATIVE LONG DURATION TEST RESULTS FOR IP-SOFC CELLS 46

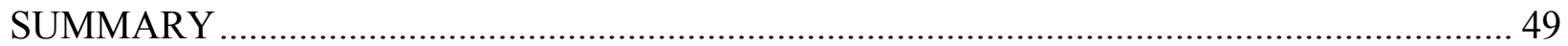

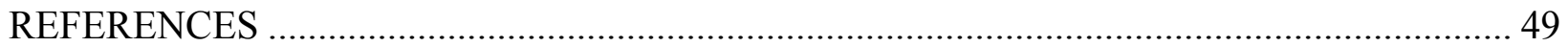




\section{FIGURES}

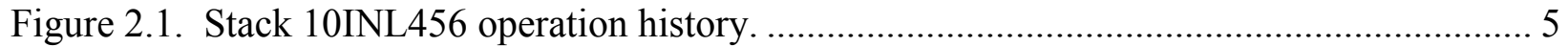

Figure 2.2. Stack 10LSGM459 initial steam electrolysis I-V sweep.................................... 5

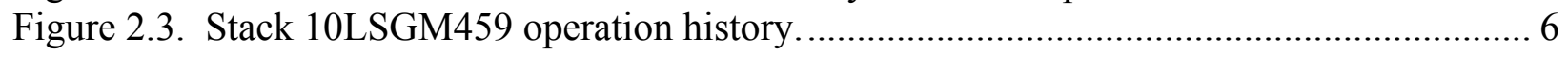

Figure 2.4. Stack 10HXF460 initial I-V sweep. .......................................................... 7

Figure 2.5. Stack 10HXF460 life history ..................................................................... 7

Figure 2.6. Oxygen electrode delamination using Alloy-X contacting felt.............................. 8

Figure 2.7. Stack 10EXP463 initial I-V sweep............................................................... 9

Figure 2.8. Stack 10EXP463 operation history. ............................................................. 9

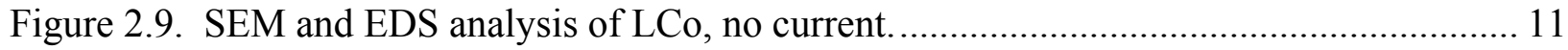

Figure 2.10. SEM and EDS analysis of LCo, with current................................................ 11

Figure 2.11. SEM and EDS analysis of LSCo, with current................................................. 12

Figure 2.12. Contact resistance coupon comparison of LSCo and LCo.................................. 12

Figure 2.13. Stack 10LCo464 operating history............................................................. 13

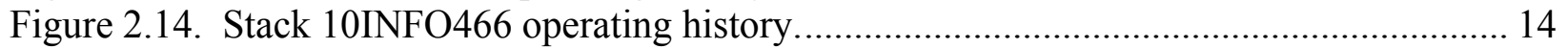

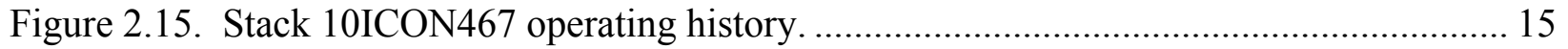

Figure 2.16. Stack 10INL468 operating history. ............................................................. 16

Figure 3.1. Schematic of the INL high temperature solid oxide electrolysis apparatus............. 19

Figure 3.2. Photograph of the INL high-temperature electrolysis laboratory............................ 20

Figure 3.3. Detail of button cell................................................................................. 21

Figure 3.4. Open-cell potential during heatup, measured and. predicted.............................. 25

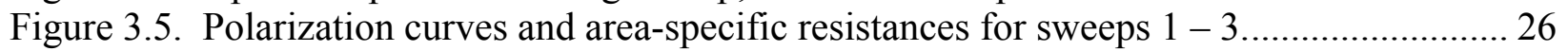

Figure 3.6. Measured outlet gas compositions, with comparisons to predictions from the

chemical equilibrium coelectrolysis model, sweeps 1 - 3 ................................................ 27

Figure 3.7. Measured outlet dewpoint values, with comparisons to predictions from the chemical

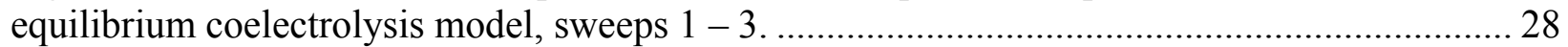

Figure 4.1. 10-cell stack mounted on test fixture on furnace base, ready to test..................... 29

Figure 4.2. Close-up of 10-cell stack, showing intra-cell thermocouples, voltage leads, and

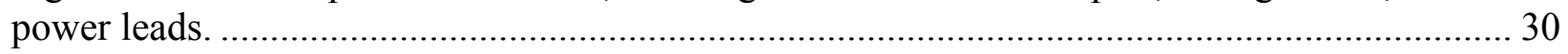

Figure 4.3. Heat-up results for stacks \#1, \#2, and \#3 ...................................................... 32

Figure 4.4. Polarization curves for $\mathrm{H} 2 \mathrm{O}$ electrolysis, $\mathrm{H} 2 \mathrm{O} / \mathrm{CO} 2$ coelectrolysis versus $\mathrm{CO} 2$

coelectrolysis, with mean ASR values............................................................................... 33

Figure 4.5. Internal stack temperature (thermocouple \#2) for various test conditions............... 34

Figure 4.6. Effect of varying chemical equilibrium coelectrolysis model equilibrium

temperature (Eq. 9) with comparison to Test 1 experimental data........................................... 36

Figure 4.7. Test 2 experimental and chemical equilibrium coelectrolysis model results, Teq $=$

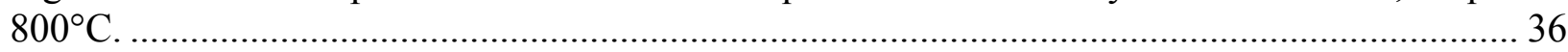

Figure 4.8. Test 3 experimental and chemical equilibrium coelectrolysis model results, Teq

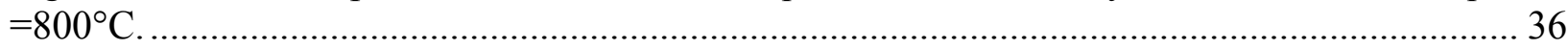

Figure 4.9. Test 4 experimental and chemical equilibrium coelectrolysis model results, Teq $=$

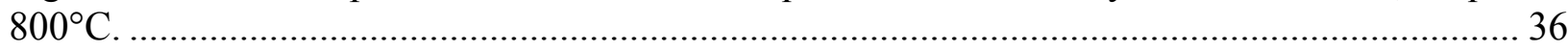

Figure 4.10. Test 5 experimental and chemical equilibrium coelectrolysis model results, Teq $=$

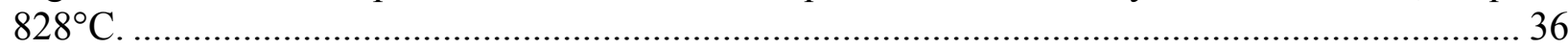

Figure 4.11. Test 6 experimental and chemical equilibrium coelectrolysis model results, Teq $=$

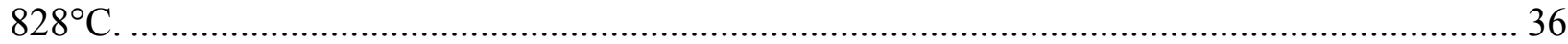




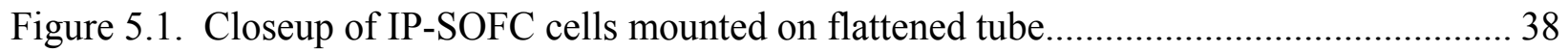

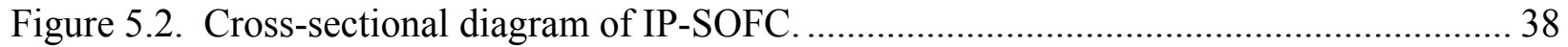

Figure 5.3. Porous support tube used in IP-SOFC [12] ...................................................... 39

Figure 5.4. Rolls-Royce IP-SOFC tube bundles............................................................... 40

Figure 5.5. Rolls-Royce IP-SOFC tube bundles [14] ................................................... 40

Figure 5.6. Schematic of INL testing apparatus for IP-SOFC testing. .................................. 40

Figure 5.7. Photograph of INL IP-SOFC testing apparatus............................................ 41

Figure 5.8. Pre-test photograph of triple tube installation inside test box in furnace................ 42

Figure 5.9. Polarization curves for Test $\# 1,800^{\circ} \mathrm{C}$, forward and reverse................................ 44

Figure 5.10. Polarization curves for sweep 8, tubes $1-3,-$ intentional steam starvation at

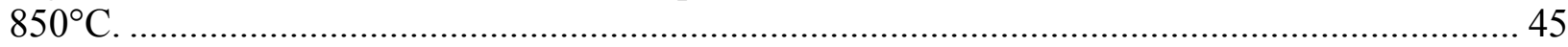

Figure 5.11. Polarization curves for sweep 15, tubes 1-3, 900 C. Steam starvation is evident.

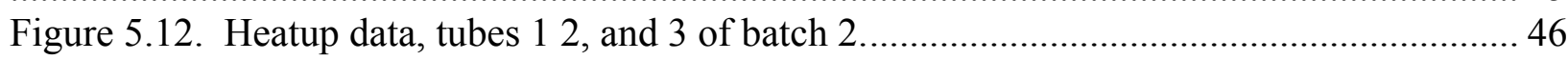

Figure 5.13. Polarization curves and ASR values for sweeps 1-4, tube \#1 of batch 2............. 46

Figure 5.14. Long-duration test data for tube \#1 of batch 2 ........................................... 47

Figure 5.15. Sweeps conducted at 22 hours for tube \#1, batch 2 ....................................... 47

Figure 5.16. Before and after photographs of IP-SOFC tube \#1, long duration test. ................. 48 


\section{TABLES}

Table 2-1. Stack 10INFO466 cell and interconnect coating configuration. ............................. 13

Table 2-2. Stack 10ICON467 cell and interconnect coating configuration............................. 14

Table 2-3. Single cell test summary............................................................................ 17

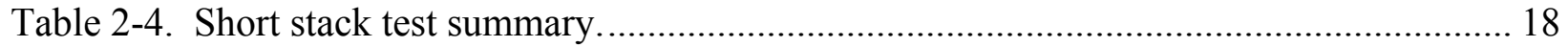

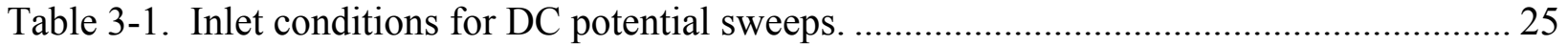

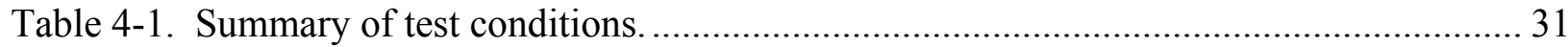

Table 4-2. Comparison of measured versus predicted open cell potentials and thermal neutral

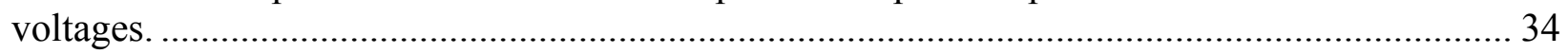

Table 5-1: Thicknesses of printed layers of active cells................................. 39

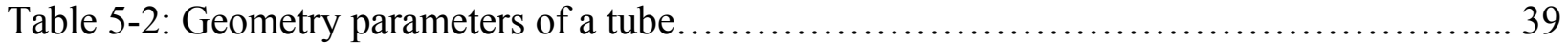

Table 5-3 Summary of Rolls-Royce polarization test conditions..........................43 


\section{NOMENCLATURE}

$A_{\text {cell }} \quad$ cell active area, $\mathrm{cm}^{2}$

ASR area-specific resistance, $\mathrm{Ohm} \cdot \mathrm{cm}^{2}$

$F \quad$ Faraday number, $\mathrm{J} / \mathrm{V} \cdot \mathrm{mol}$

$\Delta G_{f} \quad$ Gibbs energy of formation, $\mathrm{J} / \mathrm{mol}$

$i$ current density, $\mathrm{A} / \mathrm{cm}^{2}$

I cell current, A

$\dot{N} \quad$ molar flow rate, $\mathrm{mol} / \mathrm{s}$

$P \quad$ pressure, $\mathrm{kPa}$

$P_{A} \quad$ partial pressure of component $\mathrm{A}$ at inlet, $\mathrm{kPa}$

$Q_{s, A} \quad$ standard volume flow rate of component A

$R_{u} \quad$ universal gas constant, $\mathrm{J} / \mathrm{mol} \cdot \mathrm{K}$

$T$ temperature, $\mathrm{K}$

$V_{o p} \quad$ cell operating voltage, $\mathrm{V}$

$V_{\text {ref }} \quad$ cell reference voltage, $\mathrm{V}$

$y_{A} \quad$ mole fraction of component $\mathrm{A}$

\section{Subscripts}

e electrolysis

$0 \quad$ cold inlet state

1 hot inlet state, pre-electrolysis

2 hot outlet state, post-electrolysis

$i \quad$ inlet

$o \quad$ outlet

std standard state 


\section{INTRODUCTION}

This report provides documentation of experimental research activities performed at the Idaho National Laboratory (INL) and at Ceramatec, Inc. during FY07 under the DOE Nuclear Hydrogen Initiative, High Temperature Electrolysis (HTE) Program.

Single-cell tests were completed to assess the performance of solid-oxide electrolysis cells operating over a temperature range of 800 to $850^{\circ} \mathrm{C}$ in the steam electrolysis and coelectrolysis modes. In the coelectrolysis mode, steam and carbon dioxide are simultaneously electrolyzed for the direct production of syngas. Syngas, a mixture of hydrogen and carbon monoxide, can be used for the production of synthetic liquid fuels via Fischer-Tropsch processes. This concept, coupled with nuclear energy, provides a possible path to reduced greenhouse gas emissions and increased energy independence, without the major infrastructure shift that would be required for a purely hydrogen-based transportation system [1]. Furthermore, if the carbon dioxide feedstock is obtained from biomass, the entire concept would be climate-neutral.

The INL coelectrolysis research program is an LDRD-funded outgrowth of the high-temperature steam electrolysis research program funded by the Department of Energy Nuclear Hydrogen Initiative (NHI). Under the NHI, the INL has been developing efficient high-temperature hydrogen production technologies based on solid oxide fuel cell (SOFC) technology and materials [2-4]. The zirconia electrolytes used for SOFCs conduct oxygen ions, so they can be used to electrolyze $\mathrm{H}_{2} \mathrm{O}$ to $\mathrm{H}_{2}$ and/or $\mathrm{CO}_{2}$ to $\mathrm{CO}$. When both steam and carbon dioxide are present simultaneously in the feed stream, the total amounts of hydrogen and carbon monoxide that are produced depend on the electrolysis current. The relative amount of hydrogen produced versus carbon monoxide is determined by the relative amounts of steam, hydrogen (included in the feed stream as a reducing agent) and carbon dioxide included in the feed stream and by the effect of the shift reaction:

$$
\mathrm{CO}_{2}+\mathrm{H}_{2}<=>\mathrm{H}_{2} \mathrm{O}+\mathrm{CO}
$$

The desired molar ratio of hydrogen to carbon monoxide in the gaseous product depends on the particular liquid fuel to be produced as a final product, but a 2-to-1 ratio of $\mathrm{H}_{2}$ to $\mathrm{CO}$ is typical.

The INL coelectrolysis research program includes experimental, modeling, and computational fluid dynamics (CFD) activities. This paper will provide results of single-cell coelectrolysis experiments, with comparisons to predictions obtained from a chemical equilibrium coelectrolysis (CEC) model. This model was developed for prediction of final gas compositions and thermal energy requirements.

The experiments were performed over a range of inlet flow rates of steam, carbon dioxide, hydrogen and nitrogen and over a range of current densities $\left(-0.1\right.$ to $\left.0.25 \mathrm{~A} / \mathrm{cm}^{2}\right)$ using single electrolyte-supported button electrolysis cells. Steam and carbon dioxide consumption rates associated with electrolysis were measured directly using inlet and outlet dewpoint instrumentation and a gas chromatograph, respectively. Cell operating potentials and cell current were varied using a programmable power supply. Measured values of open-cell potential and outlet gas composition were compared to predictions obtained from a chemical equilibrium 
coelectrolysis model developed specifically for this program. Model predictions of outlet gas composition based on an effective equilibrium temperature are shown to agree well with measurements. Cell area-specific resistance values were similar for steam electrolysis and coelectrolysis.

This paper presents results of recent single cell and short stack experiments conducted at the INL and Ceramatec studying steam electrolysis and coelectrolysis of steam and carbon dioxide. Electrochemical performance of the stack was evaluated over a range of temperatures, compositions, and flow rates. The apparatus used for these tests is heavily instrumented, with precision mass-flow controllers, on-line dewpoint and $\mathrm{CO}_{2}$ sensors, and numerous pressure and temperature measurement stations. It also includes a gas chromatograph for analyzing outlet gas compositions. Comparisons of measured compositions to predictions obtained from a chemical equilibrium co-electrolysis model are presented, along with corresponding polarization curves. Results indicate excellent agreement between predicted and measured outlet compositions. Coelectrolysis significantly increases the yield of syngas over the reverse water gas shift reaction equilibrium composition. The process appears to be a promising technique for large-scale syngas production.

The INL has expanded the scope of its HTE research activities to include evaluation of the performance of tubular-shaped cells for efficient hydrogen production. These geometries have been developed to alleviate sealing and electrolyte strength problems by reducing the number of seals required, and allowing greater thermal compliance for the ceramic materials. However, tubular designs suffer from reduced overall power density compared to planar designs. Assessment of various tubular designs may show that the decreased power density could be a reasonable penalty to pay for improved seal performance and cell life.

Several manufacturers have developed tubular SOFC designs (Toshiba, Accumentrics, SiemensWestinghouse, and others). Through an internally-funded INL Laboratory Directed Research and Development project, a CRADA was established with Rolls-Royce Fuel Cell Systems Ltd., a developer and manufacturer of solid-oxide fuel cells. The Integrated Planar Solid Oxide Fuel Cell (IP-SOFC) design developed by Rolls-Royce is of particular interest to the INL for electrolysis testing. In spite of the name, the IP-SOFC design is actually comprised of highaspect-ratio flattened tubes, upon which the electrolysis cells are deposited by a wet-slurry screen-printing process. Each tube has 20 electrolysis cells, 10 on each side of the tube. This design eliminates most of the seals necessary in a planar design while attempting to maintain a relatively high power density.

The INL obtained five Rolls-Royce IP-SOFC tubes and tested them in-house as electrolyzers. The INL has also developed computational fluid dynamics (CFD) computer models for the IPSOFC design. This work takes advantage of the existing high-temperature electrolysis test facility at the Bonneville County Technology Center. The first Rolls-Royce tube was used for system checkout and shakedown tests. Three new tubes were then installed and tested simultaneously by conducting voltage sweeps at various operating temperatures ranging from 800 to $950^{\circ} \mathrm{C}$. Upon conclusion of these tests, the original tube used for system checkout was reinstalled and thermally cycled to determine durability. Finally, the remaining untested tube was installed for long duration testing, which is on-going at this time. Section 4 of this report summarizes the findings of this testing program. 


\section{SINGLE CELL AND SHORT STACK TESTING AT CERAMATEC}

The Ceramatec subcontract statement of work (SOW) under the DOE NHI project with the INL calls for fabrication and testing of single cells and short stacks (i.e. 10 cell stacks). Required FY07 deliverables, in addition to the module for the Integrated Laboratory Scale (ILS) electrolysis testing system, include two advanced single cells, and a 10x10 cm 10-cell stack for testing at the INL. In previous years a specific number of single cell and short stack tests at Ceramatec were also prescribed. However this year, due to a significant budget reduction over previous years concurrent with production of a second ILS module, no quotas were stated for single cell or short stack testing at Ceramatec. An exception being the requirement for a test planned to be conducted at Ceramatec of a 20x20cm short stack as part of the FY07 contract. However, qualification tests were allowed in the SOW, wherein Ceramatec could explore performance and lifetime improvement and validate fabrication processes prior to making the required deliveries and $20 \times 20 \mathrm{~cm}$ short stack tests.

Some cell and stack testing was also performed in support of a closely aligned project funded as an INL LDRD and involving co-electrolysis of steam and carbon dioxide. In general, these single cells and short stacks were initially tested in steam electrolysis mode to provide a baseline for comparison of performance in co-electrolysis mode. Where relevant, information gained in this test program was incorporated into the NHI work.

At this stage of development, the primary objective of the single cell and short stack testing is to determine if materials, design or process changes yield the desired improvement in performance and operating life. In contrast, the ILS objectives address system scale-up, balance of plant (BOP) performance and showcasing the capability of the technology at increased production rates. During FY07, single cell and short stack testing at Ceramatec demonstrated advances in electrolysis stack performance and stability.

Another important purpose of single cell and short stack testing is as a quality control tool, to detect fabrication process anomalies, and to help track down and correct the root cause as quickly as possible so that they don't make their way into larger systems. This mode of testing was the focus of single cell and short stack activities through much of FY07. While this was unexpected, the problem was successfully identified and the corrective actions implemented.

While the majority of the Ceramatec high temperature electrolysis effort was directed to the NHI program, other relevant high temperature electrolysis results are included for completeness and chronological consistency. A total of eleven (11) short electrolysis stacks have been fabricated and or tested for INL projects in the reporting period. Of these 11 stacks, 3 were tested at INL for the co-electrolysis LDRD project, and one LSGM stack was tested at Ceramatec as part of an intermediate temperature electrolysis activity. The intermediate temperature electrolysis concept is motivated by the need to explore the potential of steam electrolysis at reduced temperatures, approaching those expected from advanced reactor alternatives to the gas cooled reactor.

A total of 71 single cells were fabricated (25 cells for co-electrolysis and intermediate temperature electrolysis, 46 supporting the NHI steam electrolysis tasks), with all but 6 tested at 
this time. The co-electrolysis cells were used to characterize electrode performance with carbon dioxide containing reactant streams. Intermediate temperature electrolysis cells were used to characterize the performance of alternative electrode and electrolyte materials operating at temperatures below $800^{\circ} \mathrm{C}$. Seven of the $46 \mathrm{NHI}$ single cells were used with an experimental dual dopant $(\mathrm{ScYb})$ electrolyte as a possible solution to electrolyte aging (increase in electrolyte resistance with time) and the observed presence of tetragonal (partially stabilized) zirconia phase detected at Argonne National Laboratory (ANL) in cells from tested stacks. No performance advantage over the standard scandia doped cells was noted. The electrolyte for these cells were prepared by ball milling an addition of ytterbium oxide (ytterbia) in the scandia stabilized zirconia (ScSZ) slip, and co-sintering the blended oxides. The ScSZ powder is a homogeneous single-phase powder produced by a co-precipitation process. Indications are that ytterbia is not being incorporated into the zirconia lattice. Further process development is required before additional dual dopant cells are tested. The remaining cells tested on the NHI project were either electrode ink batch qualification cells, or QC cells (aka rider cells) processed along side batches of $10 \mathrm{~cm}$ cells.

A co-electrolysis short stack designated 10INL456, started 18 Sep 2006, continued operation through 12 October 2006 (see Figure 2.1). This stack utilized the same construction methods and materials as were used in the $2 \times 60$ cell half ILS module tested earlier that summer with one exception. A paper-thin sheet of nickel felt was placed between the hydrogen electrode (electrolysis cathode or fuel cell anode) and the nickel flowfield of the interconnect. It was expected that the long nickel fibers in the felt would increase in-plane electrical conductivity and reduce contact resistance of the electrode-interconnect couple. Sintering of the nickel flake used in the contacting layer was thought to be one mechanism of degradation, and it was reasoned that the long fibers of the nickel felt would negate the effects of sintering or coarsening of this layer. The addition of nickel felt appears to be effective, as 10INL456 showed both high performance and lower degradation compared with the previous best electrolysis stack performance demonstrated in the half ILS module. This stack was operated at 800C through its entire period of operation. Its performance in steam electrolysis mode should be virtually identical to that shown below in co-electrolysis mode $\left(\mathrm{CO}_{2}\right.$ and $\mathrm{H}_{2} \mathrm{O}$ electrolysis). Note the cell to cell consistency of operating voltages shown in the grap for the 52 -cell groups. The test was terminated prematurely due to a communication mixup. An identical stack designated 10INL456b, was constructed along side 10INL456 and was tested in co-electrolysis mode at INL in December of 2006. Its performance may have been affected by the longer period between assembly and testing, or by other test system issues.

The intermediate temperature electrolyte stack, designated variously as 10LSGM458 and 10LSGM459 was tested from November 1-8, 2006. This 10-cell stack utilized strontium doped lanthanum gallate (LSGM) electrolyte supported cells with customized Ceramatec proprietary electrode materials. This stack was also prematurely terminated by inadvertently selecting the wrong furnace number for cool down from a menu in the furnace control screen on the LabView based data acquisition system. The initial $800^{\circ} \mathrm{C}$ current voltage (I-V) sweep shows a stack area specific resistance (ASR) of $1.05 \mathrm{ohm}-\mathrm{cm}^{2}$ as shown in Figure 2.2. The stack was then cooled to $700^{\circ} \mathrm{C}$ for lifetime testing as shown in Figure 2.3. Again, this stack showed good uniformity in operating voltage among the 52 -cell groups. 


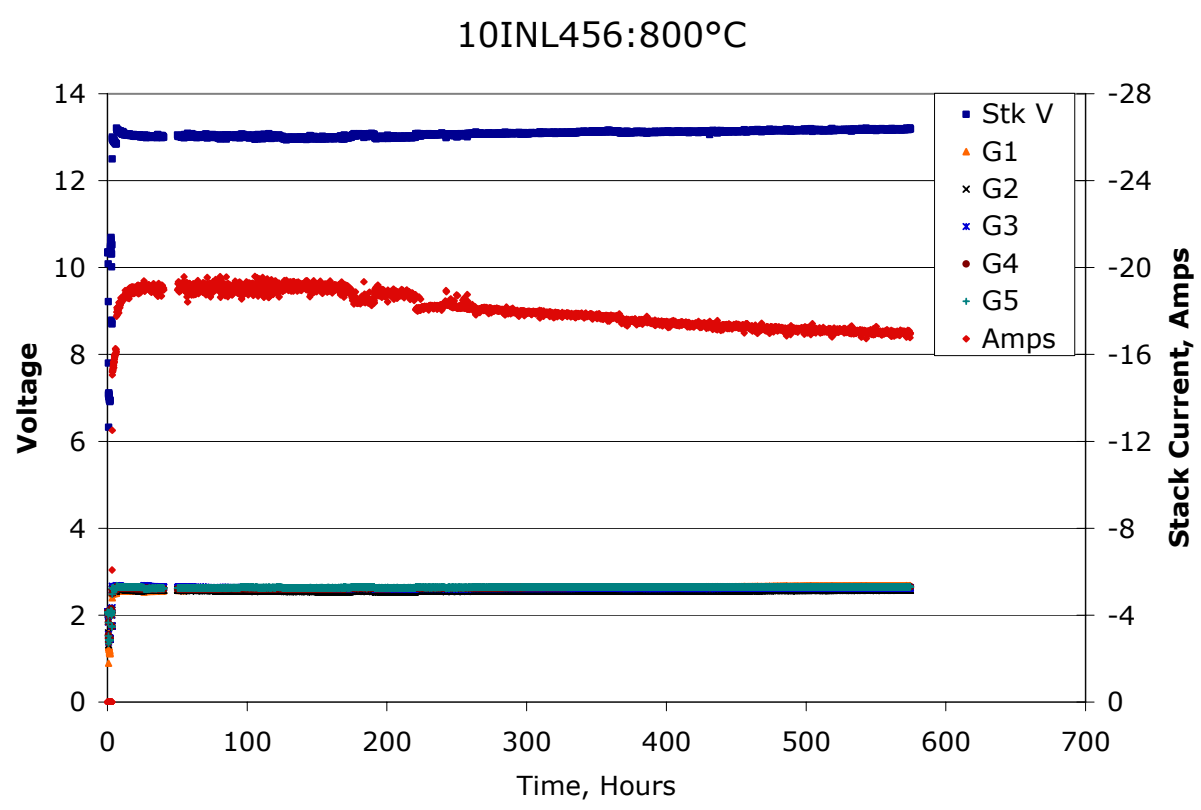

Figure 2.1. Stack 10INL456 operation history.

10LSGM459: $800^{\circ} \mathrm{C}$

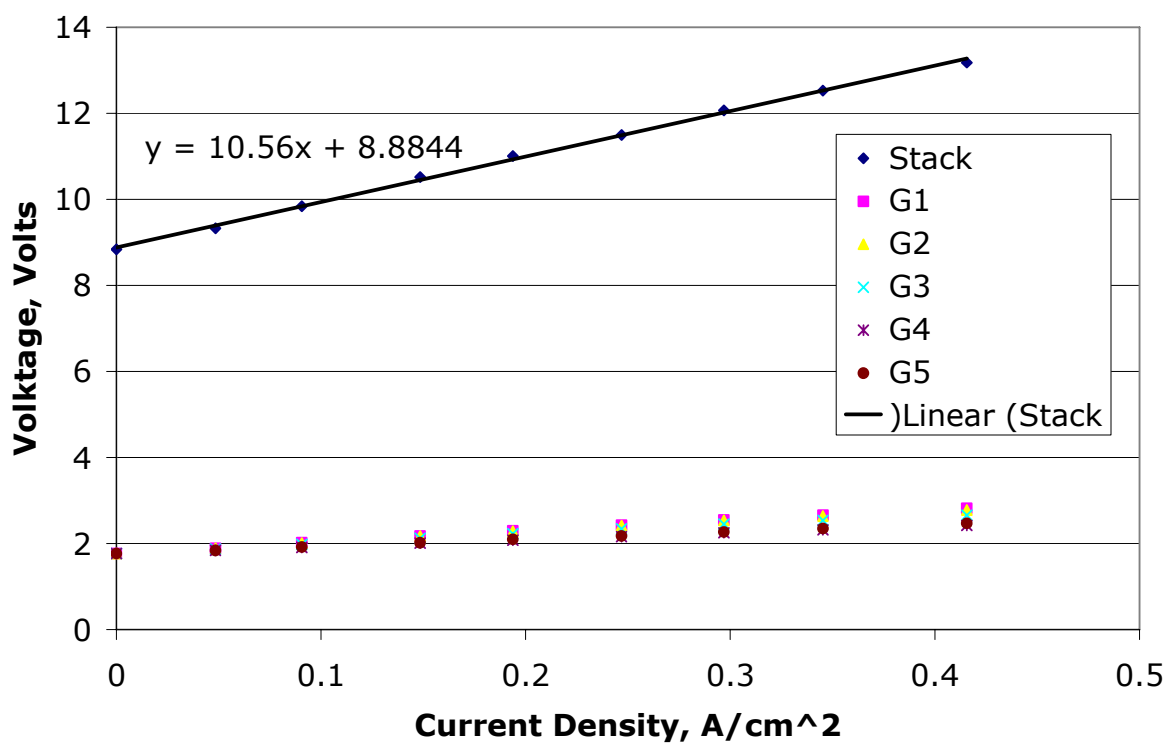

Figure 2.2. Stack 10LSGM459 initial steam electrolysis I-V sweep.

The first stack tested specifically for the NHI project this fiscal year, designated 10HXF460, was operated from December 1-18, 2006. The encouraging results using a nickel felt cellinterconnect contact layer lead to interest in finding a comparable material for the oxygen electrode contact layer. The oxygen electrode interconnect flowfield corrugation material is alloy-X (Hastelloy-X or H-X), which has shown to have excellent high temperature oxidation 
resistance. With suitable treatment, coupons of H-X sheet have shown surface oxide scale resistance as low as $5 \mathrm{~m} \Omega-\mathrm{cm}^{2}$. Ceramatec was able to obtain samples of $\mathrm{H}-\mathrm{X}$ felt, though it was thicker than desired and had to be compressed to an acceptable thickness for the stacking process. It was treated with a process based on the $\mathrm{H}-\mathrm{X}$ interconnect component coating process and placed in the stack between the cell and H-X flowfield. The initial I-V sweep shown in Figure 2.4 below yielded a disappointingly high stack ASR of $2.7 \Omega-\mathrm{cm}^{2}$. However stack performance improved with time to a performance comparable to previous top performing stacks before undergoing a rapid degradation as shown in Figure 2.5. After 271 hours of operation the stack was switched to fuel cell (SOFC) operation mode for a comparison of degradation rates between electrolysis and SOFC modes. The performance was lower in SOFC mode, but the degradation rate slowed.

Post test examination of the stack showed extensive delamination of the oxygen electrode as shown in Figure 2.6. Chromium poisoning of the electrode may be aggravated by the high surface area of $\mathrm{H}-\mathrm{X}$ felt in direct contact with the entire electrode surface. $\mathrm{H}-\mathrm{X}$ also has good high temperature structural properties, and a much higher thermal expansion coefficient (CTE) than the cell, which may explain the electrode delamination phenomena. While H-X felt may not provide the desired result, this test shows the value of improved contacting.

10LSGM459, $700^{\circ} \mathrm{C}$

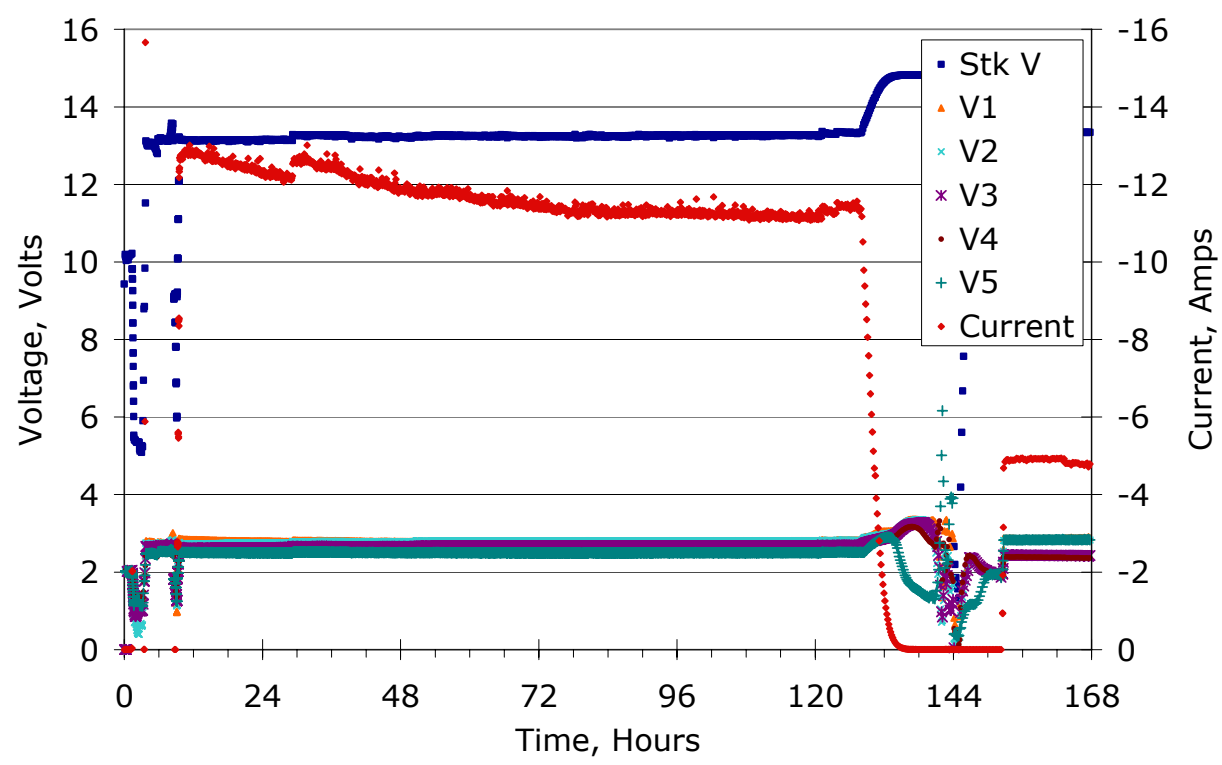

Figure 2.3. Stack 10LSGM459 operation history. 
$10 \mathrm{HXF} 460: 800^{\circ} \mathrm{C}$

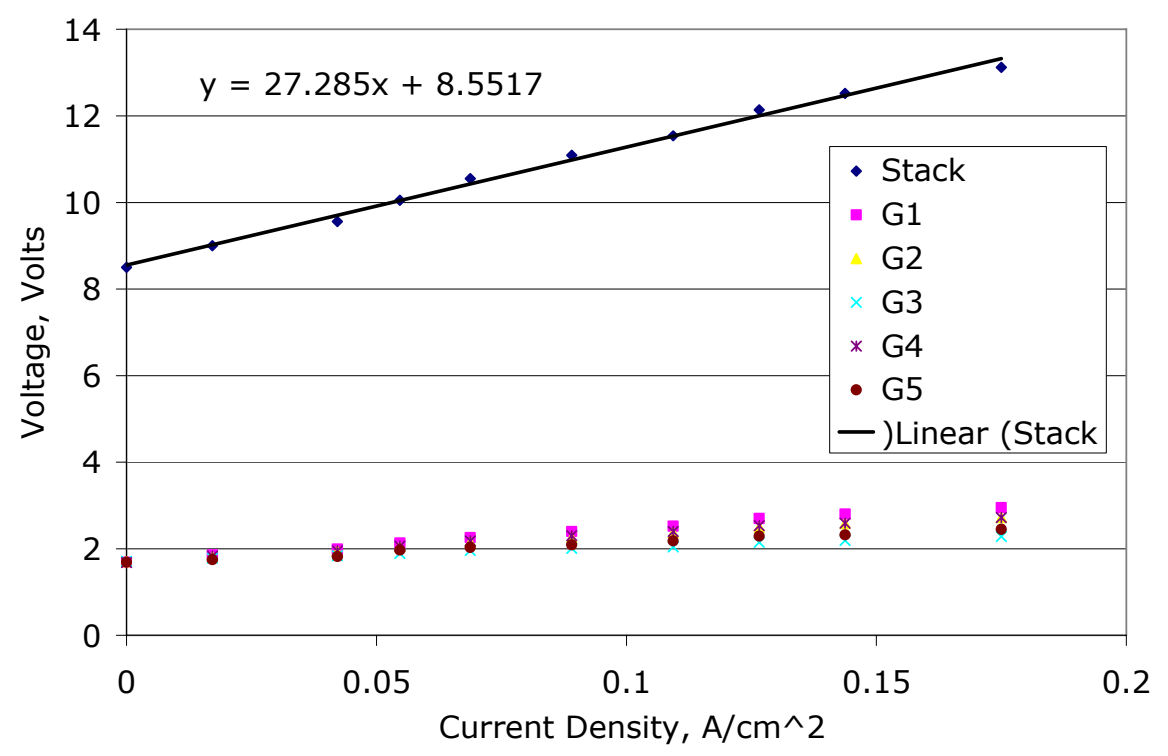

Figure 2.4. Stack 10HXF460 initial I-V sweep.

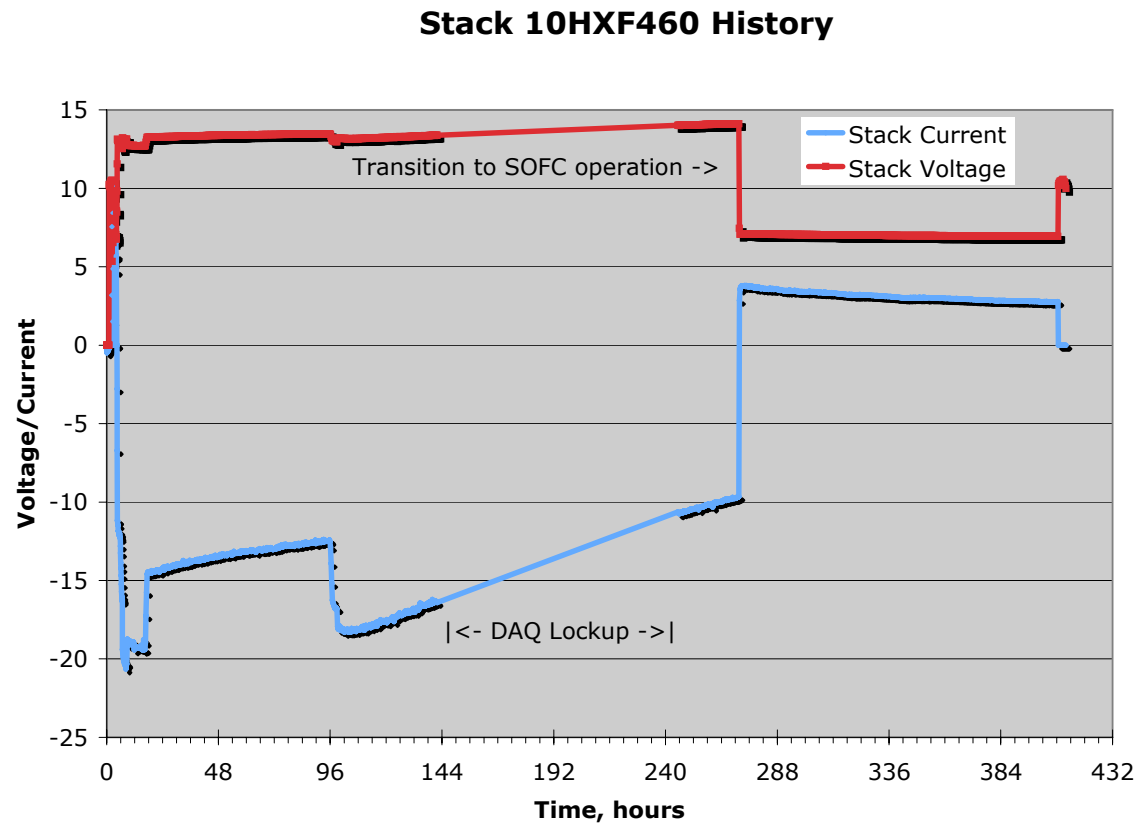

Figure 2.5. Stack 10HXF460 life history. 


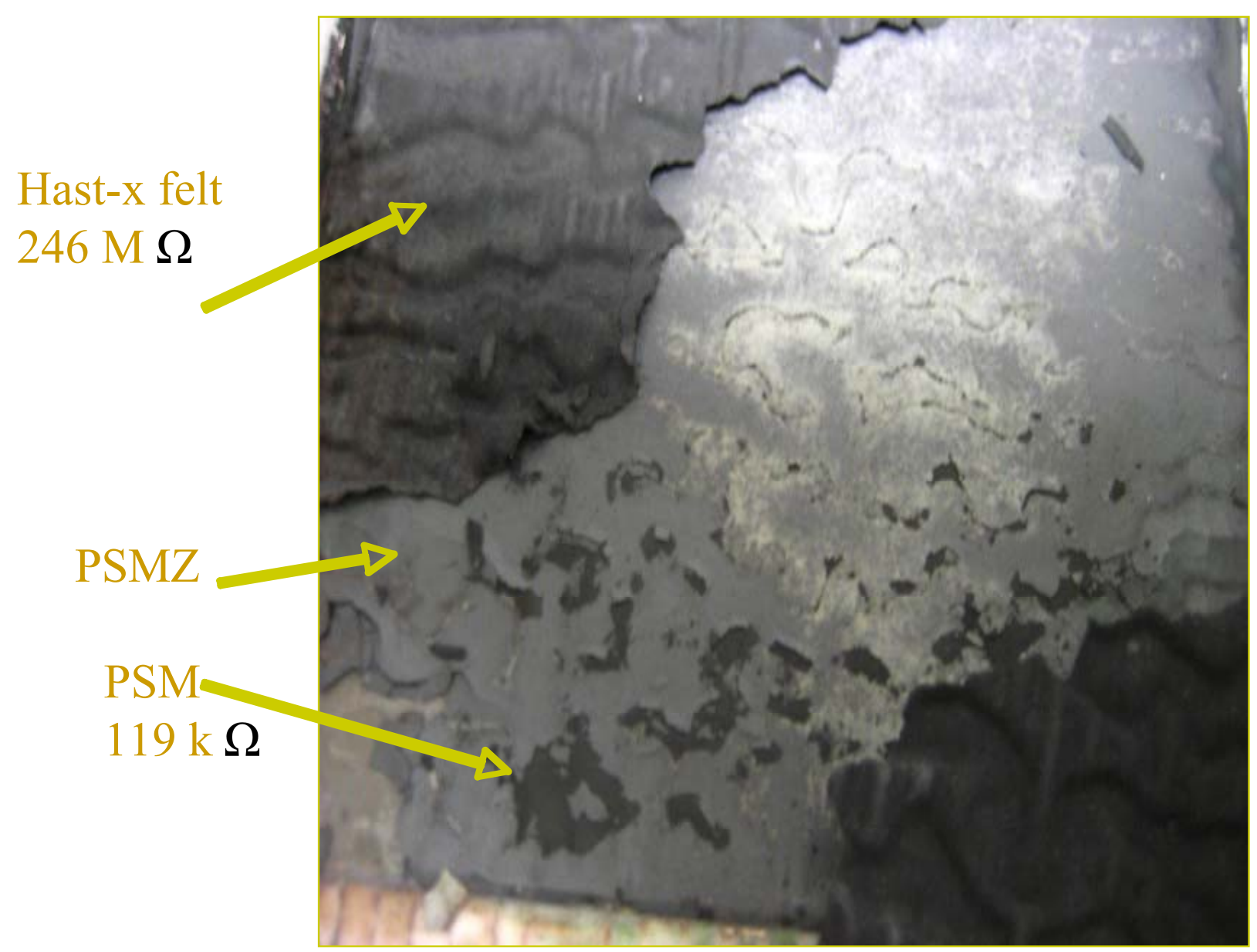

Figure 2.6. Oxygen electrode delamination using Alloy-X contacting felt.

From the end of 2005 through 2006 cells were printed using a single batch of hydrogen electrode ink, NMCIX_051003, made from the powder batch NMCP_050818. Cells made with this ink performed well, with typical single cell resistance of $\overline{0.7} \Omega-\mathrm{cm}^{2}$ and with recent stack performance approaching $1 \Omega-\mathrm{cm}^{2}$. A new batch of hydrogen electrode ink was prepared in September 2006. Single cells were likely made for ink qualification, but were not tested in a timely manner due to a backlog of cells for testing at that time. This new ink batch, NMC ink_060915, was used for the10x10cm cells in the first ILS module to be tested in September of 2007. Before delivery of the module, a 10-cell stack, 10EXP463 was tested to establish a baseline performance of the components in the 4x60 cell ILS module. The initial I-V sweep and operating history for stack 10EXP463 are shown in Figure 2.7 and Figure 2.8. Stack performance was approximately half that of stack 10INL456. The only difference in construction of the stack was the use of the new batch of electrode ink. 


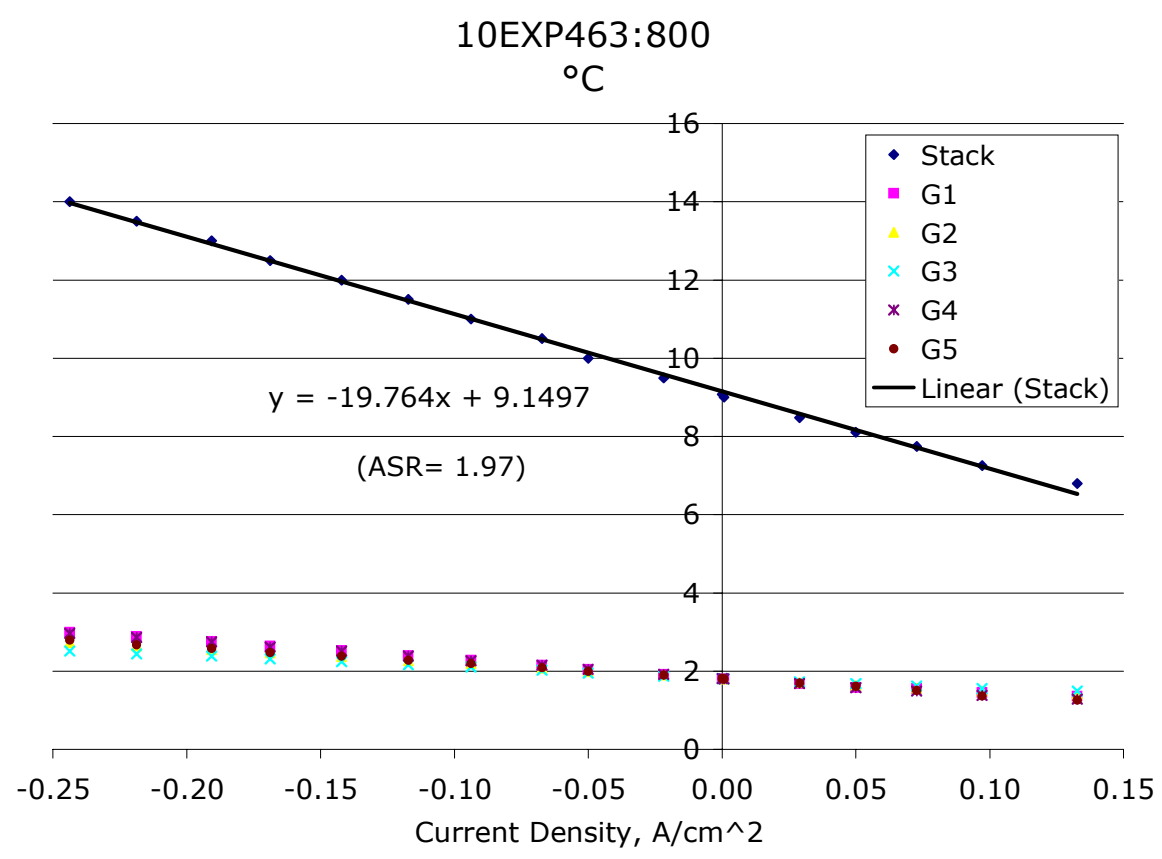

Figure 2.7. Stack 10EXP463 initial I-V sweep.

Given the large difference in performance and the anode batch being the only known change, attention was focused on the anode process. The position of powder synthesis and ink preparation technician has a history of frequent turnover. There had been several changes of personnel in the powder and ink position since the prior good electrode ink was made. The technician who prepared the recent poorly performing batch had left Ceramatec for graduate studies several months before the batch was used. Additional hydrogen electrode ink batches,

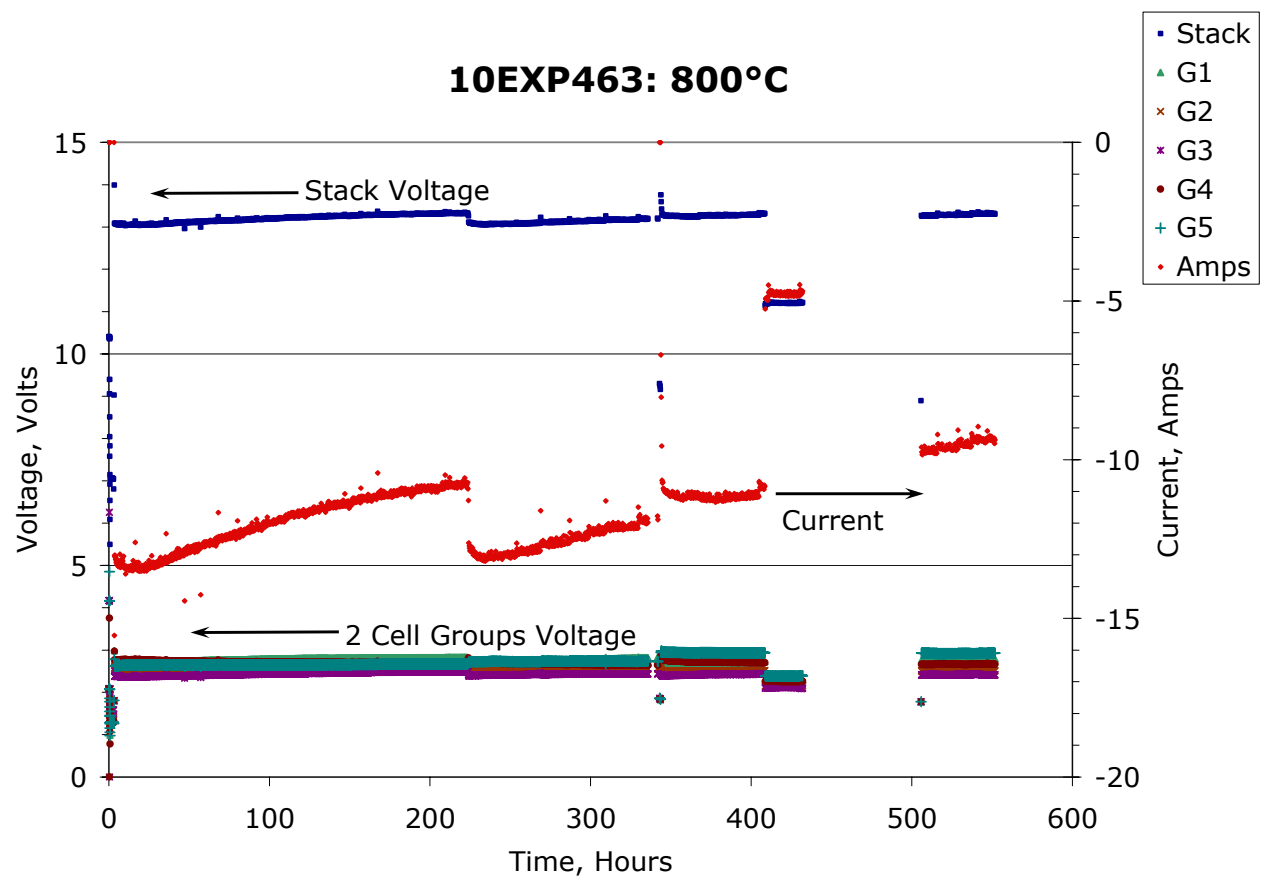

Figure 2.8. Stack 10EXP463 operation history. 
prepared by the current technician and his predecessor were found to have poor performance. Some investigation determined that a critical process step, a step that is unique to the hydrogen electrode among the many materials synthesized with the same basic process, had been lost in the transition from one technician to the next. The process was well documented in the master procedure, but was lost by the practice of using documentation from the most recent batch. Further, it was found that a source for one of the raw materials had been changed to be consistent with the supplier of all the other components. The need for the additional process step and the material supplier specification are not obvious, neither can they be determined from any theoretical or first-principles logic. Both requirements were found after an in depth survey of historical process variation followed by a careful correlation with resulting electrode performance, well over a decade ago.

A request was made for preparation of new ink batches using the master process documentation and specified supplier. However when the lot of material was received from the specified supplier it was found to contain impurities, which the supplier confirmed after being informed of the problem. They then had to produce another batch. In the mean time, several powder lots were made using the correct process but material from an alternative supplier. One of these batches was subsequently used to produce several qualification cells. Initial single cell testing showed ASR values greater than $1 \Omega-\mathrm{cm}^{2}$. However other cells using this electrode ink showed performance about $0.7 \Omega-\mathrm{cm}^{2}$, comparable to the previous good electrode. As it was the best available electrode ink it was used for the next several stacks.

Another issue noted in post test analysis of interconnect components at ANL, and confirmed in Ceramatec's observations from the mid 1990's, was that Sr in LSCo reacts with chromium in the protective oxide scale of the metal interconnect and forms a highly resistive strontium chromate spinel layer. In light of this, Ceramatec began evaluating LCo (Lanthanum Cobaltite Perovskite, i.,e. LSCo with no Sr) as a possible replacement for LSCo. Contact resistance coupons have been tested and examined by SEM. A series of SEM micrographs with EDS analysis (energy dispersive spectra) and contact resistance testing results are shown in Figure 2.9 - Figure 2.11 below. The LCo as a contacting layer on the stainless separator plate and H-X flowfields appears to be an improvement over LSCo, even though it has a lower bulk electronic conductivity. One practical issue appears to be being able to fire the LCo on the metal surface and have it adhere as well as LSCo. Progress has been made with this issue. The LCo shows about half the contact resistance and an order of magnitude lower rate of increase in resistance over time compared with LSCo (Figure 2.12). Therefore, the next four short stack tests were planned with compare LCo and LSCO conductive coatings on the oxygen evolution side of the metal interconnects. Unfortunately the performance data from these tests are confounded by variability in the best available hydrogen electrode ink batch. 
SEM- LCo no current, $850^{\circ} \mathrm{C}$ for 500 hours-
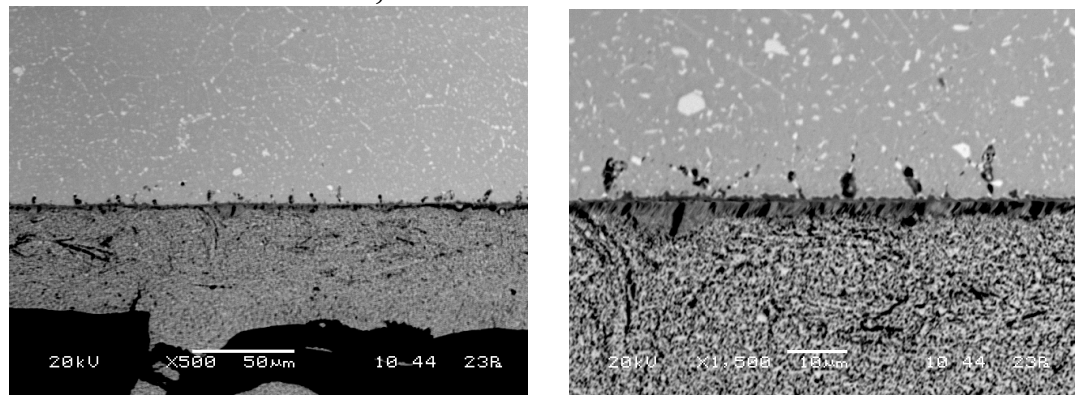

Hast X metal EDS-

LCo/Hast X interface EDS-
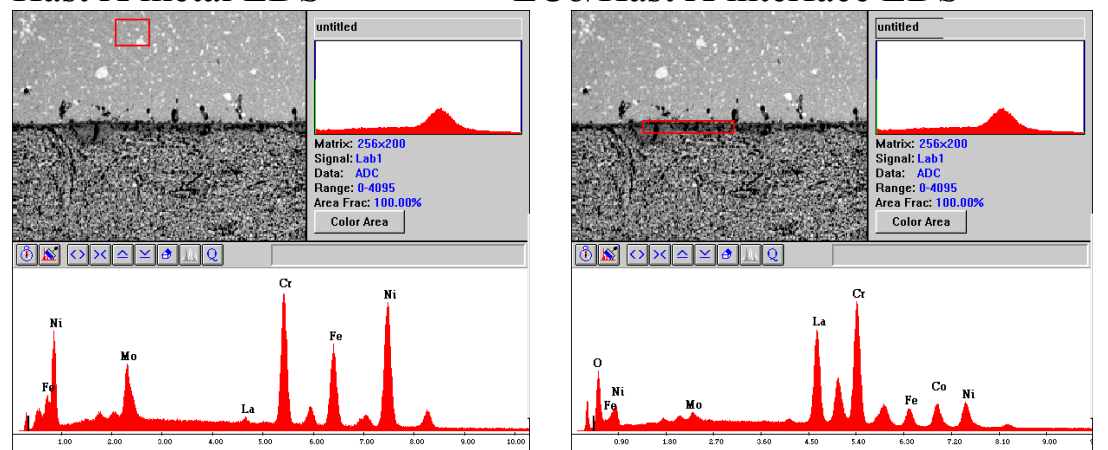

LCo EDS-

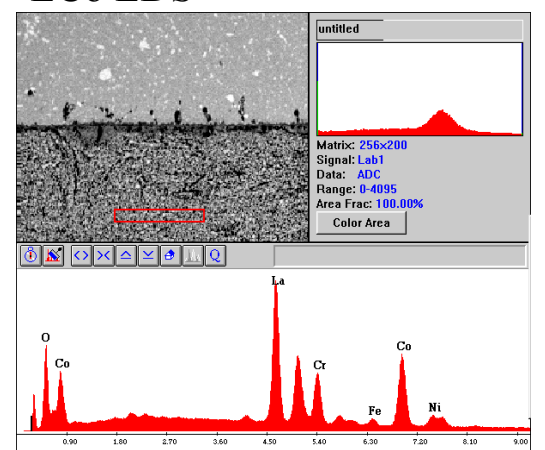

Figure 2.9. SEM and EDS analysis of LCo, no current.

LCo with current, $850^{\circ} \mathrm{C}$ for 500 hours-

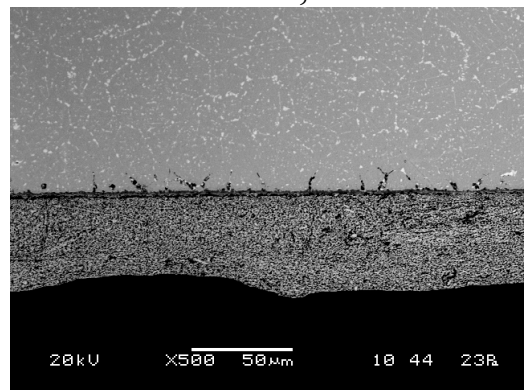

LCo/Hast X interface EDS-

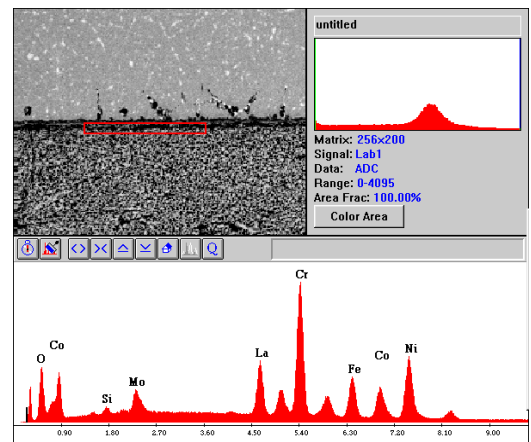

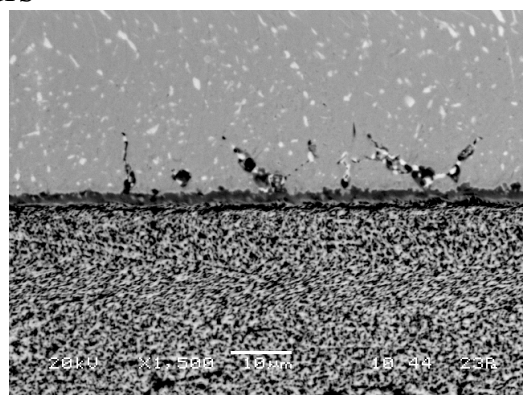

LCo EDS-

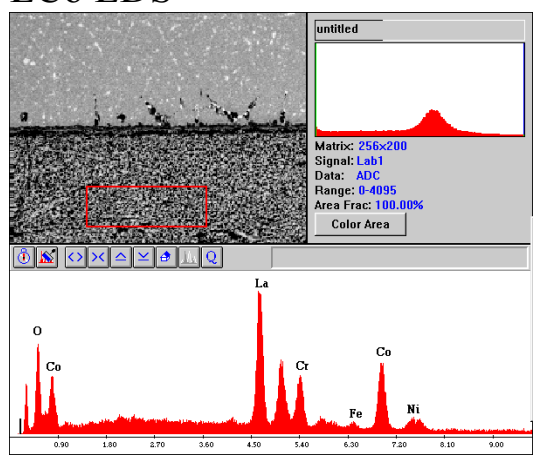

Figure 2.10. SEM and EDS analysis of LCo, with current. 
LSCo with current, $850^{\circ} \mathrm{C}$ for 500 hours-
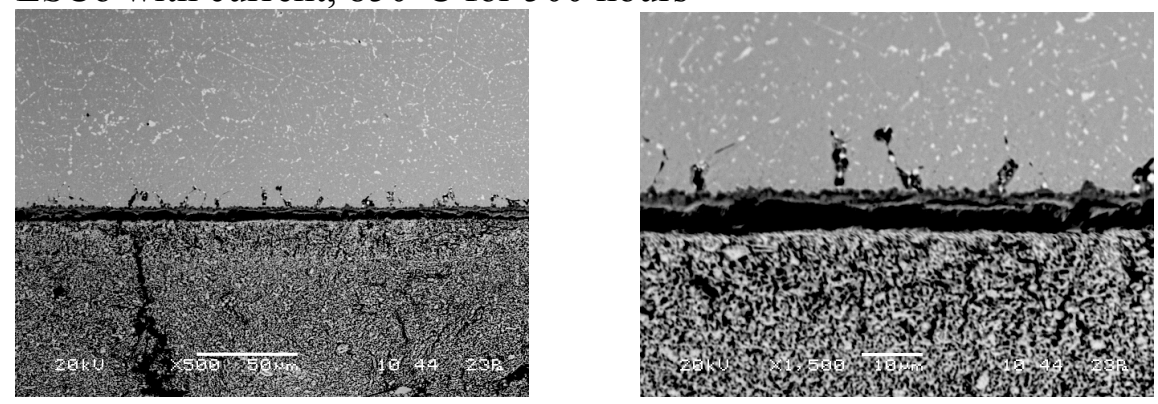

LSCo/Hast X interface EDS-
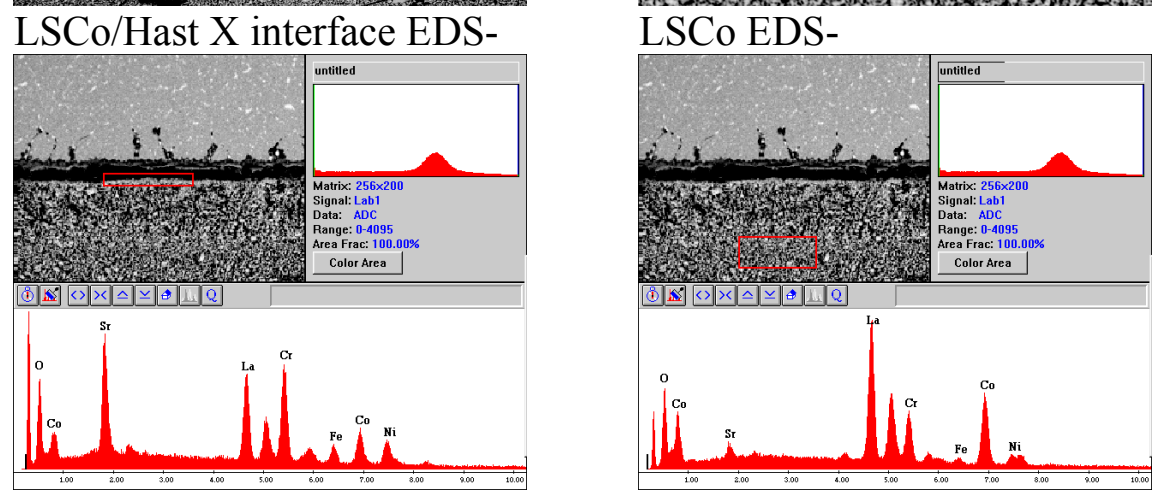

Figure 2.11. SEM and EDS analysis of LSCo, with current.

LSCo vs LCo Bond Layer on Hast X Alloy with Current (500mA at 850C)

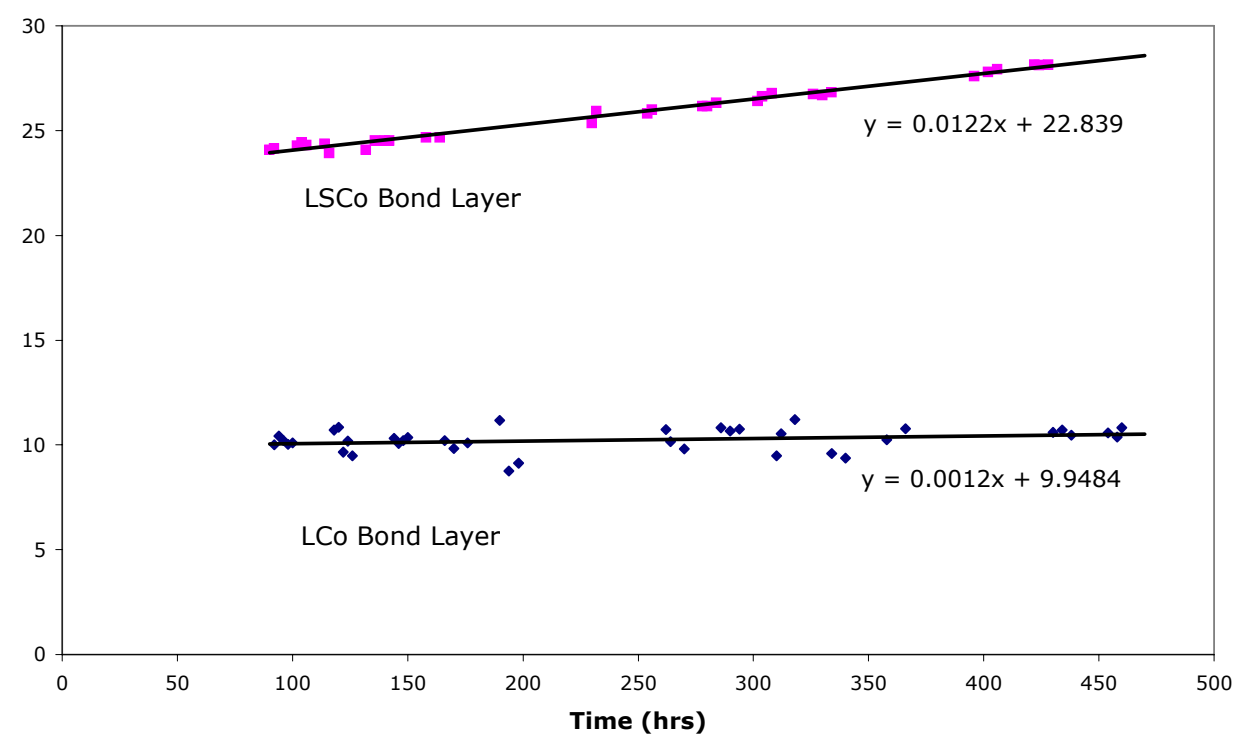

Figure 2.12. Contact resistance coupon comparison of LSCo and LCo.

Stack 10LCo464 used the LCO coating on the interconnect separator plate and flow field, as well as the contact layer on the cell. The initial stack ASR of $2.6 \Omega-\mathrm{cm}^{2}$ was relatively high even 
given the variability in single cell performance shown using this hydrogen electrode ink batch. The stack was operated 5/3-5/30 as shown in Figure 2.13.

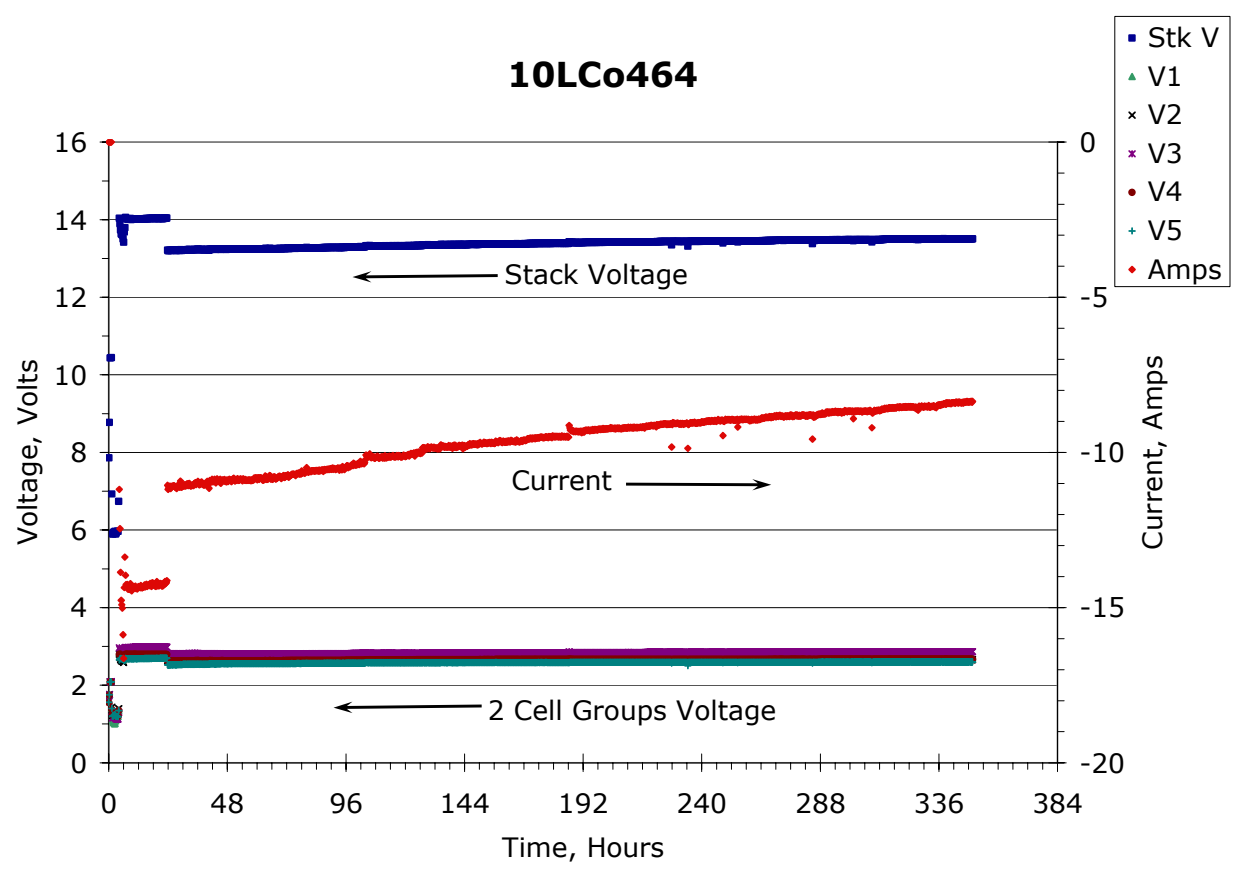

Figure 2.13. Stack 10LCo464 operating history.

Stack 10INL465 was built for testing at INL the week following testing of stack 10LCO464 at Ceramatec. After noting the poor performance of stack 10LCO464, there was concern that the high surface area LCO powder used as the cell contacting layer might restrict the oxygen evolution from the electrode. Therefore the LCO contacting layer was removed from the cells and replaced with the standard LSCO before stack assembly. The interconnect components LCO coatings were left in place. The stack, tested at INL showed poor performance. It is thought that the hydrogen electrode is more likely the root cause of the poor performance than the LCO coating.

A pair of stacks, 10INFO466 and 10ICON467 were tested from 5/21 to 6/26 in a dual stack test furnace for additional study of the LSCo vs. LCo interconnect coating. As noted previously, these stacks both used the NMC_070327 hydrogen electrode ink, which was still the best available material. Stack 10INFO466 configuration is summarized in Table 2-1 below. Cells are numbered in stacking order, from the bottom of the stack (oxygen electrode single flow

Table 2-1. Stack $10 \mathrm{INFO} 466$ cell and interconnect coating configuration.

\begin{tabular}{|l|l|l|}
\hline Cell number & \multicolumn{1}{|c|}{ Cell contact layer } & Interconnect Coating \\
\hline $1-3$ & LCo & LCo \\
\hline $4-5$ & LCo removed and LSCo applied & LCo \\
\hline \hline $6-10$ & LSCo & LSCo \\
\hline
\end{tabular}


interconnect) to the top (hydrogen electrode single flow interconnect).

After stack installation in the test stand, cell group voltages are numbered from the top of the stack to the bottom. Due to the unusual configuration of this stack, cell diagnostic voltage leads grouped cells 1-3, 4-5, 6, 7-8, and 9-10 as shown in the Figure 2.14 below. If significant changes in relative resistance of the various groups had developed the group voltages would shift relative to each other even thought the total stack voltage was regulated at the power supply. Some drift in stack voltage is generally seen, not due to power supply variation, but as a result of changing lead resistance losses as the stack current decays. Cells 4-5, which had the LCo removed and LSCo applied, show slightly higher operating voltage (lower performance) than cells 7-8 or 9-10. It appears that the $\mathrm{LSCo} / \mathrm{LCo}$ variations have minor effect, but the test is somewhat inconclusive due to the hydrogen electrode performance variability.

\section{Stack 10INFO466 History}

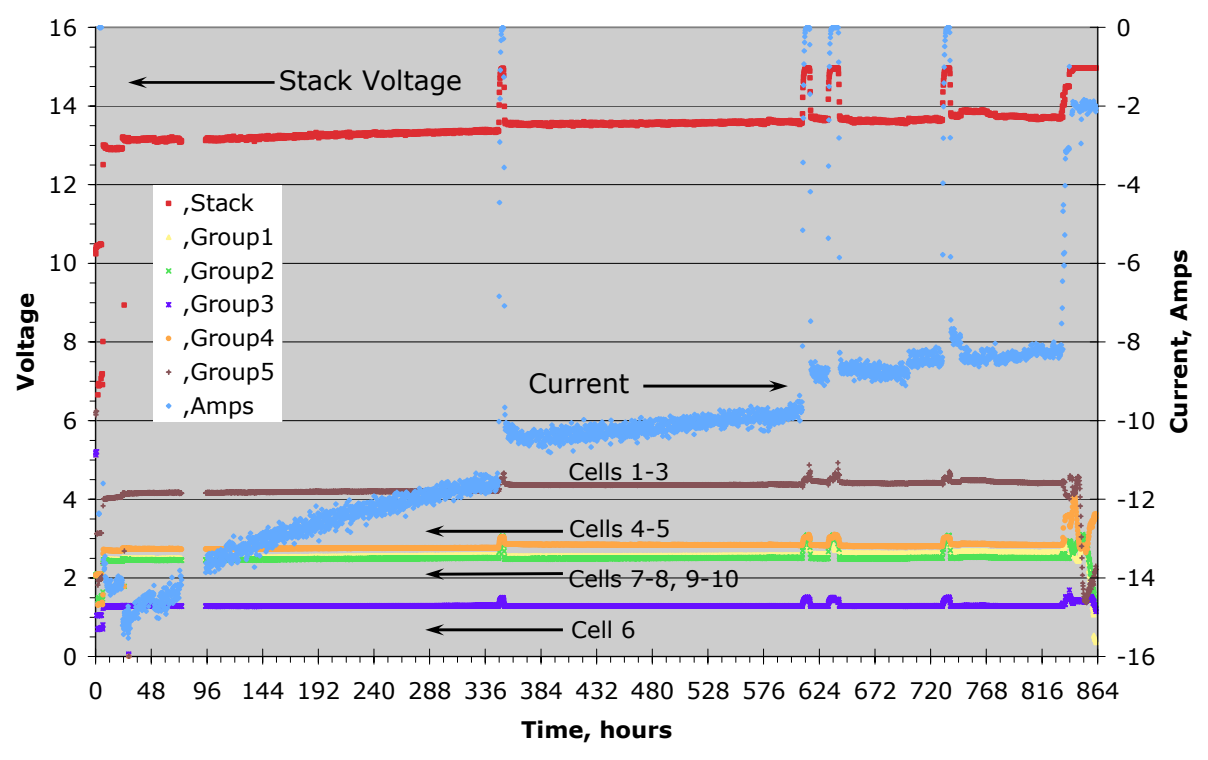

Figure 2.14. Stack $10 \mathrm{INFO} 466$ operating history.

Stack 10ICON467 was constructed with a slightly different configuration as shown in the Table 2-2 below.

This stack experienced some shorting of thermocouple and voltage leads at startup. The shorting problems were resolved, but may have been detrimental to the stack performance. Further, the

Table 2-2. Stack 10ICON467 cell and interconnect coating configuration.

\begin{tabular}{|l|l|l|}
\hline Cell number & Cell contact layer & Interconnect Coating \\
\hline $1-5$ & LSCo & LCo \\
\hline $6-10$ & LSCo & LSCo \\
\hline
\end{tabular}

heated bubbler that is used as a steam source to the stack was not functioning properly. The water level was unstable, causing wide fluctuations in bubbler temperature, and suspected leakage due to the temperature swings. Eventually, it was decided to operate the stack in 
Stack 10ICON467 History

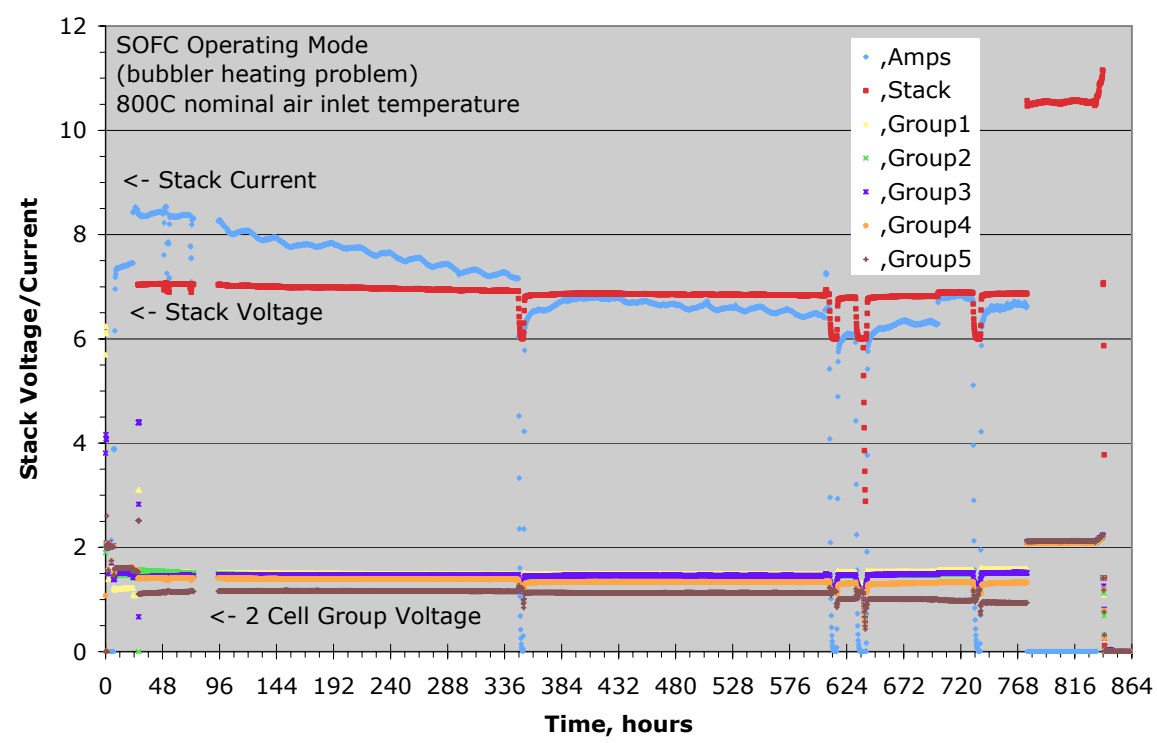

Figure 2.15. Stack 10ICON467 operating history.

SOFC mode to obtain degradation data. Stack performance was poor, however since the stack was in the same test furnace as stack 10INFO466, stack 10ICON467 was operated until the termination of testing of stack 10INFO466. This test station is being converted to a single 20x20 $\mathrm{cm}$ stack test station.

As of the end of July, a standard process hydrogen electrode ink had not been successfully qualified. However, a number of ink batches had recently been prepared for an Air Force SBIR project to develop a sulfur tolerant SOFC anode composition. One of these inks (designated Sul Tol 10-70:30), made as a baseline or control batch using the standard composition and process with the exception of one non-standard raw material source noted, had been qualified with 5 single cell showing ASR values from 0.88-0.95 $\Omega-\mathrm{cm}^{2}$. While this ASR range is a bit high, the grouping was more consistent than the ink batch used in recent stack tests. The Sul Tol 10-70:30 ink batch was used in stack 10INL468, which was tested at Ceramatec, and stack 10INL469, which was tested at INL. Cells using this ink will be used to construct at least two of the 60 cell stacks for the second ILS module. Stack 10INL468 used standard materials and processes (e.g. no LCo testing), with the exception of the electrode component supplier noted previously. Initial stack performance was good, though slightly lower than the previous best performance demonstrated in stack 10INL456 as expected given the $\sim 0.2 \Omega-\mathrm{cm}^{2}$ higher single cell ASR of this electrode ink batch. This stack was operated from 7/23-8/27 as shown inFigure 2.16 below. The stack was operated in a test station having product hydrogen exit piping, rather than the more common configuration that allows the hydrogen product to burn in the test furnace. Problems with the heat tracing in this piping periodically obstructed the line with condensate, which seems to have adversely affected the stack lifetime. 


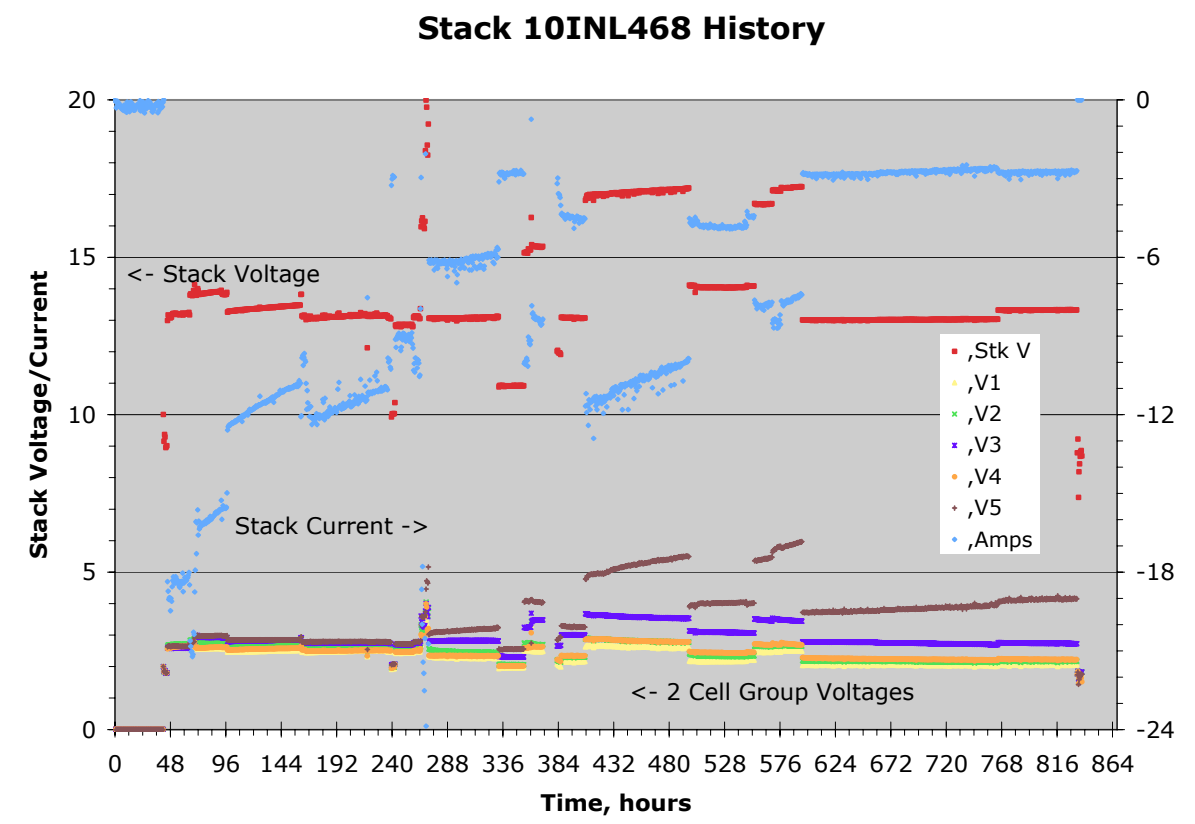

Figure 2.16. Stack 10INL468 operating history.

A different heat up and reduction profile used with stack 10INL469 tested at INL resulted in a $20 \%$ higher hydrogen production rate compared with the identically constructed stack 10INL468. The performance of stack 10INL469 surpassed that of the previous best performance achieved September 2006 with stack 10INL456. The hydrogen electrode ink qualification issue is close to being resolved. However the problem of turnover in that position continues with the technician who has worked through these issues this year departing for a new career field, after spending one week training a new hire technician.

Summary single cell and stack test tables are provided below. 
Table 2-3. Single cell test summary.

\begin{tabular}{|c|c|c|c|c|c|c|c|c|}
\hline Cell ID & Who & Electrolyte \# & Elyt. type & Anode \# & Cathode \# & ocv & |800C ASR & 2nd ASR \\
\hline INLCO2_01 & Brian & rm09102A & 6ScEs & NMCI03x_040510 & PSMI03_030522-1 & & & \\
\hline INLCO2_02 & Brian & $\mathrm{rm09102A}$ & 6ScEs & NMCI03x_040510 & PSMI03_030522-1 & & & \\
\hline INLCO2_03 & Brian & $\mathrm{rm09102A}$ & 6ScEs & NMCI03x_040510 & PSMI03_030522-1 & 1.07 & 0.79 & 0.79 \\
\hline INLCO2_ 04 & Brian & RM09165 & LSGM & NMC90:10 040510 & LSCo $90: 10$ & 0.98 & 2 & \\
\hline INLCO2_05 & Brian & $\mathrm{E}-3 \mathrm{~F} 30$ & 6ScEs & NMC_051003 & PSMZ-051210 PSM-051213 & 1.1 & 1.02 & 1.02 \\
\hline INLCO2_06 & Brian & $\mathrm{E}-3 \mathrm{~F} 30$ & $6 \mathrm{ScEs}$ & NMC_051003 & PSMZ-051210 PSM-051213 & 1.08 & 0.9 & 0.9 \\
\hline INLCe_07 & Brian & from D.L. & $\mathrm{CeO} 2$ & NMC_040510 & LSCo $90: 10$ & 0.745 & $4.6(700)$ & \\
\hline INL_LSGM08 & brian & RM4609 thin & LSGM & NMC90:10 040510 & LSCo 90:10 & 1.10 & 0.830 & \\
\hline INLCe09 & Brian & from D.L. & $\mathrm{CeO} 2$ & NMC_040510 & LSCo $90: 10$ & 0.865 & 2.56 & \\
\hline INL_LSGM10 & brian & RM4609 thin & LSGM & NMC90:10_040510 & LSCo 90:10 & 0.88 & 2.540 & \\
\hline INL_LSGM11 & brian & RM09165 & LSGM & NMC90:10 040510 & LSCo 90:10 & 1.06 & 4.9 & \\
\hline INL_LSGM12 & brian & RM09165 & LSGM & NMC90:10 040510 & LSCo 90:10 & 1.059 & 0.77 & \\
\hline INLCe13 & Brian & Akash cast & $\mathrm{CeO} 2$ & NMC_040510 & LSCo $90: 10$ & 0.771 & 1.75 & \\
\hline INLCe14 & Brian & Akash cast & $\mathrm{CeO} 2$ & NMC90:10 040510 & LSCo $90: 10$ & 0.693 & 14 & 2.3 (elec.) \\
\hline INL_LSGM15 & brian & RM4609 thin & LSGM & NMC90:10 040510 & LSCo $90: 10$ & 1.05 & 0.690 & \\
\hline INLCe16 & Brian & Akash cast & $\mathrm{CeO} 2$ & NMC90:10 040510 & LSCo $90: 10$ & 0.53 & 9.4 & \\
\hline INL_LSGM17 & brian & RM09165 & LSGM & $\begin{array}{lll}\text { NMC90:10 } & 040510\end{array}$ & LSCo $90: 10$ & 0.99 & 1.4 & \\
\hline INL_LSGM18 & brian & RM09165 & LSGM & $\begin{array}{lll}\text { NMC90:10 } & 040510 \\
\end{array}$ & LSCo 90:10 & 1.08 & 5 & \\
\hline INL_LSGM19 & brian & RM09165 & LSGM & $\begin{array}{ll}\text { NMC90:10 } & 040510 \\
\end{array}$ & LSCo $90: 10$ & & not tested & \\
\hline INLCe20 & Brian & RM & $\mathrm{CeO} 2$ & NMC 040510 & LSCo 90:10 & 0.8 & 0.59 & \\
\hline INLCe21 & Brian & RM & $\mathrm{CeO} 2$ & NMC 040510 & LSCo 90:10 & 0.786 & 0.47 & \\
\hline INL LSGM22 & brian & RM & LSGM & $\begin{array}{ll}\text { NMC90:10 } & 040510 \\
\end{array}$ & LSCo 90:10 & 1.05 & 1.6 & \\
\hline INL_LSGM23 & brian & RM & LSGM & $\begin{array}{lll}\text { NMC90:10 } & 040510 \\
\end{array}$ & LSCo $90: 10$ & 1.01 & 1.5 & \\
\hline INL_LSGM24 & brian & RM & LSGM & NMC 060915 & LSCo 90:10 & 1.04 & 0.98 & \\
\hline INL_LSGM25 & brian & RM & LSGM & NMC_060915 & LSCo 90:10 & 1.03 & 0.79 & \\
\hline INLQC26 & Dennis & & & & & 1.09 & 1 & \\
\hline INLQC27 & Dennis & & & & & 1.03 & 0.89 & \\
\hline INLQC28 & Dennis & & & & & 1.109 & 0.77 & \\
\hline INLQC29 & Dennis & & & & & & & \\
\hline INLCe30 & Brian & RM & $\mathrm{CeO} 2$ & NMC 040510 & LSCo $90: 10$ & 0.82 & 2.6 & \\
\hline INKQC032207 & $\mathrm{BH}$ & $\mathrm{BH} 110606$ & $6 \mathrm{Sc} \mathrm{Zr}$ & NMC 070227 & PSMZ 061120 / PSM 061120 & 1.055 & 0.81 & 0.81 \\
\hline INKQC032207B & $\mathrm{BH}$ & BH110606 & $6 \mathrm{Sc} \mathrm{Zr}$ & NMC 070227 & PSMZ 061120 / PSM 061120 & 1.075 & 1.24 & 1.08 \\
\hline INKQC032907L & $\mathrm{BH}$ & BH110606 & $6 \mathrm{Sc} \mathrm{Zr}$ & NMC 070227 & PSMZ 061120 / PSM 061120 & 1.035 & 1.24 & 1.08 \\
\hline INKQC032907M & $\mathrm{BH}$ & BH110606 & $6 \mathrm{Sc} \mathrm{Zr}$ & NMC 070227 & PSMZ 061120 / PSM 061120 & 1.000 & 1.01 & 1.08 \\
\hline INKQC032907D & $\mathrm{BH}$ & BH110606 & $6 \mathrm{Sc} \mathrm{Zr}$ & NMC 070227 & PSMZ 061120 / PSM 061120 & 1.075 & 1.01 & 1.08 \\
\hline Yb041707 & $\mathrm{BH}$ & BH110606 & Yb ScZr & NMC_070327 & PSMZ_061120/PSM_061120 & 1.080 & 0.84 & 0.82 \\
\hline Yb041807 & $\mathrm{BH}$ & BH110606 & Yb ScZr & NMC 070327 & PSMZ 061120 / PSM 061120 & 1.110 & 0.89 & 0.91 \\
\hline INKQC042507 & $\mathrm{BH}$ & AS030607 & Scandia & NMC_070327 & PSMZ_061120/PSM_061120 & 1.080 & 0.80 & 0.80 \\
\hline INKQC042707 & $\mathrm{BH}$ & AS030607 & Scandia & NMC_070327 & PSMZ 061120 / PSM_061120 & 1.029 & 0.80 & 0.81 \\
\hline INKQC050407 & $\mathrm{BH}$ & AS030607 & Scandia & NMC_070327 & PSMZ_070419/PSM_070419 & 1.084 & 2.44 & 2.06 \\
\hline INKQC050707 & $\mathrm{BH}$ & AS030607 & Scandia & NMC_070327 & PSMZ_070419/PSM_070419 & 1.108 & 1.31 & 1.37 \\
\hline INKQC052507 & $\mathrm{BH}$ & AS030607 & Scandia & NMC_070327 & PSMZ_070419/PSM_070419 & 1.066 & 2.37 & 2.02 \\
\hline INKQC053007 & $\mathrm{BH}$ & AS030607 & Scandia & NMC_070327 & PSMZ_070419/PSM_070419 & 1.073 & 1.80 & 1.65 \\
\hline Yb052907 & $\mathrm{BH}$ & $\mathrm{BHYbSc}$ & YbSc & NMC_070327 & PSMZ_070419/PSM_070419 & 1.080 & 4.70 & 4.50 \\
\hline Yb053007 & $\mathrm{BH}$ & $\mathrm{BHYbSc}$ & YbSc & NMC_070327 & PSMZ_070419/PSM_070419 & 1.098 & 3.08 & 2.87 \\
\hline Yb060107 & $\mathrm{BH}$ & $\mathrm{BHYbSc}$ & YbSc & NMC 070327 & PSMZ 070419/PSM 070419 & & & \\
\hline train071407 J & JW & R-AS041707 & $6 \mathrm{Sc} \mathrm{Zr}$ & NMC_070327 & PSMZ_070419/PSM_070419 & 1.092 & 1.18 & 1.33 \\
\hline train061407 & JW/I & R-AS041707 & $6 \mathrm{Sc} \mathrm{Zr}$ & NMC_070327 & PSMZ_070419/PSM_070419 & 1.052 & 0.97 & 1.11 \\
\hline train062007a & $\mathrm{I} / \mathrm{JW}$ & R-AS041707 & $6 \mathrm{Sc} \mathrm{Zr}$ & NMC_070327 & PSMZ_061120/PSM_061120 & 1.090 & 0.80 & 0.83 \\
\hline train062007b & $\mathrm{I}$ & R-AS041707 & $6 \mathrm{Sc} \mathrm{Zr}$ & NMC_070327 & PSMZ_070419/PSM_070419 & 1.073 & 0.83 & 0.89 \\
\hline train062007c & $\mathrm{I}$ & R-AS041707 & $6 \mathrm{Sc} \mathrm{Zr}$ & NMC_070327 & PSMZ_061120/PSM_061120 & 1.088 & 0.87 & 0.91 \\
\hline train $062007 d$ & JW & R-AS041707 & $6 \mathrm{Sc} \mathrm{Zr}$ & NMC_070327 & PSMZ_061120/PSM_061120 & 0.982 & 0.86 & 0.88 \\
\hline train $062007 \mathrm{e}$ & JW & R-AS041707 & $6 \mathrm{Sc} \mathrm{Zr}$ & NMC_070327 & PSMZ_061120/PSM_061120 & 0.977 & 0.89 & 0.87 \\
\hline train $062007 \mathrm{f}$ & JW & R-AS041707 & $6 \mathrm{Sc} \mathrm{Zr}$ & NMC_070327 & PSMZ_070419/PSM_070419 & 1.020 & 0.78 & 0.98 \\
\hline cc training1 & AS & R-AS041707 & $6 \mathrm{Sc} \mathrm{Zr}$ & NMC 070618 & PSMZ 060814 / PSM 060814 & 0.972 & 0.94 & 0.92 \\
\hline cc training2 & AS & R-AS041707 & $6 \mathrm{Sc} \mathrm{Zr}$ & NMC 070618 & PSMZ 060814 / PSM 060814 & & & \\
\hline Yb070307 & $\mathrm{BH}$ & YB & YbSc & NMC 70:30 comp.D Sol. Tolerant & PSMZ_061120/PSM_061120 & 1.077 & 1.7 & 0.85 \\
\hline Yb070907 & $\mathrm{BH}$ & YB & YbSc & NMC $70: 30$ comp.D Sol. Tolerant & PSMZ $061120 /$ PSM 061120 & 1.047 & 1.6 & 1.08 \\
\hline rid-070507b & $\mathrm{kc} / \mathrm{dl}$ & AS 070507 & 6 ScES & Sulfer tol. $10-70: 30$ & PSMZ $061120 / \mathrm{PSM} 061120$ & 1.0844 & 0.94 & 0.97 \\
\hline rid-070507a & $\mathrm{kc} / \mathrm{dl}$ & AS 070507 & 6 ScES & Sulfer tol. $10-70: 30$ & PSMZ $061120 /$ PSM 061120 & 1.0835 & 0.88 & 0.87 \\
\hline rid-070507c & $\mathrm{kc} / \mathrm{dl}$ & AS 070507 & 6 ScES & Sulfer tol. $10-70: 30$ & PSMZ 061120 / PSM 061120 & 1.0587 & 0.89 & 0.92 \\
\hline INKQC 070702a & $\mathrm{KC}$ & R-AS 041707 & 6 ScES & NMC 070702 & PSMZ 070419 / PSM 061120 & 1.0867 & 1.05 & 1.08 \\
\hline IQC070702\#39 & $\mathrm{KC}$ & R-AS 041707 & 6 ScES & NMC 070702 & PSMZ 070419 / PSM 061120 & 1.0804 & 1.50 & 1.66 \\
\hline IQC070702\#40 & $\mathrm{KC}$ & R-AS 041707 & 6 ScES & NMC_070702 & PSMZ 070419 / PSM 061120 & 1.0846 & 1.85 & 1.93 \\
\hline & BH & & LSGM & NMC-90:10 & LSCo & 0.92 & 25.4 & 8.20 \\
\hline & BH & & LSGM & NMC-90:10 & LSCo & 1.04 & 118 & 19.60 \\
\hline ST080707b & BH & AS030607 & Scandia & Ni.95Mg.5Ce.88Ca.12 70:30 & PSMZ 061120 / PSM 061120 & 1.0433 & 0.7441 & 0.76 \\
\hline ST080707d & BH & AS030607 & Scandia & Ni.90Mg.10Ce.88Ca.12 70:30 & PSMZ 061120 / PSM 061120 & 1.0854 & 0.8122 & 0.84 \\
\hline LSGM0810 & BH & RM4609 thin & LSGM & water based Ni.90Mg.10CeCa-70:30 & LSCo $90: 10$ & 1.046 & 3.26 & 2.20 \\
\hline CoElec083107a & JW & R-AS-041707 & $6 \mathrm{ScZr}$ & Sulf tol. 10-70:30 & PSMZ/PSM 061120 & 1.048 & 0.95 & 0.94 \\
\hline CoElec083107b & JW & R-AS-041707 & $6 \mathrm{ScZr}$ & Sulf tol. 10-70:30 & PSMZ/PSM 061120 & 1.050 & 0.95 & \\
\hline
\end{tabular}


Table 2-4. Short stack test summary.

\begin{tabular}{|c|c|c|c|c|c|}
\hline Stack ID & Project & Test Start Date & Test End Date & Performance Metrics & End of test \\
\hline 10INL456 & INL co-electrolysis & 18 -Sep-2006 & \multicolumn{2}{|c|}{12 -Oct-2006 $19.6 \mathrm{~A}$ at $13 \mathrm{~V}, 800 \mathrm{C}$} & $16.4 \mathrm{~A}$ at $13.25 \mathrm{~V}, 800 \mathrm{C}, 576 \mathrm{hr}$ \\
\hline 10INL456b & INL co-electrolysis & 12-Dec-2006 & \multirow{2}{*}{\multicolumn{2}{|c|}{ 8-Nov-2006 1.05ASR 800C, 13A, 13.2V, }} & \\
\hline 10LSGM458 & INL intermediate temp & 1 -Nov-2006 & & & $711.4 \mathrm{~A}, 13.3 \mathrm{~V}, 128 \mathrm{hr}$ \\
\hline $10 \mathrm{HXF} 460$ & INL DOE NHI & 1-Dec-2006 & \multicolumn{2}{|c|}{ 18-Dec-2006 2.7ASR 800C, 20.3A 13.1V' } & $9.7 \mathrm{~A}, 14 \mathrm{~V}, 271 \mathrm{hr}$ \\
\hline 10EXP463 & INL DOE NHI & $12-\mathrm{Feb}-2007$ & \multirow{2}{*}{$\begin{array}{r}\text { 7-Mar-2007 } \\
\text { 30-May-2007 }\end{array}$} & 1.97ASR 800C, 13A $13 \mathrm{~V}$ & $9.4 \mathrm{~A}, 13.3 \mathrm{~V}, 552 \mathrm{hr}$ \\
\hline $10 \mathrm{LCO} 464$ & INL DOE NHI & 3-May-2007 & & $11.1 \mathrm{~A} 13.2 \mathrm{~V}, 800 \mathrm{C}$ & $8.4 \mathrm{~A} 13.5 \mathrm{~V}, 350 \mathrm{hr}$ \\
\hline 10INL465 & INL co-electrolysis & 8-May-2007 & & & \\
\hline $10 I N F O 466$ & INL DOE NHI & 21-May-2007 & & $15.5 \mathrm{~A} 13.1 \mathrm{~V}, 800 \mathrm{C}$ & $8.2 \mathrm{~A} 13.7 \mathrm{~V}, 834$ hours \\
\hline $10 \mathrm{ICON} 467$ & INL DOE NHI & 21-May-2007 & $26-$ Jun-2007 & $8.5 \mathrm{~A} 7.0 \mathrm{~V}, 800 \mathrm{C}$ & $6.6 \mathrm{~A} 6.9 \mathrm{~V}, 11 \mathrm{Voc}, 776$ hours \\
\hline 10INL468 & INL DOE NHI & 23-Jul-2007 & \multirow{2}{*}{ 27-Aug-2007 } & \multirow{2}{*}{$\begin{array}{l}18.6 \mathrm{~A} 13.2 \mathrm{~V}, 800 \mathrm{C} \\
23.5 \mathrm{~A} 13.3 \mathrm{~V}, 800 \mathrm{C}\end{array}$} & $2.7 \mathrm{~A} 13.3 \mathrm{~V}, 833$ hours \\
\hline 10INL469 & INL co-electrolysis & 9-Aug-2007 & & & \\
\hline Stack ID & \multicolumn{3}{|l|}{ Test Purpose } & \multicolumn{2}{|l|}{ Comments } \\
\hline$\overline{10 I N L 456}$ & \multirow{2}{*}{\multicolumn{3}{|c|}{ Test with Ni felt bond layer }} & \multirow{2}{*}{\multicolumn{2}{|c|}{$\begin{array}{l}\text { Test terminated early - miscommunication } \\
\text { Tested at INL }\end{array}$}} \\
\hline 10INL456b & & & & & \\
\hline 10LSGM458 & \multirow{2}{*}{\multicolumn{3}{|c|}{$\begin{array}{l}\text { Intermediate temperature electrolyte (LSGM) } \\
\text { Hast-X felt bond layer on oxygen electrode }\end{array}$}} & \\
\hline $10 \mathrm{HXF} 460$ & & & & \multirow{2}{*}{\multicolumn{2}{|c|}{$\begin{array}{l}\text { Degraded quickly, } 02 \text { electrode delam post test photos } \\
\text { Same as stack } 10 \text { INL } 456 \text { except new H2 electrode batch, corner chipped multiple ba }\end{array}$}} \\
\hline $10 \mathrm{EXP} 463$ & \multicolumn{3}{|c|}{$\begin{array}{l}\text { Hast-X felt bond layer on oxygen electrode } \\
\text { Qual of ILS Module \#1 Cells }\end{array}$} & & \\
\hline $10 \mathrm{LCO} 464$ & \multirow{2}{*}{\multicolumn{3}{|c|}{ Test LCO bond layer, comparable 10 INL 465 shipped to INL }} & \multicolumn{2}{|c|}{$\begin{array}{l}\text { Same as stack } 101 \text { INL } 456 \text { except new H2 electrode batch, corner chipped multiple b } \\
\text { LLCO bond layers high BET, H2 electrode batch mixed ASR in single cell tests }\end{array}$} \\
\hline 10INL465 & & & & \multicolumn{2}{|l|}{ Tested at INL } \\
\hline $10 I N F O 466$ & \multicolumn{3}{|c|}{ LCO icons vs. LSCO, w/ LSCO contacting on cell } & \multirow{2}{*}{\multicolumn{2}{|c|}{$\begin{array}{l}\text { H2 electrode from mixed results batch } \\
\text { In dual skutt with 10INFO } 466 \text {, bubbler heat problem, SOFC operation, initial TC and voltage lead shorting }\end{array}$}} \\
\hline 10ICON467 & \multicolumn{3}{|c|}{ LCO icons vs. LSCO, w/LSCO contacting on cell } & & \\
\hline 10INL468 & \multirow{2}{*}{\multicolumn{3}{|c|}{$\begin{array}{l}\text { Standard process with H2 electrode from S-tol } \\
\text { steam, steam-CO2 \& Dry CO2 sweep comparisons }\end{array}$}} & \multirow{2}{*}{\multicolumn{2}{|c|}{ H2 exhaust blockage with condensate, $\mathrm{H} 2$ electrode standard except Ni source }} \\
\hline 10INL469 & & & & & \\
\hline
\end{tabular}




\section{SINGLE CELL TESTS AT THE INL}

\subsection{INL EXPERIMENTAL APPARATUS}

A schematic of the experimental apparatus used for single-cell and short-stack high-temperature electrolysis testing is presented in Figure 3.1. A photograph of the hardware is presented in Figure 3.2. Primary components include gas supply cylinders, mass-flow controllers, a humidifier, on-line dewpoint and $\mathrm{CO}_{2}$ measurement stations, temperature and pressure measurement, high temperature furnaces, a solid oxide electrolysis cell or stack, and a precision microchannel gas chromatograph. Nitrogen is used as an inert carrier gas. Inlet flow rates of nitrogen, hydrogen, carbon dioxide and air are established by means of precision mass-flow controllers. Hydrogen is included in the inlet flow as a reducing gas in order to prevent oxidation of the Nickel cermet electrode material. Air flow to the stack is supplied by the shop air system, after passing through a two-stage extractor / dryer unit. The nitrogen/ hydrogen / $\mathrm{CO}_{2}$ gas mixture is mixed with steam by means of a heated humidifier. The dewpoint temperature of the nitrogen / hydrogen $/ \mathrm{CO}_{2} /$ steam gas mixture exiting the humidifier is monitored continuously using a precision dewpoint sensor. All gas lines located downstream of the humidifier are heat-traced in order to prevent steam condensation. Inlet and outlet $\mathrm{CO}_{2}$

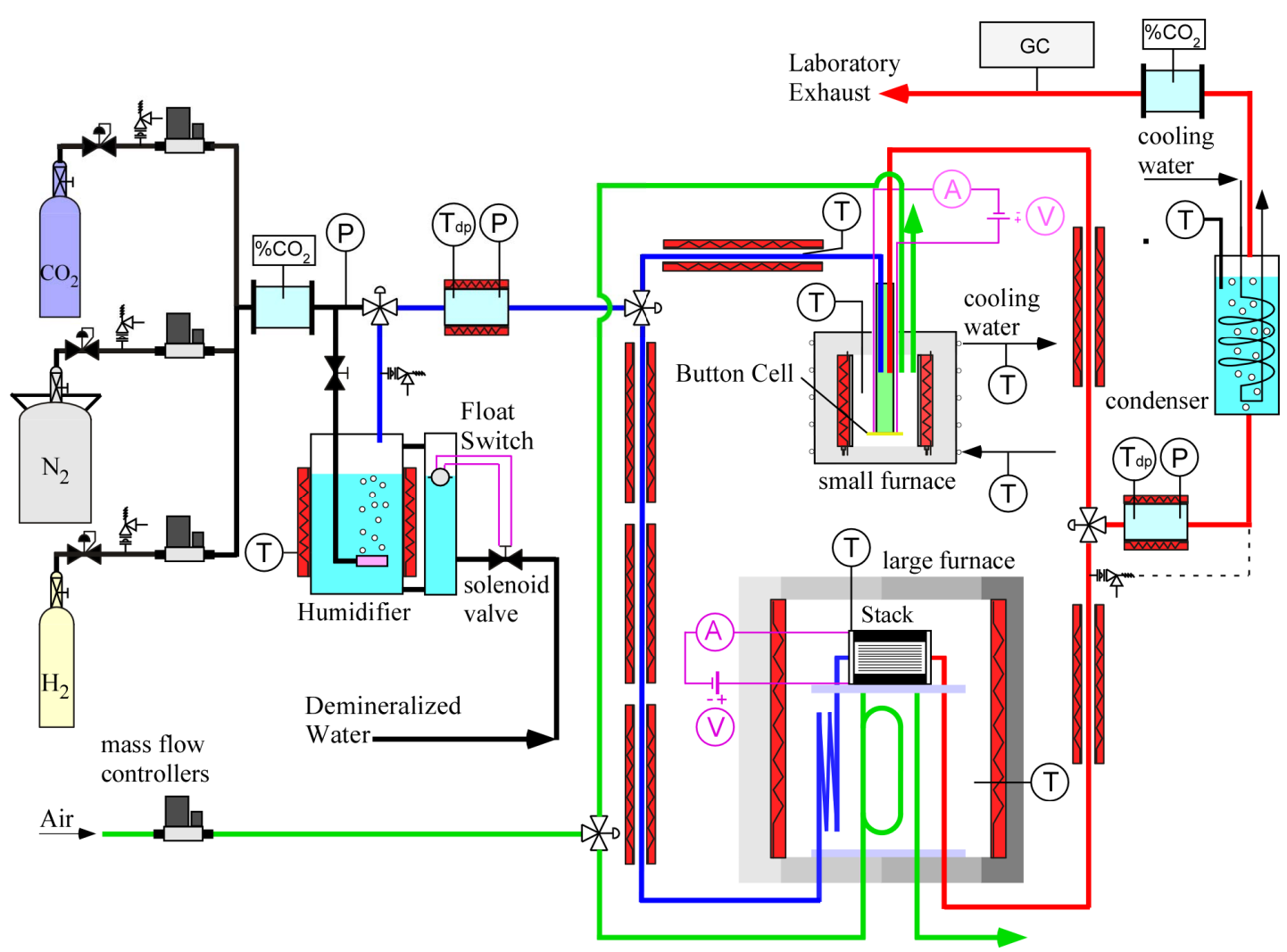

Figure 3.1. Schematic of the INL high temperature solid oxide electrolysis apparatus. 
concentrations are also monitored continuously using on-line infra-red $\mathrm{CO}_{2}$ sensors.

For single-cell testing, an electrolysis button cell is bonded to the bottom of a zirconia tube, as shown in Figure 3.3. During testing, the tube is suspended in the furnace. This cell is an electrolyte-supported single button cell with a scandia-stabilized zirconia electrolyte, about 150 $\mu \mathrm{m}$ thick. The outside electrode, which acts as the cathode in fuel cell mode and the anode in electrolysis mode, is a doped manganite. The inside electrode (electrolysis cathode) material is a nickel cermet. Both button-cell electrodes incorporate a platinum wire mesh for current distribution. The button cell includes both an active cell area $\left(2.5 \mathrm{~cm}^{2}\right.$ for the cell shown) and a reference cell area. The active cell area is wired with both power lead wires and voltage taps. The reference cell area is wired only with voltage taps, allowing for continuous monitoring of open-cell potential. The button cell is bonded to the end of a large (OD = 1.25 in., ID =1.1 in.) zirconia tube using a glass seal. The power lead and voltage wires are routed to the far end of the zirconia tube via several small-diameter alumina tubes fixed to the outside of the zirconia manifold tube. A type-K stainless-steel sheathed thermocouple, is mounted on the manifold tube and bent around in front of the button cell in order to allow for continuous monitoring of the button-cell temperature.

The inlet gas mixture enters this tube, directing the gas to the steam/hydrogen $/ \mathrm{CO}_{2}$ side (inside) of the cell. The cell is maintained at an appropriate operating temperature $\left(800\right.$ to $\left.850^{\circ} \mathrm{C}\right)$ via computer-based feedback control. The furnace also preheats the inlet gas mixture and the air sweep gas. Oxygen produced by electrolysis is captured by the sweep gas stream and expelled into the laboratory. The syngas product stream exits the zirconia tube and is directed towards the

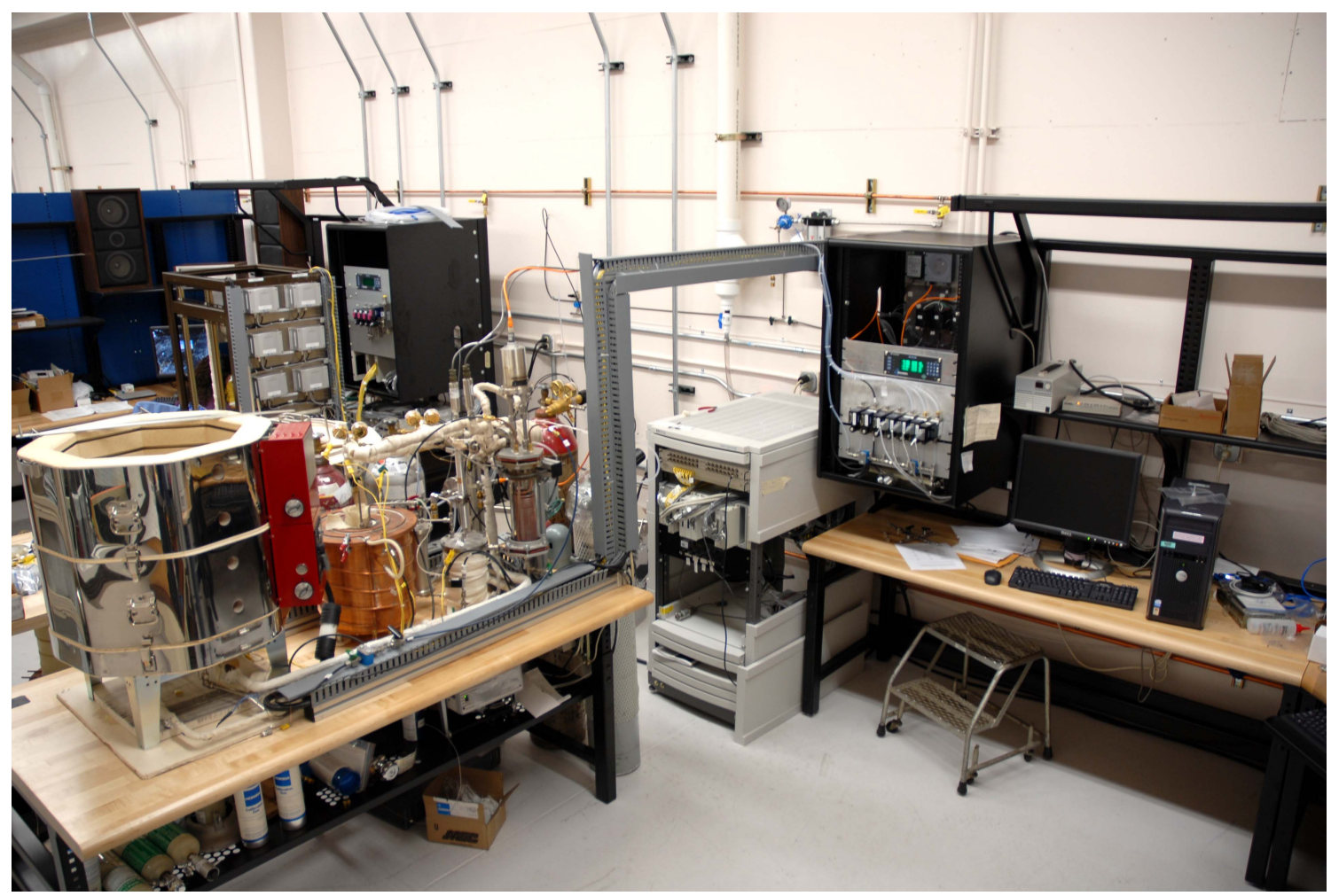

Figure 3.2. Photograph of the INL high-temperature electrolysis laboratory. 


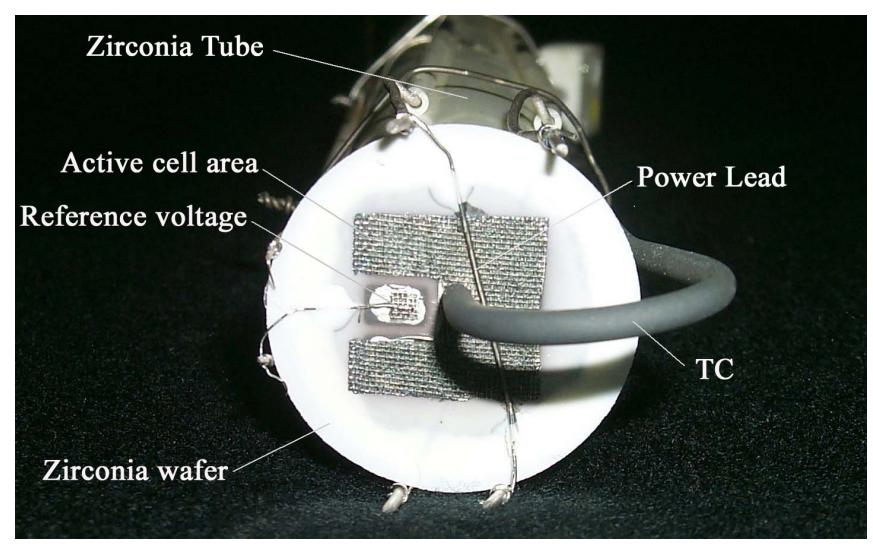

Figure 3.3. Detail of button cell.

downstream dewpoint and $\mathrm{CO}_{2}$ sensors and then to a condenser through a heat-traced line. The condenser removes most of the residual steam from the exhaust. The final exhaust stream is vented outside the laboratory through the roof. Rates of steam and $\mathrm{CO}_{2}$ electrolysis are monitored by the measured change in inlet and outlet steam and $\mathrm{CO}_{2}$ concentration as measured by the on-line sensors. In addition, a Gas Chromatograph (GC) has been incorporated into the facility downstream of the condenser to precisely quantify the composition of the dry constituents in the electrolysis product stream (including any $\mathrm{CH}_{4}$ that may be produced).

\subsection{PROCEDURE}

Prior to each test, a slow automated ramp-up of the electrolysis cell temperature is performed until the desired test temperature is achieved. Heating times of $4-8$ hours are used to take the cell from room temperature to $800^{\circ} \mathrm{C}$. During this time, the desired humidifier, humidity sensing station, and heat trace temperatures are established. Nitrogen, hydrogen, $\mathrm{CO}_{2}$ and air gas flow rates are also set using the mass-flow controller electronics. When the furnace temperature reaches about $450^{\circ} \mathrm{C}$, data recording is initiated in order to document details of the heatup process, including open-cell potential.

Coelectrolysis details were examined by performing stepwise DC potential sweeps, allowing steady-state conditions to be established before recording data at each operating point. Due to the low gas flow rates associated with single-cell testing, about 10 minutes were required at each operating voltage for steady-state conditions to be established at the outlet dewpoint, outlet $\mathrm{CO}_{2}$, and $\mathrm{GC}$ measurement stations. The outlet on-line $\mathrm{CO}_{2}$ sensor was used primarily to indicate when steady-state conditions were achieved at the outlet. Since these large time intervals were required for steady-state, relatively large voltage increments of typically $100 \mathrm{mV}$ were used in performing the sweeps. Even so, a complete steady-state sweep required about $4-5$ hours to complete.

\subsection{DATA REDUCTION}

Inlet and outlet gas stream dewpoint temperatures were directly measured in this work. For the coelectrolysis system, the outlet dewpoint value is dependent on the inlet value, the current density, and the shift reaction equilibrium. At open-cell conditions the outlet dewpoint value is higher than the inlet value due to the shift reaction. Measured dewpoints permit direct determination of inlet and outlet steam mole fractions, for comparison against equilibrium predictions. From the measured dewpoint temperatures, water vapor pressures may be calculated 
from an appropriate correlation (e.g., Antoine correlation). The inlet and outlet mole fractions of steam can then be obtained from:

$$
y_{H 2 O, i}=\frac{P_{H 2 O, i}}{P} ; \quad y_{H 2 O, o}=\frac{P_{H 2 O, o}}{P}
$$

where $\mathrm{P}$ is the total pressure at the measurement station, which is directly measured in this study at both dewpoint stations.

It should be noted that since the mole fraction of steam in the inlet gas flow is determined strictly by the dewpoint temperature, the total inlet volumetric flow rate of steam is therefore directly proportional to the sum of the volumetric flow rates of nitrogen, hydrogen and $\mathrm{CO}_{2}$ :

$$
Q_{s, \mathrm{H}_{2} \mathrm{O}, i}=\frac{\left(Q_{s, \mathrm{~N}_{2}, i}+Q_{s, \mathrm{H}_{2}, i}+Q_{s, \mathrm{CO}_{2}}\right) y_{\mathrm{H}_{2} \mathrm{O}, i}}{1-y_{\mathrm{H}_{2} \mathrm{O}, i}}
$$

The inlet mole fractions of the other components can then be evaluated as the ratio of the molar or volumetric flow rate of each component to the total molar or volumetric flow rate. For example, for carbon dioxide:

$$
y_{\mathrm{CO}_{2}, i}=\frac{Q_{s, \mathrm{CO}_{2}}}{\sum_{j} Q_{s, j}} ; \dot{N}_{\mathrm{CO}_{2}}=Q_{s, \mathrm{CO}_{2}} \frac{P_{s t d}}{R_{u} T_{s t d}} ;
$$

For coelectrolysis, the magnitude of the total steam plus $\mathrm{CO}_{2}$ flow rates is important in determining whether or not oxygen starvation is likely to occur during electrolysis operation.

An important performance parameter that quantifies the losses associated with the operation of solid-oxide electrolysis cells is the area-specific resistance (ASR). This quantity is defined as:

$$
A S R=\frac{V_{o p}-V_{r e f}}{i}
$$

where $V_{o p}$ is the applied operating potential, $V_{\text {ref }}$ is the reference or open-cell potential and $i$ is the current density $\left(I / A_{\text {cell }}, \mathrm{A} / \mathrm{cm}^{2}\right)$. In calculating area-specific resistance, we have used the reference voltage measured using the reference electrode on the button cell at each operating condition. Although it always represents an open-cell potential, this reference voltage varies slightly from the zero-current value as the current through the active cell is varied. This variation is due to the change in local gas composition at the electrode surfaces during cell operation.

\subsection{INL CHEMICAL EQUILIBRIUM MODEL}

The open-cell potential for the mixed coelectrolysis system can be calculated as a function of temperature using the Nernst equation for either steam-hydrogen or for $\mathrm{CO}_{2}-\mathrm{CO}$, provided the equilibrium composition of the components is used in the evaluating the equation. Therefore, prior to applying the Nernst equation, the equilibrium composition must be determined at the operating temperature. Our chemical equilibrium coelectrolysis model determines the equilibrium composition of the system as follows.

The overall shift reaction that occurs during heatup from the cold unmixed inlet conditions to the hot pre-electrolyzer state can be represented as: 


$$
\begin{aligned}
y_{0, \mathrm{CO}} \mathrm{CO}+y_{0, \mathrm{CO} 2} \mathrm{CO}_{2}+y_{0, \mathrm{H} 2} \mathrm{H}_{2}+y_{0, \mathrm{H} 2 \mathrm{O}} \mathrm{H}_{2} \mathrm{O} \rightarrow & \\
\mathrm{y}_{1, \mathrm{CO}} \mathrm{CO} & +\mathrm{y}_{1, \mathrm{CO} 2} \mathrm{CO}_{2}+\mathrm{y}_{1, \mathrm{H} 2} \mathrm{H}_{2}+\mathrm{y}_{1, \mathrm{H} 2 \mathrm{O}} \mathrm{H}_{2} \mathrm{O}
\end{aligned}
$$

where the $y_{0}$ values represent the cold inlet mole fractions of $\mathrm{CO}, \mathrm{CO}_{2}, \mathrm{H}_{2}$, and $\mathrm{H}_{2} \mathrm{O}$, respectively, that are known from the inlet gas flow rate and dewpoint measurements. The unknown hot equilibrium mole fractions of the four species at the electrolyzer temperature, prior to electrolysis, are represented by the $y_{1}$ values. The three chemical balance equations for carbon, hydrogen, and oxygen corresponding to Eqn. (6) are:

$$
\begin{gathered}
\mathrm{y}_{0, \mathrm{CO}}+\mathrm{y}_{0, \mathrm{CO} 2}=\mathrm{y}_{1, \mathrm{CO}}+\mathrm{y}_{1, \mathrm{CO} 2} \\
2 \mathrm{y}_{0, \mathrm{H} 2}+2 \mathrm{y}_{0, \mathrm{H} 2 \mathrm{O}}=2 \mathrm{y}_{1, \mathrm{H} 2}+2 \mathrm{y}_{1, \mathrm{H} 2 \mathrm{O}} \\
\mathrm{y}_{0, \mathrm{CO}}+2 \mathrm{y}_{0, \mathrm{CO} 2}+\mathrm{y}_{0, \mathrm{H} 2 \mathrm{O}}=\mathrm{y}_{1, \mathrm{CO}}+2 \mathrm{y}_{1, \mathrm{CO} 2}+\mathrm{y}_{1, \mathrm{H} 2 \mathrm{O}}
\end{gathered}
$$

The final equation invokes the equilibrium constant for the shift reaction:

$$
K_{e q}(T)=\frac{y_{1, C O 2} y_{1, H 2}}{y_{1, C O} y_{1, H 2 O}}
$$

completing a system of four equations and four unknowns. Simultaneous solution of this system of equations yields the hot inlet composition.

Once the hot inlet equilibrium composition is determined, the Nernst potential can be calculated from:

$$
V_{N}=\frac{-\Delta G_{f, H_{2} O}(T)}{2 F}-\frac{R_{u} T}{2 F} \ln \left[\left(\frac{y_{1, H 2 O}}{y_{1, H 2} y_{O 2}^{1 / 2}}\right)\left(\frac{P}{P_{s t d}}\right)^{-1 / 2}\right]=\frac{-\Delta G_{f, C O_{2}}(T)}{2 F}-\frac{R_{u} T}{2 F} \ln \left[\left(\frac{y_{1, C O 2}}{y_{1, C O} y_{O 2}^{1 / 2}}\right)\left(\frac{P}{P_{s t d}}\right)^{-1 / 2}\right]
$$

where $y_{\mathrm{O} 2}$ is the mole fraction of oxygen on the air side of the cells $\left(y_{\mathrm{O} 2} \sim 0.21\right)$. Note that the Nernst equation for either steam-hydrogen or $\mathrm{CO} 2-\mathrm{CO}$ yields the same result for the equilibrium system.

The electrolyzer outlet composition can be determined similarly, after accounting for electrochemical reduction of the system. The chemical balance equation for oxygen must be modified to account for oxygen removal from the $\mathrm{CO}_{2}$ /steam mixture. Accordingly, the oxygen balance equation becomes:

$$
y_{1, \mathrm{CO}}+2 y_{1, \mathrm{CO} 2}+y_{1, \mathrm{H} 2 \mathrm{O}}=y_{2, \mathrm{CO}}+2 y_{2, \mathrm{CO} 2}+y_{2, \mathrm{H} 2 \mathrm{O}}+\Delta n_{\mathrm{O}}
$$

where $\Delta n_{O}$ is the relative molar rate of monatomic oxygen removal from the $\mathrm{CO}_{2} /$ steam mixture given by:

$$
\Delta n_{O}=\frac{I_{e}}{2 F \dot{N}_{T o t}}
$$


In this equation, $I_{e}$ is the total ionic current, given by the product of the stack electrical current and the number of cells (only one in this case), $\dot{N}_{T o t}$ is the total molar flow rate on the $\mathrm{CO}_{2} /$ steam side, including any inert gas flows, and $F$ is the Faraday number. Finally, using the modified oxygen balance equation, the post-electrolyzer equilibrium composition (state 2) can be determined as a function of temperature from simultaneous solution of three chemical balance equations and the equilibrium constant equation.

This calculated final equilibrium composition can be compared to measurements obtained with the downstream dewpoint sensor for steam and with the gas chromatograph for the other gases. However, since these downstream gas composition measurements are obtained at near-room temperatures, these measured compositions are not necessarily expected to agree with predicted outlet compositions evaluated at the furnace temperature. During cool-down from the furnace temperature to room temperature, the gas composition can change, in accordance with the temperature dependence of the shift-reaction equilibrium constant. However, predictions evaluated at some lower "effective" equilibrium temperature, below which the reaction becomes kinetically frozen, can be used for comparison to the measurements $[6,7]$.

The coelectrolysis chemical equilibrium model has been expanded to include an energy balance across the electrolyzer [8]. In this form, the CEC model allows for accurate determination of coelectrolysis outlet temperature, composition (anode and cathode sides), mean Nernst potential, operating voltage and electrolyzer power based on specified inlet gas flow rates, heat loss or gain, current density, and cell $A S R(T)$. Alternately, for isothermal operation, it allows for determination of outlet composition, mean Nernst potential, operating voltage, electrolyzer power, and the isothermal heat requirement for specified inlet gas flow rates, operating temperature, current density and $A S R(T)$. This version of the model was developed for incorporation into large-scale system analyses [9].

\subsection{INL SINGLE-CELL EXPERIMENTAL RESULTS}

Open-cell potentials are monitored continuously during heatup as a system diagnostic. A significant departure of measured open-cell potentials from predicted values can indicate a problem such as a cracked cell or a short circuit. A plot of open-cell potentials measured during heatup with both the active cell $\left(V_{o p}\right)$ and the reference cell $\left(V_{r e f}\right)$ is presented in Figure 3.4. The gas flow rates and inlet dewpoint values used during the heatup are indicated in the figure. Predicted Nernst potentials based on temperature-dependent equilibrium compositions, and Eqn. (11) are also shown. Above $500^{\circ} \mathrm{C}$, agreement between the measured potentials and theoretical values is generally within a few millivolts.

Coelectrolysis performance was characterized through a series of stepwise DC potential sweeps. Results of three sweeps are presented in Figure 3.5, Figure 3.6, and Figure 4.1. The furnace temperature for all three sweeps was $800^{\circ} \mathrm{C}$. Inlet gas flow rates and inlet dewpoint values for each of these three sweeps are provided in Table 3-1. The corresponding inlet volume flow rate of steam is also provided in the table. Sweep 1 had the highest steam flow rate; sweep 3 had the lowest. Note that the flow rates used for these test were quite small. Low flow rates were required in order to achieve reasonable steam and $\mathrm{CO}_{2}$ utilization values with low values of total cell current. The single cell, with an active area of $2.5 \mathrm{~cm}^{2}$, could only support a maximum total current of about $0.75 \mathrm{~A}$. 


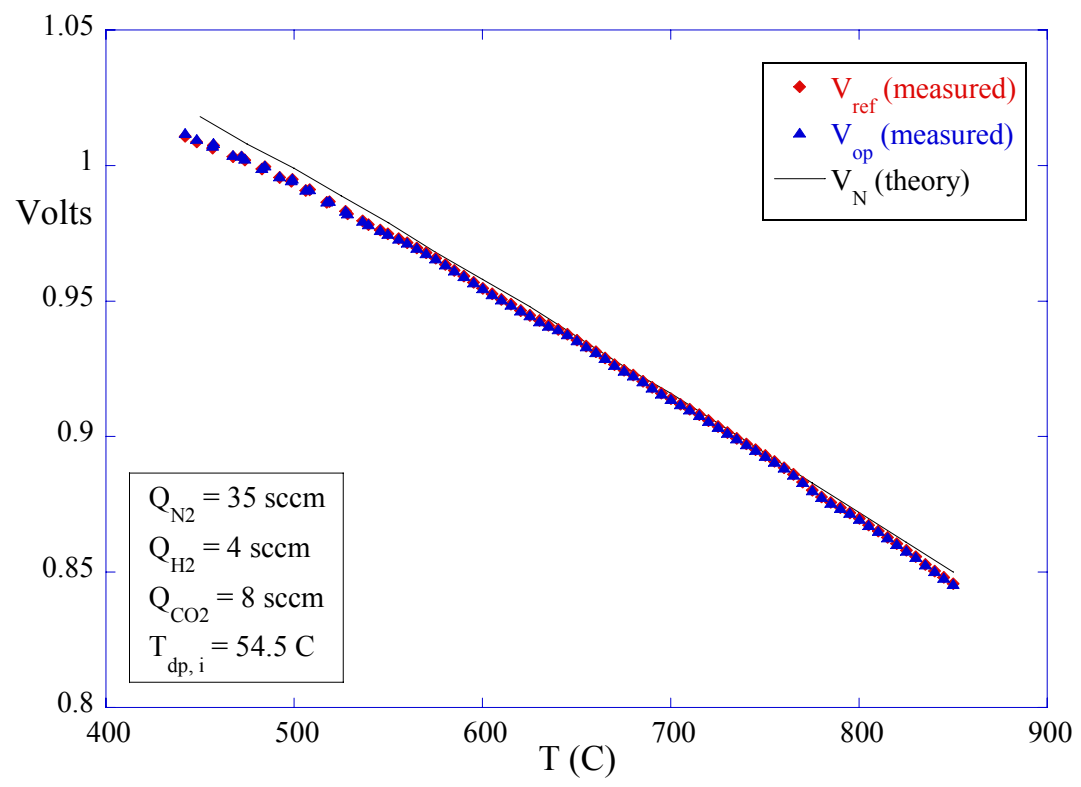

Figure 3.4. Open-cell potential during heatup, measured and. predicted.

Operating voltage, reference voltage, and cell area-specific resistance (ASR, Ohm. $\mathrm{cm}^{2}$ ) are plotted in Figure 3.5 as a function of current density. In these figures, negative values of current density represent the fuel-cell mode of operation; positive values represent the electrolysis mode. ASR values are based on the reference voltage, per Eqn. (4). Theoretical open-cell voltage $(\mathrm{OCV})$ values corresponding to the equilibrium composition and furnace temperature, calculated using Eqn. (11) are also shown in each figure at zero current density.

Polarization and ASR curves for sweep 1, shown in Figure 3.5(a), indicate a relatively high value of ASR in the fuel cell mode at the lowest current density value $\left(-0.068 \mathrm{~A} / \mathrm{cm}^{2}\right)$. This is due to the low inlet hydrogen flow rate used in this sweep. The cell is hydrogen-starved at this operating point, yielding a large concentration overpotential. Otherwise, at higher current densities, ASR values for sweep 1 are relatively constant, with an average value of 0.80 $\mathrm{Ohm} \cdot \mathrm{cm}^{2}$. The variation in reference voltage shown in these figures is due to the change in local gas composition at the electrode surfaces during cell operation. Since the ASR values plotted in these figures are based on this reference voltage, they represent true ASR values for each operating point.

Polarization and ASR curves for sweep 2, shown in Figure 3.5(b), indicate relatively high values

Table 3-1. Inlet conditions for DC potential sweeps.

\begin{tabular}{|l|c|c|c|}
\hline & Sweep 1 & Sweep 2 & Sweep 3 \\
\hline$Q_{N 2}(\mathrm{sccm})$ & 35 & 50 & 40 \\
\hline$Q_{\mathrm{H} 2}(\mathrm{sccm})$ & 4 & 3 & 8 \\
\hline$Q_{\mathrm{CO} 2}(\mathrm{sccm})$ & 8 & 6 & 8 \\
\hline$T_{d p, i}\left({ }^{\circ} \mathrm{C}\right)$ & 55.1 & 44.6 & 30.1 \\
\hline$Q_{H 2 O}(\mathrm{sccm})$ & 10.67 & 7.27 & 2.93 \\
\hline$T_{f}\left({ }^{\circ} \mathrm{C}\right)$ & 800 & 800 & 800 \\
\hline
\end{tabular}


of ASR at both current density extremes. High ASR values were observed in the fuel cell mode at a current density of -0.054 $\mathrm{A} / \mathrm{cm}^{2}$ and in the electrolysis mode at 0.233 $\mathrm{A} / \mathrm{cm}^{2}$. At the lowest current density, the high ASR value is related to hydrogen starvation in the fuel cell mode. At the highest current density, the high ASR value is related to oxygen starvation (from $\mathrm{CO}_{2}$ and steam) in the electrolysis mode. Otherwise, at intermediate values of current density, ASR values for this sweep averaged $1.19 \mathrm{Ohm} \cdot \mathrm{cm}^{2}$.

Sweep 3 had the highest hydrogen flow rate and the lowest inlet dewpoint value of the three sweeps. Polarization and ASR curves for sweep 3, shown in Figure 3.5(c) reflect the low steam content, showing a significant elevation in ASR at the highest current density values. Otherwise, at lower current densities, the average ASR value was 0.79 $\mathrm{Ohm} \cdot \mathrm{cm}^{2}$.

It should be noted that, for similar operating conditions, there was no significant difference between the ASR values measured for pure steam electrolysis and those for coelectrolysis.

The effect of electrolysis on gas composition is shown in Figure $3.6(\mathrm{a}-\mathrm{c})$. These figures plot the mole percent of $\mathrm{H}_{2}, \mathrm{CO}$, and $\mathrm{CO}_{2}$ as a function of cell current, on a dry basis, for the same three sweeps plotted in Figure 3.5. The data symbols represent measurements obtained from the gas chromatograph. The lines represent predictions based on our chemical equilibrium coelectrolysis model (CECM). Two lines are shown for each case. The dashed lines represent CECM predictions based on an effective equilibrium temperature of $700^{\circ} \mathrm{C}$. The dotted lines represent CECM predictions based on an effective equilibrium temperature of $650^{\circ} \mathrm{C}$.

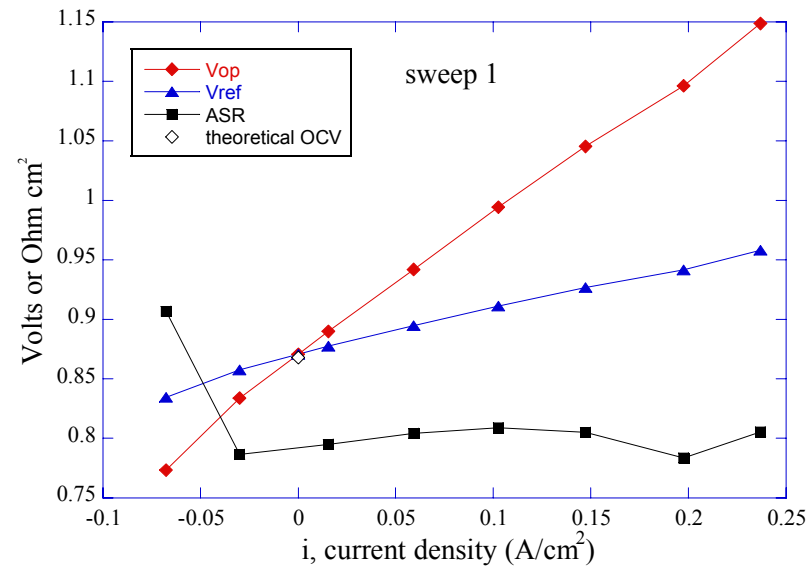

(a)

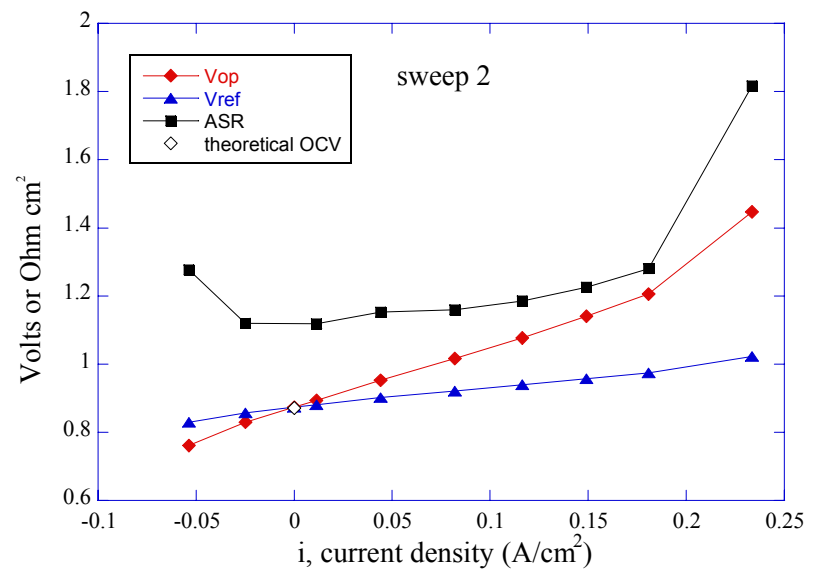

(b)

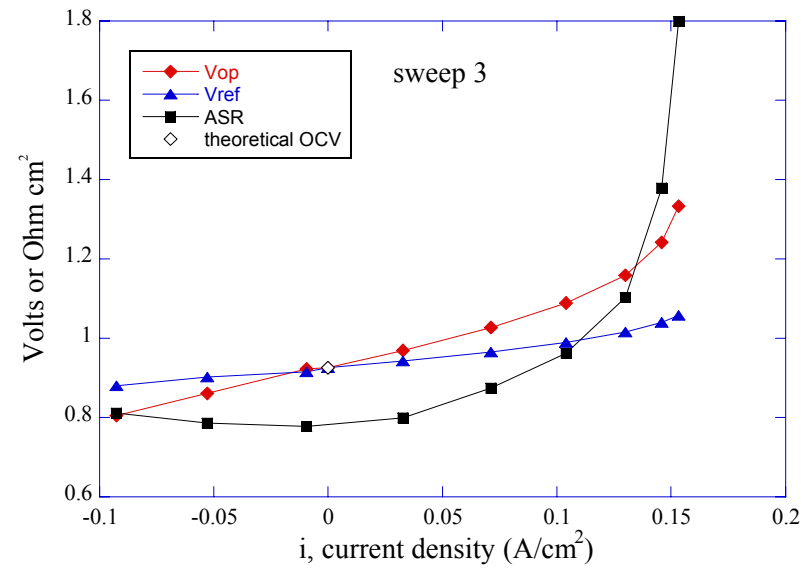

(c)

Figure 3.5. Polarization curves and area-specific resistances for sweeps $1-3$. 
During coelectrolysis, the mole fractions of $\mathrm{CO}_{2}$ and steam (not shown in Figure 3.6) decrease with current, while the mole fractions of $\mathrm{H}_{2}$ and $\mathrm{CO}$ increase. For the conditions chosen for these tests, the ratio of $\mathrm{H}_{2}$ to $\mathrm{CO}$ is close to the desired 2-to-1 value for syngas production. Measured compositions of $\mathrm{CO}_{2}$ and $\mathrm{CO}$ agree best with predictions based on an effective equilibrium temperature of $700^{\circ} \mathrm{C}$. Measured compositions of $\mathrm{H}_{2}$ agree best with predictions based on an effective equilibrium temperature of $650^{\circ} \mathrm{C}$.

The effect of electrolysis on outlet steam content is shown in Figure $4.1(\mathrm{a}-\mathrm{c})$. These figures plot the outlet dewpoint temperature of the process gas mixture as a function of cell current for the same three sweeps presented in Figure 3.5 and Figure 3.6. Outlet dewpoint temperature measurements are obtained from the downstream dewpoint sensor located upstream of the condenser unit and the GC. The inlet dewpoint values for each sweep are listed in Table 3-1. Note that the zero-current outlet dewpoint values are higher than the inlet dewpoint values, due to the shift reaction. The data symbols in Figure 4.1 represent measurements and the lines represent predictions based on the CECM. Again, the dashed lines represent CECM predictions based on an effective equilibrium temperature of $700^{\circ} \mathrm{C}$. The dotted lines represent CECM predictions based on an effective equilibrium temperature of $650^{\circ} \mathrm{C}$.

During coelectrolysis, the outlet dewpoint value decreases with cell current. Measured dewpoint values agreed best with CECM predictions based on an effective equilibrium temperature of $650^{\circ} \mathrm{C}$. Note that the outlet dewpoint temperature for sweep 3 is quite low at the highest current densities, consistent with the high $A S R$ value observed at this operating condition.

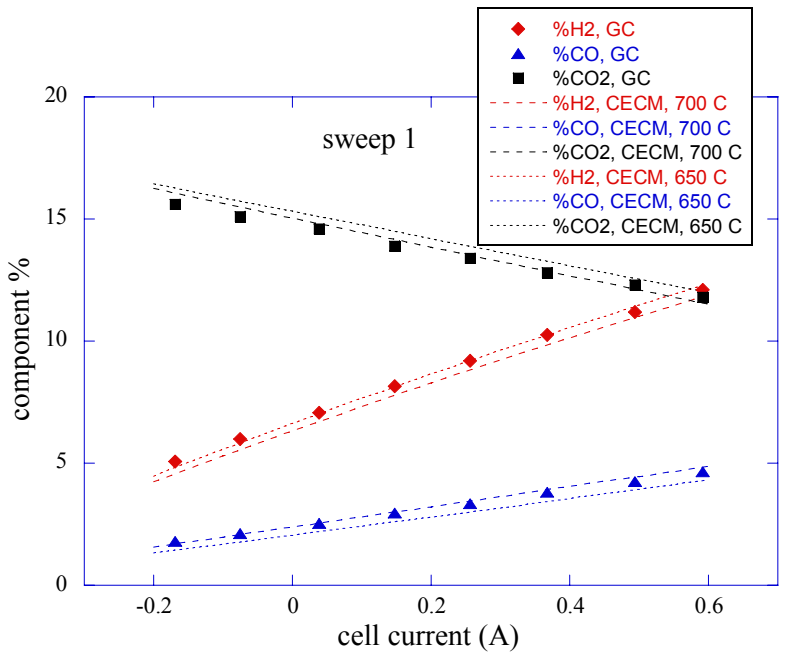

(a)

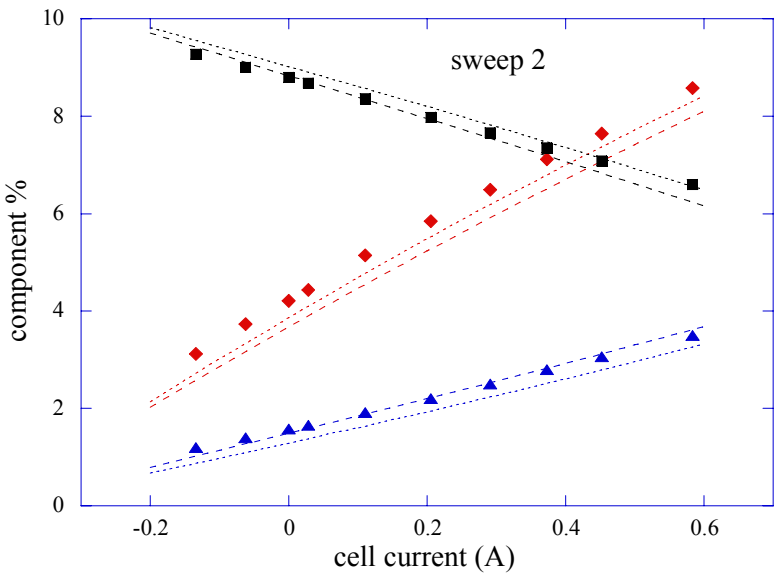

(b)

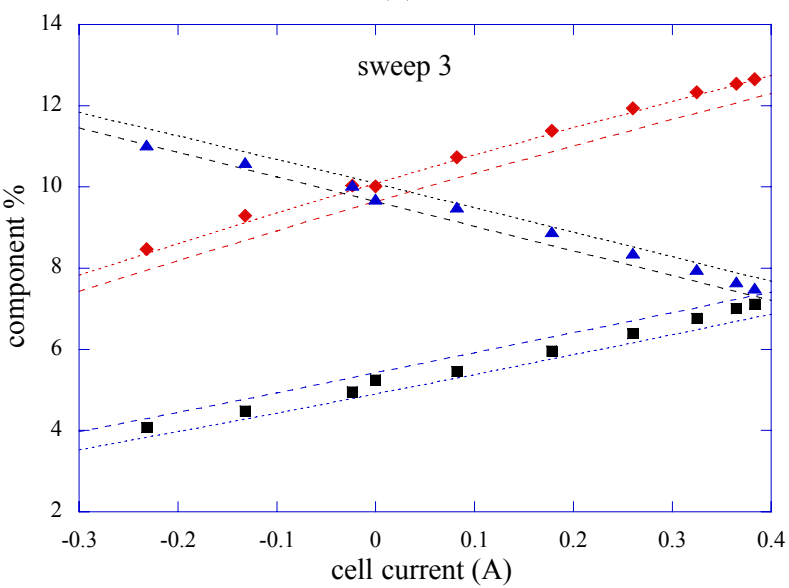

(c)

Figure 3.6. Measured outlet gas compositions, with comparisons to predictions from the chemical equilibrium coelectrolysis model, sweeps $1-3$. 


\section{INL SHORT STACK TESTS}

A series of high-temperature electrolysis tests was performed using a 10-cell planar stack operating in both steam electrolysis and coelectrolysis modes. Results of these tests will now be presented. The results include electrolysis performance at various temperatures, gas mixtures, and electrical settings. Product gas compositions, as measured via an online micro gas chromatograph (GC), are compared to predictions obtained from a chemical equilibrium/electrolysis model. Better understanding of the feasibility of producing syngas using high temperature electrolysis may initiate the systematic investigation of nuclearpowered synfuel production as a bridge to the future hydrogen economy and ultimate independence from foreign energy resources [10].

A schematic of the short planar stack-testing apparatus was presented in Figure 3.1. Downstream of the mass-flow controllers, nitrogen is mixed with smaller flows of hydrogen gas and $\mathrm{CO}_{2}$. Hydrogen is included in the inlet flow as a reducing gas in order to prevent oxidation of the nickel cermet electrode material. The nitrogen / hydrogen / $\mathrm{CO}_{2}$ gas mixture is mixed with steam by means of a heated humidifier. The humidifier water temperature is maintained at a constant setpoint value using computerized feedback control. The dewpoint temperature of the nitrogen / hydrogen / $\mathrm{CO}_{2} /$ steam gas mixture exiting the humidifier is monitored continuously using a precision dewpoint sensor. Pressure is also measured at the dewpoint measurement stations using absolute pressure transducers. Local stream pressure information is required to determine the mole fraction of steam in the gas mixture at the dew point measurement station. These measurements have indicated that the dewpoint temperature of the gas mixture leaving the humidifier is very close to the water bath temperature, but not necessarily equal to it. Inlet $\mathrm{CO}_{2}$ concentration is also monitored using an infrared $\mathrm{CO}_{2}$ sensor. Since the vapor pressure of the water and the resulting partial pressure of the steam exiting the
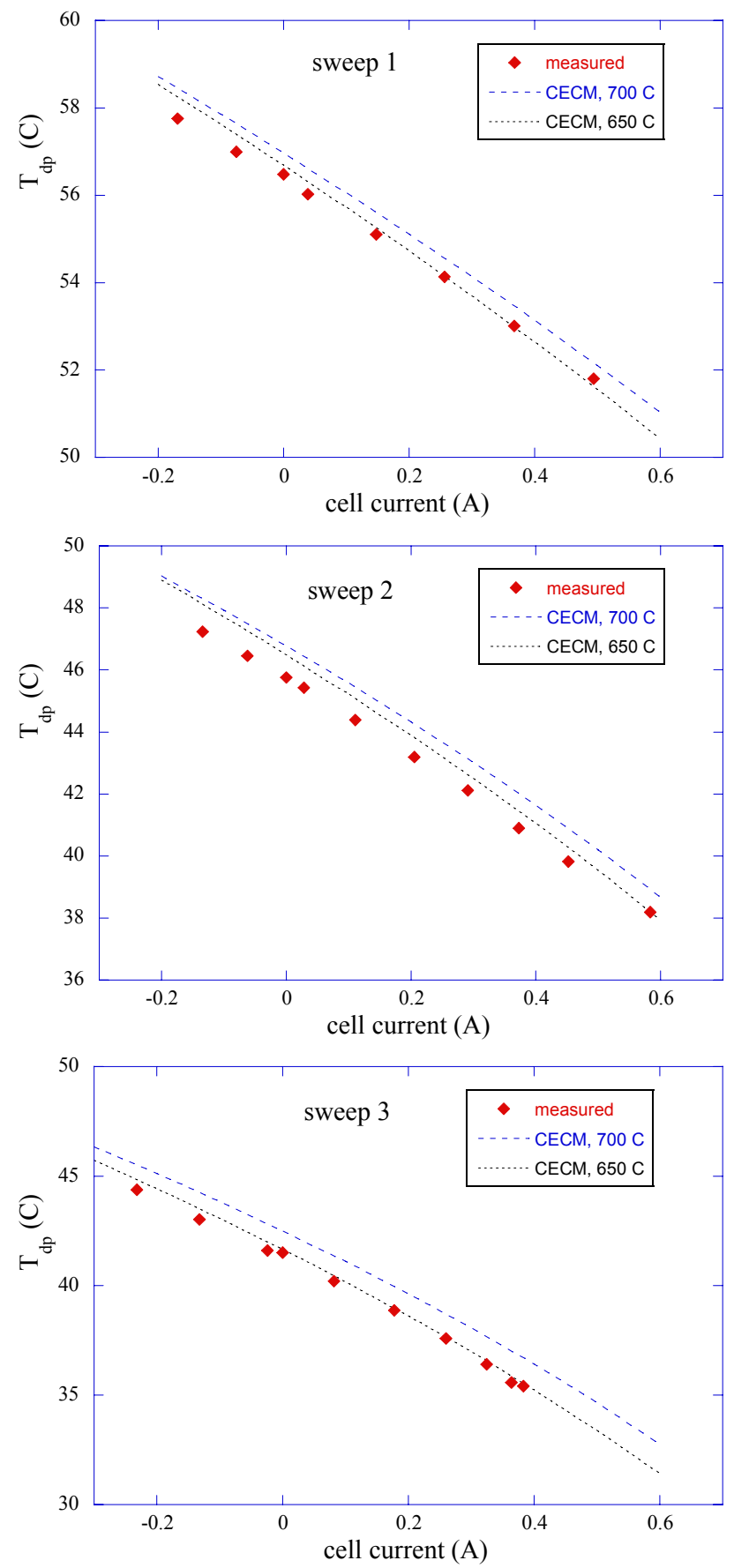

Figure 4.1. Measured outlet dewpoint values, with comparisons to predictions from the chemical equilibrium coelectrolysis model, sweeps $1-3$. 
humidifier are determined by the water bath temperature, the water vapor mass flow rate is directly proportional to the carrier gas flow rate for a specified bath temperature. Also, since the nitrogen, hydrogen, and $\mathrm{CO}_{2}$ flow rates are fixed by the mass flow controllers, and the steam partial pressure is fixed by the bath temperature, the complete inlet gas composition is precisely known at all times. All gas lines located downstream of the humidifier are heattraced in order to prevent steam condensation. Gas line temperatures are monitored by thermocouples and controlled by means of computer-controlled SCRs.

The inlet gas mixture is then directed to the high temperature furnace (Skutt Model KS818-3), capable of producing temperatures up to $1250^{\circ} \mathrm{C}$, which heats and maintains the electrolyzer at the appropriate test temperature via computer-based feedback control. The

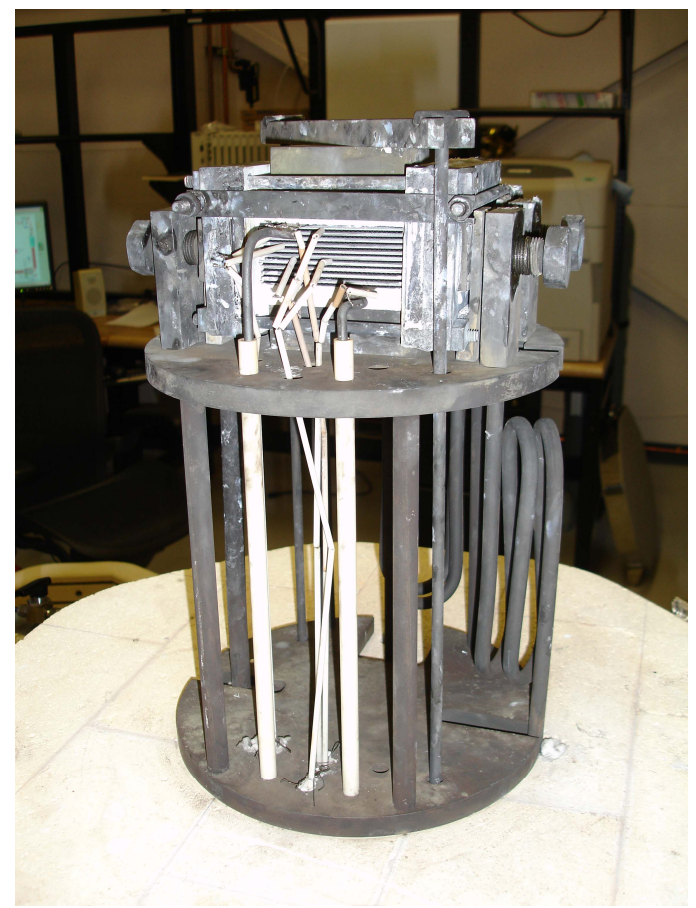

Figure 4.2. 10-cell stack mounted on test fixture on furnace base, ready to test. furnace also preheats the inlet gas mixture and the air sweep gas. A photograph of the stack, mounted on its inconel test fixture and resting on the furnace base, is shown in Figure 4.2. The power leads are inconel rods insulated with alumina tubing. The steam /hydrogen $/ \mathrm{CO}_{2}$ and air sweep inlet tubes are coiled to provide additional length for heat transfer upstream of the stack. Coelectrolysis testing was performed in the temperature range of $800-830^{\circ} \mathrm{C}$.

The stack was fabricated by Ceramatec, Inc., of Salt Lake City, UT. This stack has a per-cell active area of $64 \mathrm{~cm}^{2}$, for a total active area of $640 \mathrm{~cm}^{2}$. It is designed to operate in cross flow, with the steam /hydrogen / $\mathrm{CO}_{2}$ gas mixture entering the inlet manifold on the right side in the photograph (Figure 4.2), and exiting through the outlet manifold, visible on the left in the photograph. Airflow enters at the rear though an air inlet manifold, not visible in Figure 4.2, and exits at the front directly into the furnace.

Figure 4.3 is a close-up of the 10-cell stack air outlet plane, showing the miniature intra-cell thermocouples, voltage taps, and power lead bus bars. The power lead attachment tabs are integral with the upper and lower interconnect plates. Stack operating voltages were measured using wires that were directly spot-welded onto these tabs. Four intermediate cell voltages were monitored using small diameter wires inserted into the airflow channels. In addition, two miniature thermocouples were inserted into the airflow channels to monitor internal stack temperatures. These were inconel-sheathed, 0.020 in. $(500 \mu \mathrm{m})$ OD, mineral-insulated, ungrounded, type-K thermocouples. Thermocouple \#1 was located centrally on the top cell (cell \#1) and thermocouple \#2 was located centrally on the sixth cell from the top.

The internal components of the stack are comprised as follows. The interconnect plate is fabricated primarily from ferritic stainless steel. It includes an impermeable separator plate 
( $\sim 0.46 \mathrm{~mm}$ thick) with edge rails and two corrugated "flow fields," one on the sweep-gas side and one on the steam / hydrogen / $\mathrm{CO}_{2}$ side. The height of the flow channel formed by the edge rails and flow fields is $1.0 \mathrm{~mm}$. Each flow field includes 32 perforated flow channels across its width to provide uniform gas-flow distribution. The steam / hydrogen / $\mathrm{CO}_{2}$ flow field is fabricated from nickel foil. The sweep flow field is ferritic stainless steel. The interconnect plates and flow fields also serve as electrical conductors and current distributors. To improve performance, the sweep-side separator plates and flow fields are surface treated to form a rare-earth conductive oxide

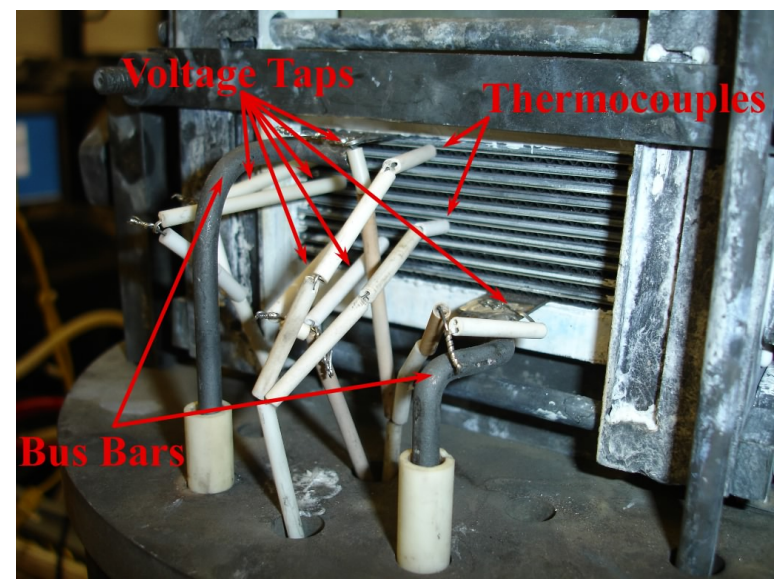

Figure 4.3. Close-up of 10-cell stack, showing intra-cell thermocouples, voltage leads, and power leads.

scale. A perovskite rare-earth coating is also applied to the separator-plate oxide scale by either screen printing or plasma spraying. On the steam / hydrogen $/ \mathrm{CO}_{2}$ side of the separator plate, a thin $(\sim 10 \mu \mathrm{m})$ nickel metal coating is applied.

The electrolyte is scandia-stabilized zirconia, $\sim 140 \mu \mathrm{m}$ thick. The sweep-side electrode (anode in the electrolysis mode) is a strontium-doped manganite. The electrode is graded, with an inner layer of manganite/zirconia $(\sim 13 \mu \mathrm{m})$ immediately adjacent to the electrolyte, a middle layer of manganite $(\sim 18 \mu \mathrm{m})$, and an outer bond layer of cobaltite. The steam / hydrogen $/ \mathrm{CO}_{2}$ electrode (cathode in the electrolysis mode) is also graded, with a nickel cermet layer $(\sim 13 \mu \mathrm{m})$ immediately adjacent to the electrolyte and a pure nickel outer layer $(\sim 10 \mu \mathrm{m})$.

The syngas product stream exiting the furnace is directed towards a second dewpoint sensor and a $\mathrm{CO}_{2}$ sensor upon exiting the furnace and then to a condenser through a heat-traced line. The condenser removes most of the residual steam from the exhaust. The final exhaust stream is vented outside the laboratory through the roof.

The rates of steam and $\mathrm{CO}_{2}$ electrolysis are measured via three different, independent methods: 1) electrical current through the stack, 2) the measured change in inlet and outlet steam and $\mathrm{CO}_{2}$ concentrations as measured by the on-line dew point and $\mathrm{CO}_{2}$ sensors, and 3) an on-line microchannel GC. The GC also tests for any additional electrolysis products, such as $\mathrm{CH}_{4}$, that may be produced.

Additional discussion of the test apparatus, experimental procedures, data reduction, and the stack construction may be found in [11].

\subsection{RESULTS, 10-CELL STACKS}

Prior to testing a multi-cell stack under coelectrolysis conditions, several single button cells ( single cells of approximately $2.5 \mathrm{~cm}^{2}$ active area) were tested, as discussed in Section 1. The success of these earlier tests prompted INL researchers to test three 10-cell stacks (Figure 4.2 and Figure 4.3) under coelectrolysis conditions in part to assess the feasibility of high temperature co-electrolysis for syngas production, as well as further test the accuracy of the coelectrolysis 
chemical equilibrium model. Several different sets of inlet compositions and operating temperatures were studied (Table 4.1).

Figure 4.4 shows the heat-up results for stacks \#1, \#2, and \#3. The first two stacks were heated under identical initial conditions: $3000 \mathrm{sccm} \mathrm{N}$ flow rate, $497 \mathrm{sccm} \mathrm{H}_{2}$ flow rate, and an inlet gas dew point temperature of $51.8 \mathrm{C}$. However, in the case of stack \#2, once all internal stack temperatures were above $350 \mathrm{C}$ (or, after about 2 hours of heat up), $750 \mathrm{sccm}$ of $\mathrm{CO}_{2}$ was also introduced. Stack 3 was heated up to $400 \mathrm{C}$ with $1000 \mathrm{sccm}$ of dry air. From 400 to $600 \mathrm{C}, 500$ sccm of dry $\mathrm{N}_{2}$ and $500 \mathrm{sccm}$ dry $\mathrm{H}_{2}$ were flowed. Beyond $600 \mathrm{C}$, the $500 \mathrm{sccm} \mathrm{N} \mathrm{N}_{2} / 500 \mathrm{sccm}$ $\mathrm{H}_{2}$ inlet mixture was humidified with the bubbler. The inlet dew point was approximately $27 \mathrm{C}$. All three stacks demonstrated remarkably similar heat-up profiles. The stacks do not exhibit an open cell potential (OCV) until above approximately 300-350 C, at which point the electrolyte begins to become an ion conductor. The orange lines represent the theoretical Nernst potentials for the gas mixtures, agreeing quite well with the measured OCVs. Of interest is that in the case of stack $\# 2$, the outlet dew point temperature begins to climb as the furnace temperature exceeds $450 \mathrm{C}$, indicating that the RSR has begun to reduce $\mathrm{CO}_{2}$ and produce $\mathrm{H}_{2} \mathrm{O}$. Also, in the case of stack \#3, the outlet dew point is higher than the inlet dew point, possibly indicating leakage.

Table 4-1. Summary of test conditions.

\begin{tabular}{|c|c|c|c|c|c|c|c|c|c|c|c|c|}
\hline \multirow[b]{2}{*}{$\begin{array}{c}\text { Test } \\
\#\end{array}$} & \multirow[b]{2}{*}{$\begin{array}{c}\text { Stack } \\
\#\end{array}$} & \multirow[b]{2}{*}{$\begin{array}{c}\text { Sweep } \\
\text { Type }\end{array}$} & \multirow[b]{2}{*}{$\begin{array}{c}\text { Stack } \\
\text { Age }\end{array}$} & \multirow[b]{2}{*}{$\begin{array}{c}T_{\text {furnace }} \\
\text { (C) }\end{array}$} & \multicolumn{3}{|c|}{ Flow Rates } & \multirow{2}{*}{$\begin{array}{l}\text { Inlet } \\
\text { Dew } \\
\text { Point } \\
\text { (C) }\end{array}$} & \multicolumn{4}{|c|}{ Molar Composition } \\
\hline & & & & & $\begin{array}{c}\mathrm{H}_{2} \\
(\mathrm{sccm})\end{array}$ & $\begin{array}{c}\mathrm{CO}_{2} \\
(\mathrm{sccm})\end{array}$ & $\begin{array}{c}\mathrm{N}_{2} \\
\text { (sccm) }\end{array}$ & & $\begin{array}{c}\mathrm{H}_{2} \\
(\mathrm{~mol} \%)\end{array}$ & $\begin{array}{c}\mathrm{CO}_{2} \\
(\mathrm{~mol} \mathrm{\%})\end{array}$ & $\begin{array}{c}\mathrm{N}_{2} \\
(\mathrm{~mol} \%)\end{array}$ & $\begin{array}{c}\mathrm{H}_{2} \mathrm{O} \\
(\mathrm{mol} \%)\end{array}$ \\
\hline 0 & 1 & Fast & Fresh & 800 & 497 & 0 & 3010 & 51.5 & 12.0 & 0 & 72.6 & 15.4 \\
\hline 1 & 1 & Fast & Fresh & 800 & 497 & 605 & 3010 & 51.5 & 10.2 & 12.4 & 61.9 & 15.5 \\
\hline 2 & 1 & Slow & Fresh & 800 & 497 & 605 & 3010 & 51.5 & 10.2 & 12.4 & 61.9 & 15.5 \\
\hline 3 & 1 & Slow & Fresh & 800 & 497 & 505 & 2510 & 45.5 & 12.6 & 12.7 & 63.3 & 11.4 \\
\hline 4 & 1 & Slow & Fresh & 800 & 497 & 705 & 1010 & 66.0 & 15.6 & 22.2 & 31.8 & 30.4 \\
\hline 5 & 1 & Slow & Fresh & 800 & 497 & 756 & 3010 & 74.0 & 6.7 & 10.1 & 40.2 & 43.0 \\
\hline 6 & 1 & Slow & Fresh & 828 & 497 & 605 & 3011 & 51.5 & 10.2 & 12.4 & 61.9 & 15.5 \\
\hline 7 & 1 & Slow & Fresh & 828 & 497 & 756 & 3513 & 65.3 & 7.3 & 11.2 & 52.0 & 29.5 \\
\hline 8 & 2 & Fast & Fresh & 800 & 450 & 0 & 1413 & 75.3 & 13.2 & 0 & 41.4 & 45.4 \\
\hline 9 & 2 & Fast & Fresh & 800 & 449 & 753 & 1414 & 59.8 & 13.2 & 22.2 & 41.6 & 23.0 \\
\hline 10 & 2 & Fast & Fresh & 800 & 334 & 564 & 1064 & 59.7 & 13.1 & 22.2 & 41.8 & 22.9 \\
\hline 11 & 2 & Fast & Fresh & 800 & 213 & 378 & 710 & 60.7 & 12.4 & 22.1 & 41.5 & 24.0 \\
\hline 12 & 2 & Slow & 1 Week & 800 & 449 & 753 & 1414 & 59.8 & 13.2 & 22.2 & 41.6 & 23.0 \\
\hline 13 & 2 & Slow & 1 Week & 800 & 334 & 564 & 1064 & 59.7 & 13.1 & 22.2 & 41.8 & 22.9 \\
\hline 14 & 2 & Slow & 1 Week & 800 & 213 & 378 & 710 & 60.7 & 12.4 & 22.1 & 41.5 & 24.0 \\
\hline 15 & 2 & Slow & 1 Week & 830 & 497 & 756 & 3513 & 65.3 & 7.4 & 11.2 & 52.0 & 29.4 \\
\hline 16 & 2 & Slow & 2 Weeks & 800 & 450 & 752 & 1410 & 60.3 & 13.2 & 22.0 & 41.3 & 23.5 \\
\hline 17 & 2 & Slow & 2 Weeks & 800 & 334 & 564 & 1064 & 60.2 & 13.0 & 22.0 & 41.5 & 23.5 \\
\hline 18 & 2 & Slow & 2 Weeks & 800 & 213 & 378 & 710 & 60.7 & 12.4 & 22.1 & 41.5 & 24.0 \\
\hline 19 & 2 & Slow & 2 Weeks & 830 & 497 & 756 & 3513 & 65.3 & 7.4 & 11.2 & 52.0 & 29.4 \\
\hline 20 & 3 & Fast & Fresh & 800 & 996 & 0 & 1009 & 80 & 22.5 & 0 & 22.7 & 54.8 \\
\hline 21 & 3 & Fast & Fresh & 800 & 996 & 1003 & 0.0 & 80 & 22.5 & 22.6 & 0 & 54.9 \\
\hline 22 & 3 & Fast & Fresh & 800 & 0 & 1500 & 0 & 0 & 0 & 100.0 & 0 & 0 \\
\hline
\end{tabular}



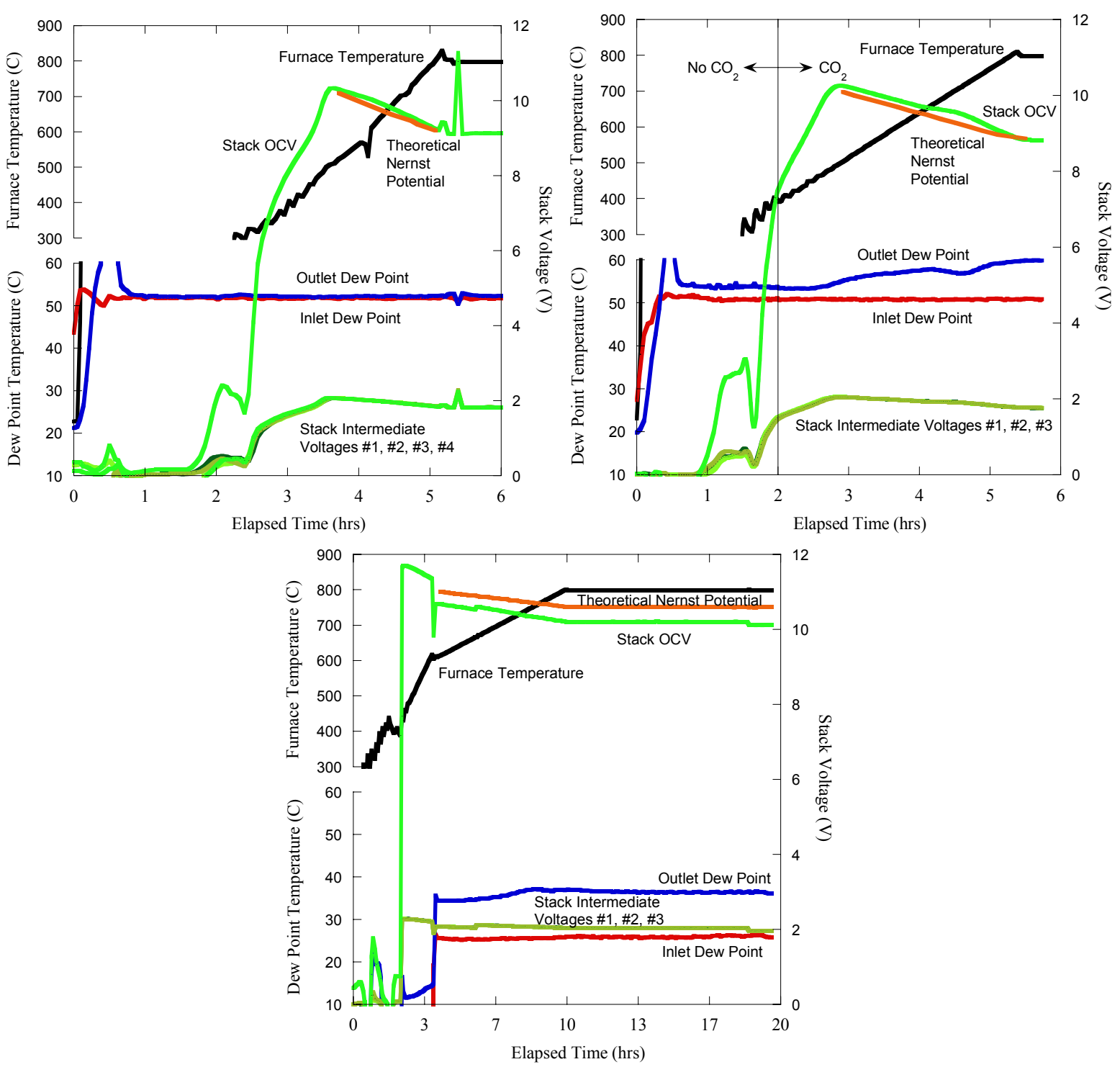

Figure 4.4. Heat-up results for stacks \#1, \#2, and \#3.

Cell area-specific resistance, ASR, quantifies the loss mechanisms associated with cell operation, including ohmic resistances, contact resistances, and ionic resistances, activation and concentration overpotentials. The ASR value is dependent on the type of electrolysis being conducted, with pure $\mathrm{CO}_{2}$ electrolysis exhibiting a significantly higher ASR than pure steam electrolysis (Ref. 1). However, in coelectrolysis the RSR is relied upon for most $\mathrm{CO}_{2}$-to-CO conversion, and steam electrolysis is the primary electrolytic reaction. Therefore, there is little change in $A S R$ from steam electrolysis to coelectrolysis. To demonstrate this, polarization curves were generated for stack \#3 for steam electrolysis, $\mathrm{H}_{2} \mathrm{O} / \mathrm{CO}_{2}$ coelectrolysis, and $\mathrm{CO}_{2}$ electrolysis. Once the stack was at the operating temperature of $800^{\circ} \mathrm{C}$, a steam electrolysis polarization curve was generated by performing a voltage sweep for the conditions labeled "Test \#20" in Table 4-1. This same voltage sweep was repeated for the coelectrolysis conditions "Test \#21" and for the $\mathrm{CO}_{2}$ electrolysis conditions "Test \#22". These results are shown in Figure 4.5. Using these data, the sweep-average apparent ASR was calculated by numerically averaging the voltage and current data: 


$$
A S R=\sum \frac{1}{n} \frac{\left(V_{o p}-V_{O C}\right) / N_{c e l l s}}{I / A_{\text {cell }}}
$$

where $n$ is the number of measurements included, $V_{o p}$ is the operating voltage, $V_{o c}$ is the measured open cell potential, and $A_{\text {cell }}$ is the active area of each cell (64 $\mathrm{cm}^{2}$ ).

There was almost no change in apparent ASR for coelectrolysis versus steam electrolysis. However, the ASR for $\mathrm{CO}_{2}$ electrolysis was significantly higher, reinforcing the hypothesis that steam electrolysis is the principal electrolysis reaction and that the RSR is mostly responsible for $\mathrm{CO}$ production.

Tests 1 through 6 comprised very slow voltage sweeps where for each power supply voltage setting the stack was allowed to reach thermal and chemical equilibrium. Thermal equilibrium was determined by watching the response of the stack internal thermocouples. Chemical equilibrium was recognized when the downstream dew point reading reached steady state. These two conditions were usually met after approximately 10 minutes at each setting.

When a solid oxide cell is operated as a fuel cell, the exothermic heat of reaction as well as ohmic heating tends to increase the cell temperature and excess air is typically required for cooling. Steam electrolysis, $\mathrm{CO}_{2}$ electrolysis, coelectrolysis, and the RSR, however, are endothermic reactions which tend to reduce the cell temperature in proportion to the electrolysis current. Ohmic heating is proportional to the square of the electrolysis current. These two effects balance each other at the thermal neutral voltage. At operating voltages below thermal neutral, the endothermic heat of reaction dominates and the cell temperature is lower than that at open cell. At operating voltages above thermal neutral, ohmic heating dominates and the cell temperature will exceed that at open cell. For pure steam electrolysis, the thermal neutral voltage is a weak function of temperature only and is equal to $1.287 \mathrm{~V}$ at $800^{\circ} \mathrm{C}$ and $1.288 \mathrm{~V}$ at $830^{\circ} \mathrm{C}$. For coelectrolysis the thermal neutral voltage is also a function of gas composition.

Figure 4.6 presents internal stack temperature depression (the difference between the temperature measured during the sweep and the temperature at open cell conditions) for thermocouple \#2 as a function of stack operating voltage for the 7 electrolysis conditions listed in Table 4-1. By curve fitting the experimental data (shown as solid lines in Figure 4.6) and solving for zero temperature depression, experimental thermal neutral voltages were estimated. Experimental open cell potentials were directly measured. Theoretical open cell potentials were calculated using the chemical equilibrium model described above. Theoretical thermal neutral voltages were estimated by extending the chemical equilibrium coelectrolysis model discussed to include an energy balance. Table 4-2 summarizes the measured versus predicted open cell potentials and thermal neutral voltages for the experimental conditions listed in Table 4-2. The average 


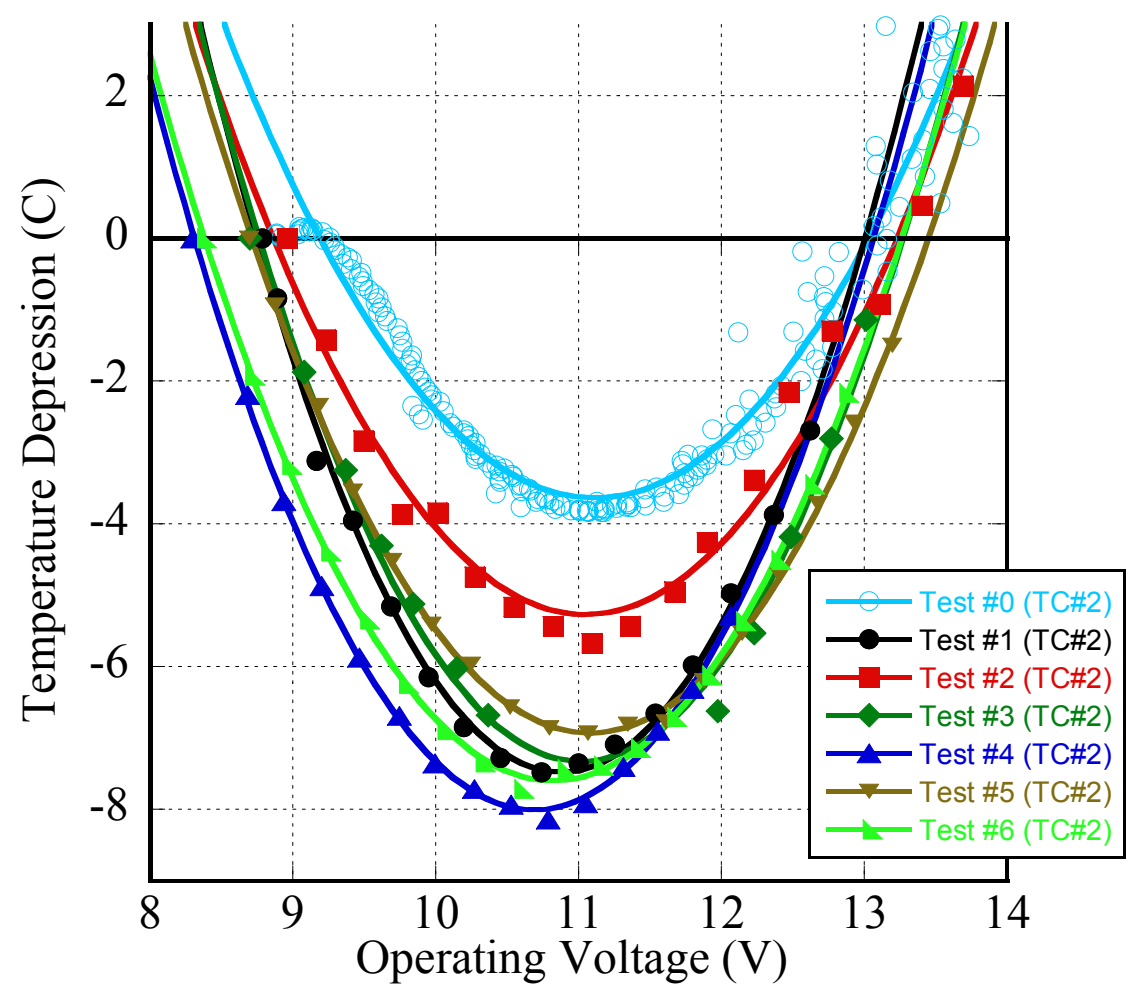

Figure 4.6. Internal stack temperature (thermocouple \#2) for various test conditions.

difference between measured and predicted thermal neutral voltages for the 6 coelectrolysis tests conducted was $17 \mathrm{mV}$.

Figure 4.7-Figure 4.12 present the steady state outlet compositions of steam, $\mathrm{CO}_{2}$, hydrogen, and $\mathrm{CO}$ as a function of electrolysis current on a dry basis for tests 1-6. Lines represent various model predictions and symbols represent experimental measurements. An in-line gas chromatograph was used to measure outlet compositions from the stack. Since the gas chromatograph requires a dry sample, the sampling location was downstream of the condenser to remove as much water from the sample as possible. The sample was passed through a dessicant as well. At this point, the sample gas stream is at approximately room temperature. As noted previously, the RSR equilibrium constant is a function of temperature, but will kinetically freeze below some temperature in the absence of the nickel catalyst. Therefore, it was not obvious what value to use for an "apparent" equilibrium temperature in the model for the products. Accordingly, the chemical equilibrium coelectrolysis model was run for several different equilibrium temperatures ranging from $650^{\circ} \mathrm{C}$ to $800^{\circ} \mathrm{C}$ (Figure 4.7). It was found that setting the chemical equilibrium coelectrolysis model equilibrium temperature equal to the furnace temperature produced the best comparisons, indicating that the

Table 4-2. Comparison of measured versus predicted open cell potentials and thermal neutral voltages.

\begin{tabular}{|c|c|c|c|c|}
\hline $\begin{array}{c}\text { Test } \\
\#\end{array}$ & \multicolumn{2}{|c|}{$\begin{array}{c}\text { Open Cell Potential } \\
\text { (volts per cell) }\end{array}$} & \multicolumn{2}{|c|}{$\begin{array}{c}\text { Thermal Neutral } \\
\text { Voltage } \\
\text { (volts per cell) }\end{array}$} \\
\hline & Measured & Predicted & Measured & Predicted \\
\hline 1 & 0.8795 & 0.8923 & 1.3004 & 1.3437 \\
\hline 2 & 0.8959 & 0.9082 & 1.3231 & 1.3476 \\
\hline 3 & 0.8700 & 0.8826 & 1.3271 & 1.3446 \\
\hline 4 & 0.8392 & 0.8421 & 1.3017 & 1.3161 \\
\hline 5 & 0.8696 & 0.8803 & 1.3447 & 1.3451 \\
\hline 6 & 0.8376 & 0.8471 & 1.3265 & 1.3285 \\
\hline
\end{tabular}


products are kinetically frozen after they leave the hot zone, probably due to lack of any significant catalyst surface and the cool-down is fairly rapid. Predicted compositions were therefore evaluated at the electrolyzer temperature for all subsequent evaluations (Figure 4.8 through Figure 4.12).

Figure 4.7 through Figure 4.12 demonstrate that even at zero current there was a drop in $\mathrm{CO}_{2}$ and $\mathrm{H}_{2}$ mole fractions from the cold inlet values, with $\mathrm{CO}$ produced. This is solely due to the RSR. As the electrolysis current was increased, the yield of syngas increased linearly while the concentration of $\mathrm{CO}_{2}$ (and $\mathrm{H}_{2} \mathrm{O}$, not shown in the figures) decreased. These figures also show overall good agreement between experimental GC data and results from the chemical equilibrium coelectrolysis model for the range of testing performed in this study. Finally, in the case of Test \#6, at the maximum current studied the product $\mathrm{H}_{2}$ concentration was doubled and product $\mathrm{CO}_{2}$ concentration was reduced to half that of the process inlet mixture. Coelectrolysis significantly increases the yield of syngas over the reverse water gas shift reaction equilibrium composition. 


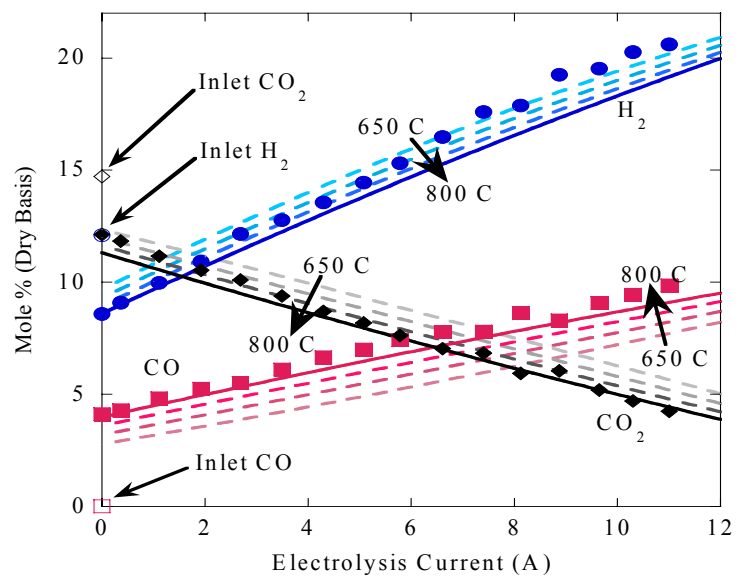

Figure 4.7. Effect of varying chemical equilibrium coelectrolysis model equilibrium temperature (Eq. 9) with comparison to Test 1 experimental data.

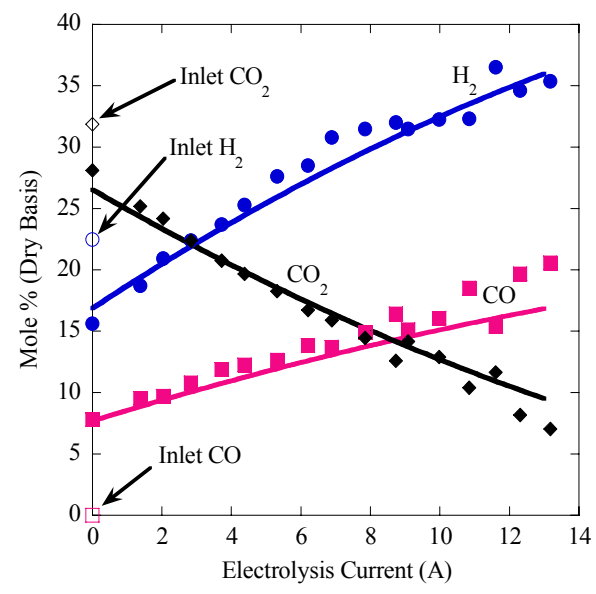

Figure 4.9. Test 3 experimental and chemical equilibrium coelectrolysis model results, Teq $=800^{\circ} \mathrm{C}$.

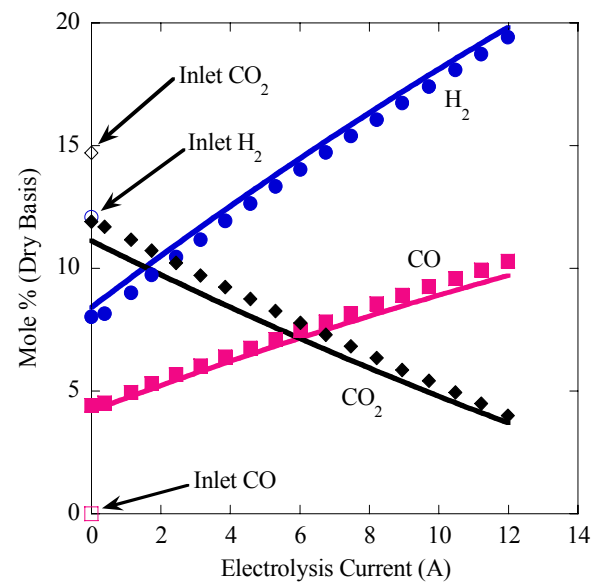

Figure 4.11. Test 5 experimental and chemical equilibrium coelectrolysis model results, $\mathrm{Teq}=828^{\circ} \mathrm{C}$.

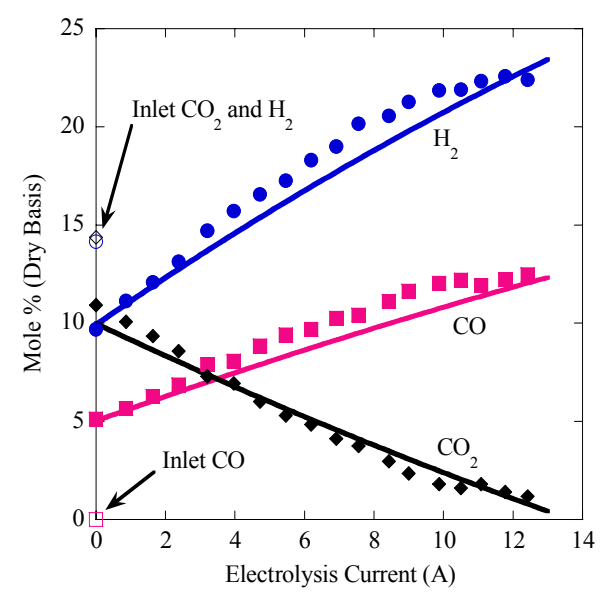

Figure 4.8. Test 2 experimental and chemical equilibrium coelectrolysis model results, Teq $=800^{\circ} \mathrm{C}$

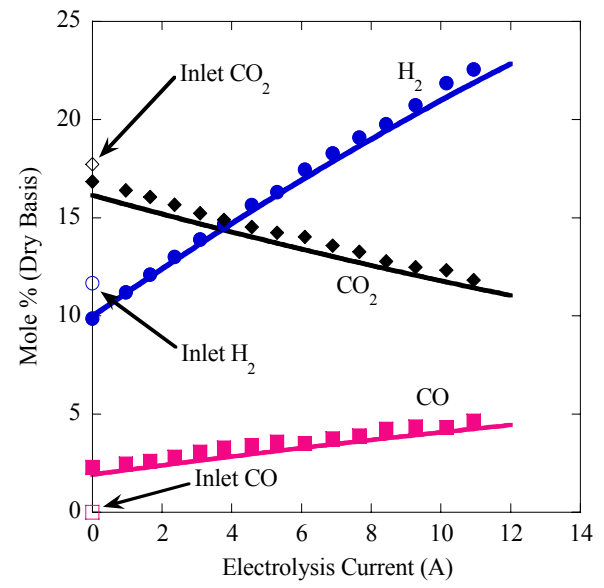

Figure 4.10. Test 4 experimental and chemical equilibrium coelectrolysis model results, $\mathrm{Teq}=800^{\circ} \mathrm{C}$.

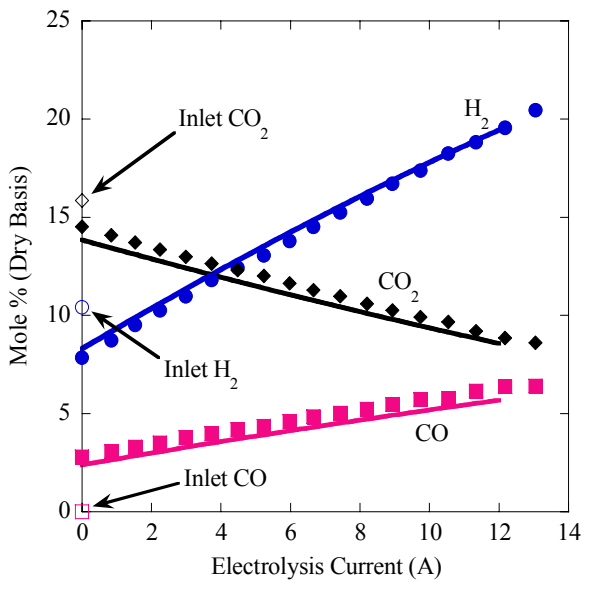

Figure 4.12. Test 6 experimental and chemical equilibrium coelectrolysis model results, $\mathrm{Teq}=828^{\circ} \mathrm{C}$. 


\section{TUBULAR CELL TESTING AT INL}

The INL is investigating High-Temperature Electrolysis (HTE) for efficient large-scale hydrogen production from nuclear energy. This process involves the use of solid-state ceramic electrode and electrolyte materials arranged to form electrolytic cells that operate in the $800-900^{\circ} \mathrm{C}$ temperature range. The electrolyzer design takes advantage of solid-oxide fuel cell (SOFC) technology and is easily scalable since it is comprised of small, modular components. A group of multiple individual cells assembled in a single unit is usually termed a stack (for planar, or flat cells) or bundle (for tubular-shaped cells). Most of the testing performed at INL to date has been on planar electrolyte-supported solid-oxide cells developed and fabricated by Ceramatec, Inc. (Salt Lake City, UT). Ceramatec electrolysis stacks are comprised of multiple planar cells of 64 $\mathrm{cm}^{2}$ per-cell active area $\left(\sim 640 \mathrm{~cm}^{2}\right.$ total active area for a ten-cell stack) with metallic interconnects and gas manifolds. This design was chosen for its known high power density due to the compact cell stacking arrangement that is characteristic of planar cells and stacks. Compactness is important for minimizing the overall size of the hydrogen-production hot zone. Testing of this design for electrolysis has revealed some problems with the mechanical strength of the electrolyte, leakage of the cell edge / manifold seals, and corrosion of metallic interconnect components. For the electrolysis mode of operation, seal performance is especially critical for efficient collection of the hydrogen product. Sealing is a well-known problem for planar stacks due to the high per-cell length of sealing material required, high operating temperatures, and material property requirements.

The INL has expanded the scope of its HTE research activities to include performance evaluation of tubular cells for efficient hydrogen production. These geometries have been developed to alleviate sealing and electrolyte strength problems by reducing the number of seals required, and allowing greater thermal compliance for the ceramic materials. However, tubular designs suffer from reduced overall power density. Assessment of various tubular designs may show that the decreased power density of tubular designs could be a reasonable penalty to pay for improved seal performance and cell life.

Several manufacturers have developed tubular SOFC designs (Toshiba, Accumentrics, SiemensWestinghouse, and others). Through an internally-funded INL Laboratory Directed Research and Development project, a CRADA was established with Rolls-Royce Fuel Cell Systems (RRFCS) Ltd., a developer and manufacturer of solid-oxide fuel cells. The Integrated Planar Solid Oxide Fuel Cell (IP-SOFC) developed by Rolls-Royce is of particular interest to the INL for electrolysis testing. In spite of the name, the Rolls-Royce design actually is comprised of high-aspect-ratio flattened tubes, upon which the electrolysis cells are deposited by a wet-slurry screen-printing process. Each tube includes 20 electrolysis cells, 10 on the top and 10 on the bottom. This design eliminates most of the seals necessary in a planar design while attempting to maintain a reasonably high power density.

The INL obtained five Rolls-Royce IP-SOFC tubes and tested them in-house in the steam electrolysis mode. This work takes advantage of the existing high-temperature electrolysis test facility at the INL. The INL has also developed computational fluid dynamics (CFD) computer models for the IP-SOFC design. The first Rolls-Royce tube was used for system checkout and shakedown tests. Three new tubes were then installed and tested simultaneously by conducting 


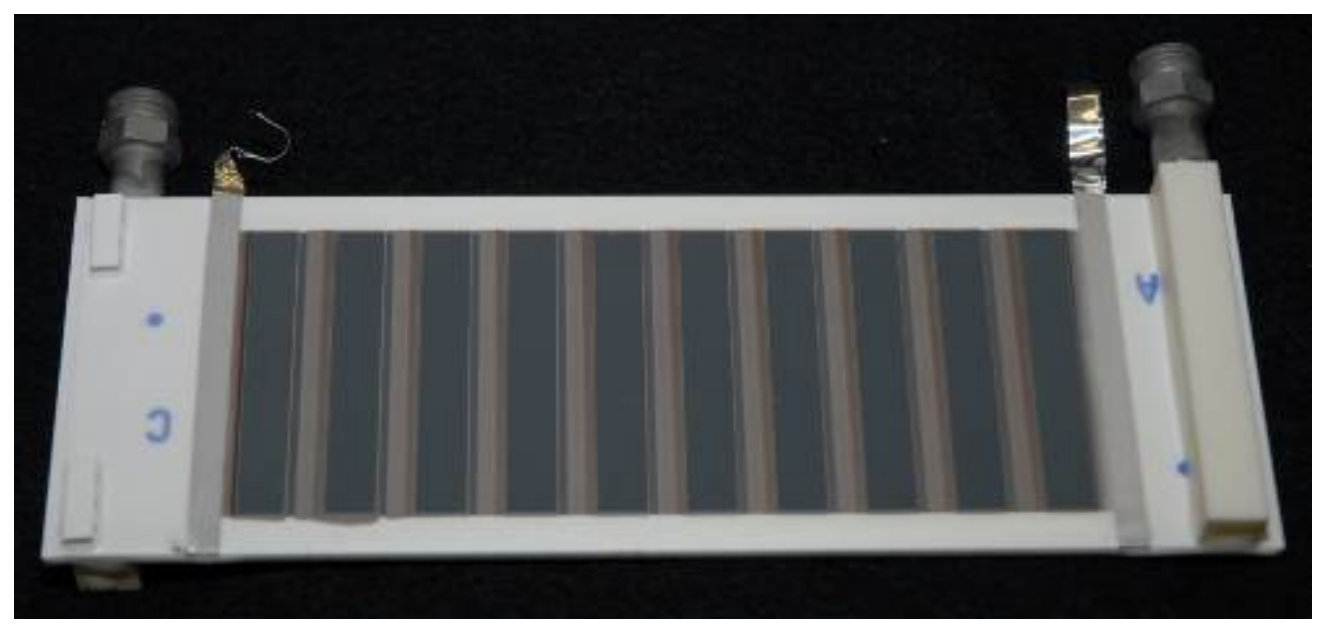

Figure 5.1. Closeup of IP-SOFC cells mounted on flattened tube.

voltage-current sweeps at various operating temperatures ranging from 800 to $950^{\circ} \mathrm{C}$. Upon conclusion of these tests, the original tube used for system checkout was reinstalled and thermally cycled to determine durability. Finally, the remaining untested tube was installed for long duration testing. This section of this report summarizes the findings of this testing program.

\subsection{ROLLS-ROYCE IP-SOFC GEOMETRY}

The Integrated Planar Solid Oxide Fuel Cell (IP-SOFC) was developed by Rolls-Royce Fuel Cell Systems in collaboration with Riso National Laboratory (Denmark). It is comprised of an array of series-connected cells deposited on the top and bottom surface of a flattened support tube (see Figure 5.1). The tubes tested at INL had 10 cells connected in series on each side of a flattened tube, with the tube sides electrically connected in parallel.

A cross section of an IP-SOFC repeat unit is shown in Figure 5.2. The anode and cathode nomenclature is for fuel cell operation. In electrolysis operation, these designations are reversed. The IP-SOFC anode material is a Ni-based cermet, including Ni-YSZ and Ni-CGO (ceriagadolinia) composites. The following description is for the design of the IP-SOFC believed to have been tested by the INL. The electrolyte layer is $15 \mu \mathrm{m}$ in thickness, yttria-stabilized zirconia (YSZ). The cathode layer is a composite of mixtures of lanthanum strontium manganite (LSM) and YSZ, screen printed onto the cell. [12] There is a thin glass layer between the anode and cathode current collectors to prevent leakage as well as electrical conduction. Table 5.1 presents

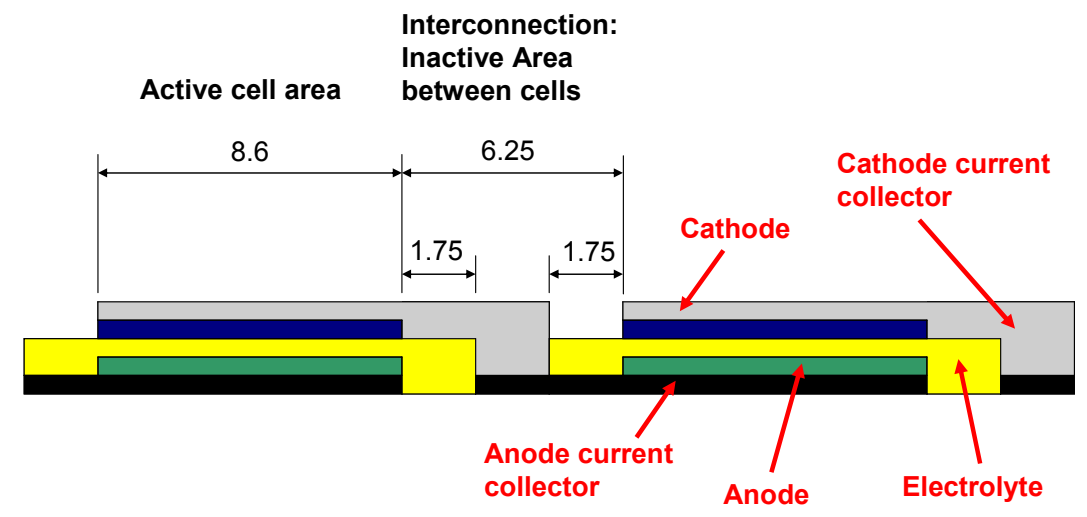

Figure 5.2. Cross-sectional diagram of IP-SOFC. 


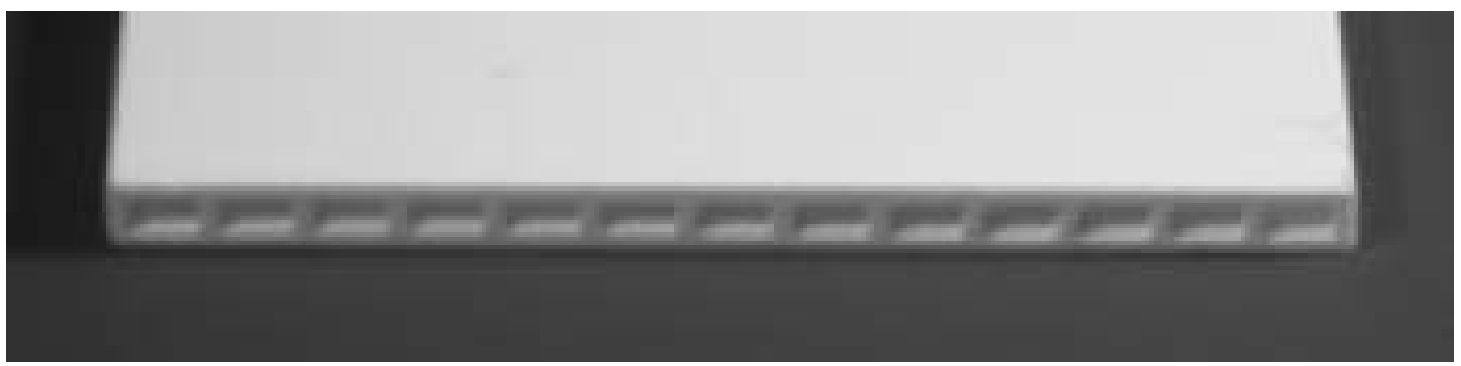

Figure 5.3. Porous support tube used in IP-SOFC [12].

the thicknesses of the various layers.

The porous support tube is depicted in Figure 5.3 and is fabricated from a composite ceramic material of magnesia and alumina. This composition provides a suitable coefficient of thermal expansion as well as low material cost and high electrical resistivity. The tube is designed to provide support for the cells that are screenprinted onto its surface and serves as a conduit for the hydrogen / steam mixture to reach the anode surfaces by traveling axially along the flow channels and diffusing through the porous microstructure to the cell active area. The outer inactive area of the tube is coated with a glass sealant. Table 5.2 summarizes the main geometric parameters of a tube [13].

Fuel is delivered to the tubes via inlet and outlet manifolds. Electrical connections are made at each end of the multi-cell tubes. Because of this, the current path is in the plane of the cells, as opposed to perpendicular to the cell plane in the case of planar geometries.

Multiple tubes can be subsequently stacked into bundles, as shown in Figure 5.4, and ultimately into a megawatt scale, stationary power generator shown conceptually in Figure 5.5.
Table 5.1: Thicknesses of printed layers of active cells [11].

\begin{tabular}{|l|l|}
\hline Layer & $\begin{array}{l}\text { Thickness } \\
{[\mu \mathrm{m}]}\end{array}$ \\
\hline $\begin{array}{l}\text { Anode current } \\
\text { collector }\end{array}$ & 10.0 \\
\hline Anode & 10.0 \\
\hline Electrolyte & 15.0 \\
\hline Cathode & 10.0 \\
\hline Cathode current & 10.0
\end{tabular}

Table 5.2: Geometry parameters of a tube.

\begin{tabular}{|l|l|}
\hline Tube width [mm] & 68 \\
\hline Tube length [mm] & 195 \\
\hline Tube thickness [mm] & 3.48 \\
\hline No. of cells per tube side & 10 \\
\hline Width of active cells [mm] & 60 \\
\hline No. of channels inside the tube & 15 \\
\hline Channel width [mm] & 3.38 \\
\hline Channel height [mm] & 1.88
\end{tabular}




\subsection{INL EXPERIMENTAL APPARATUS}

A schematic of the apparatus used for electrolysis testing of the IP-SOFC tubes at the INL is shown in Figure 5.6. A photograph of the overall setup follows in Figure 5.7. Primary components include nitrogen and hydrogen gas supplies, gas mass-flow controllers, a Bronkhorst controlled evaporation steam generator unit, humidifiers, dewpoint measurement stations, temperature and pressure measurement, high temperature furnace, solid oxide electrolysis cell, condenser, and exhaust vent. The system is designed to test up to three Rolls Royce IP-SOFC tubes simultaneously and independently. For this reason, there are

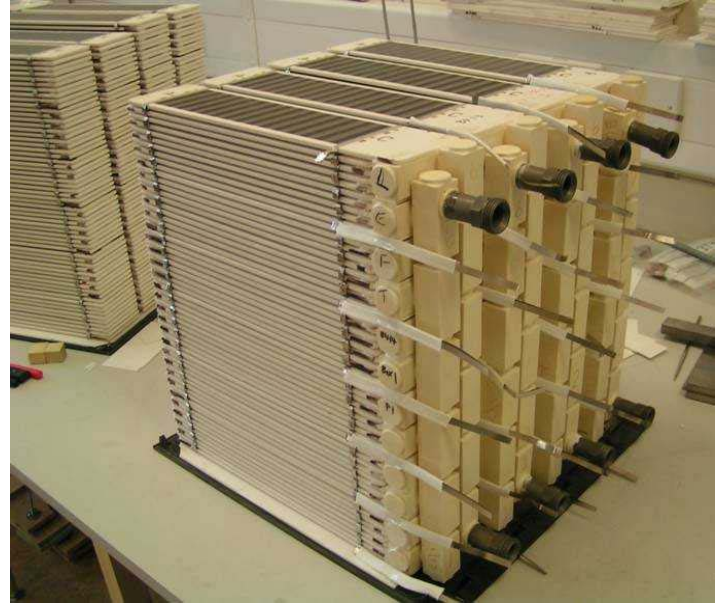

Figure 5.4. Rolls-Royce IP-SOFC tube bundles.

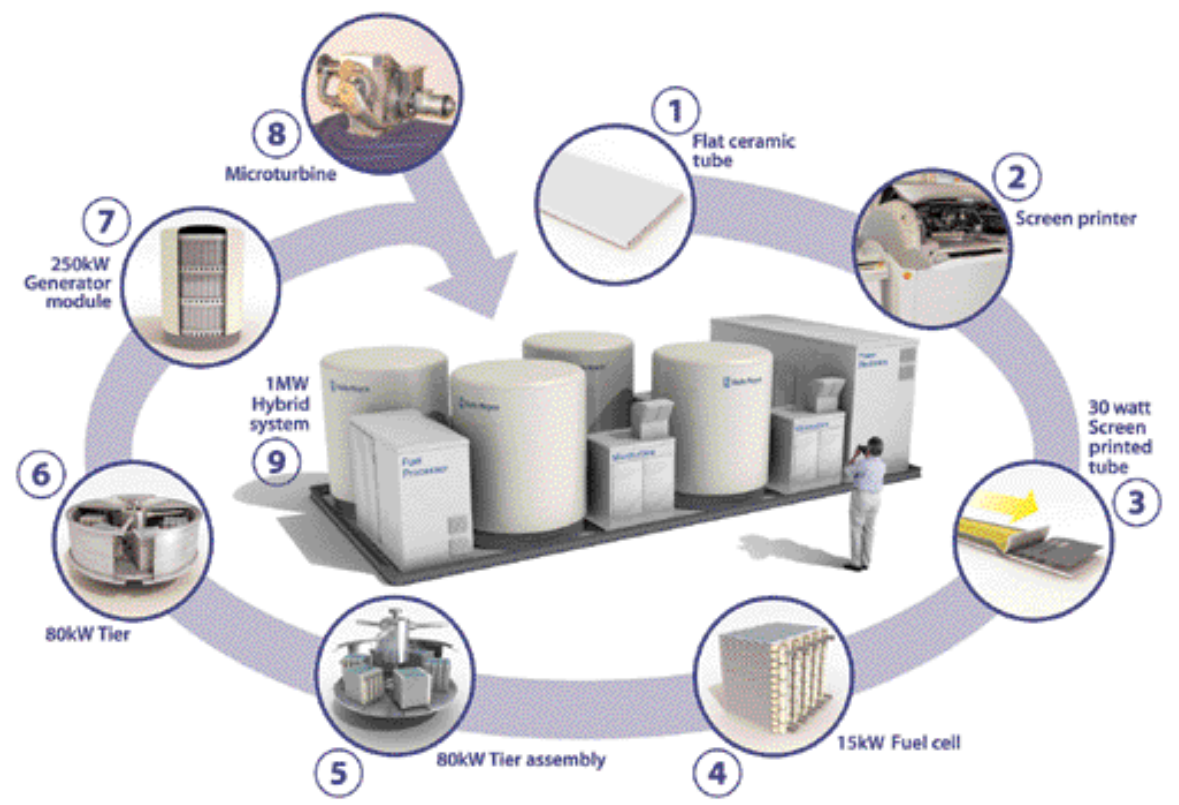

Figure 5.5. Rolls-Royce IP-SOFC tube bundles [14].

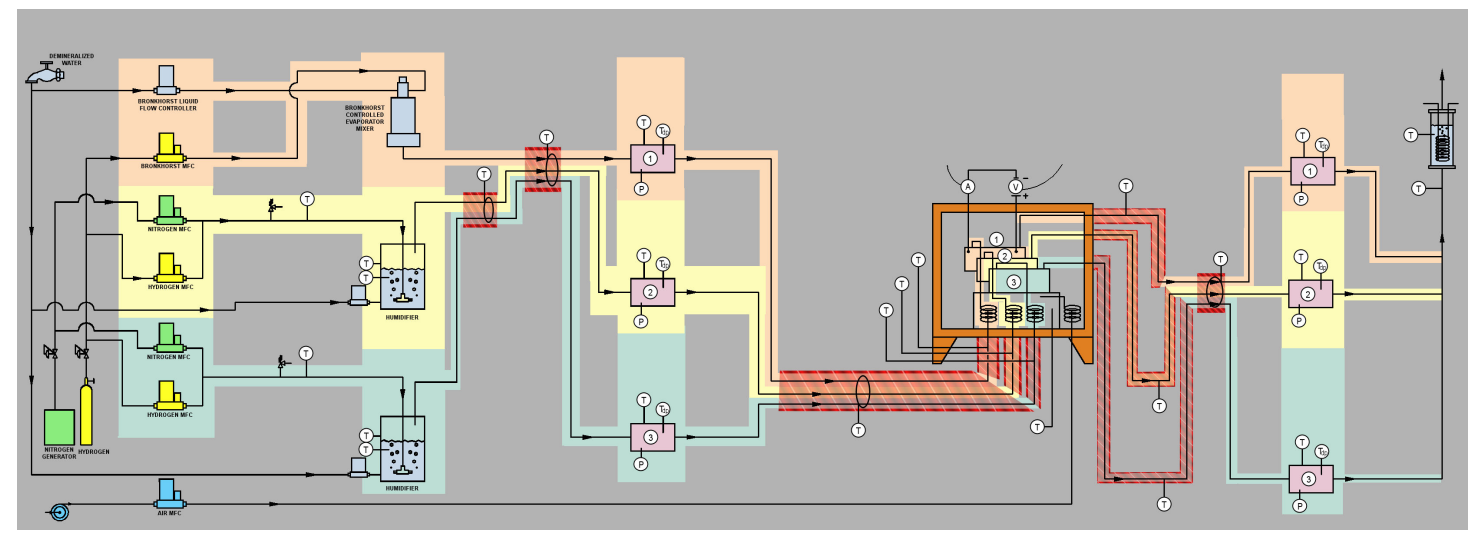

Figure 5.6. Schematic of INL testing apparatus for IP-SOFC testing. 


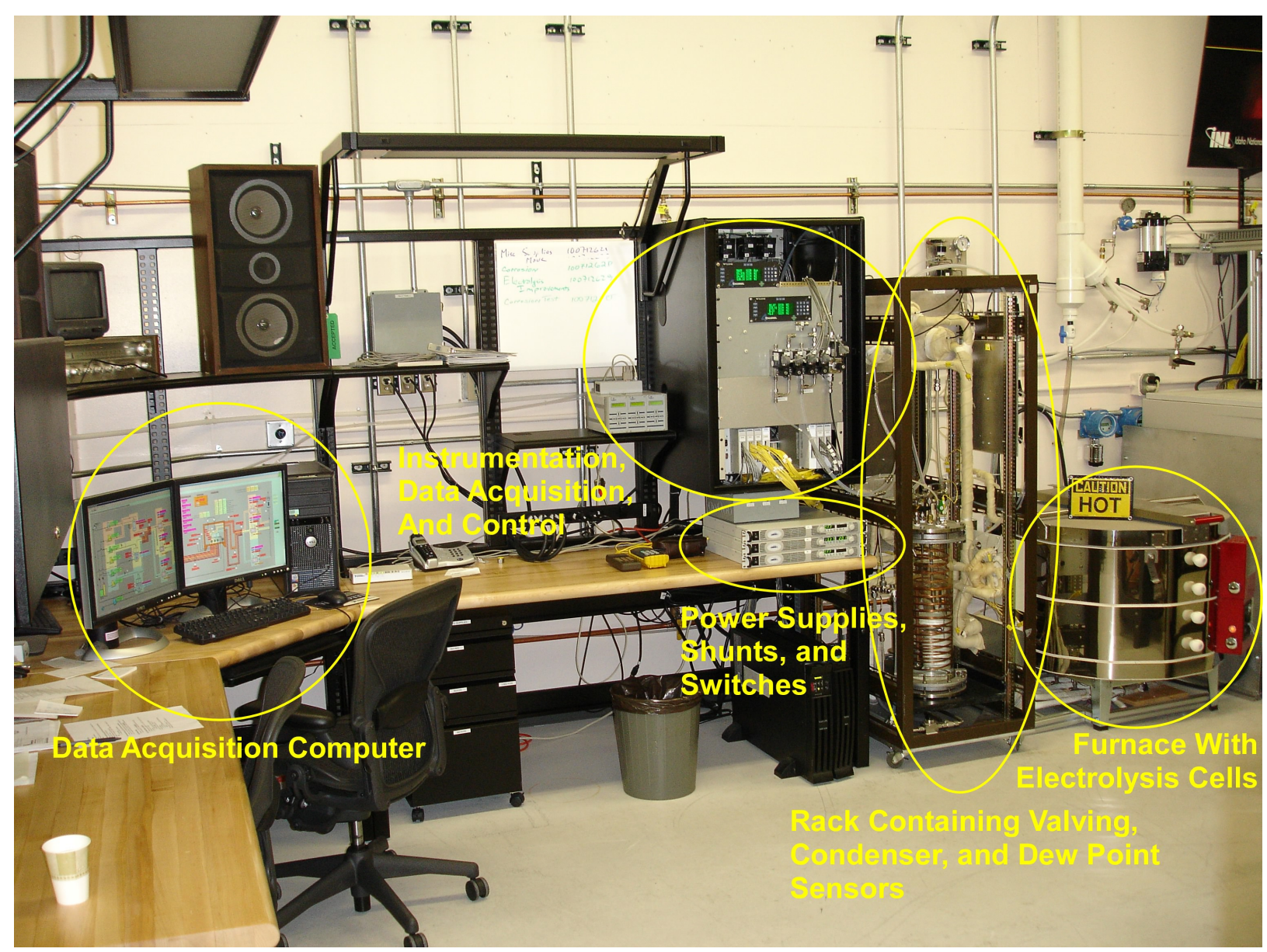

Figure 5.7. Photograph of INL IP-SOFC testing apparatus.

three independent flow paths through a single high-temperature furnace. These are designated as Path 1, Path 2, and Path 3. The three paths are very similar except with regard to the method of introducing steam. Path 1 uses a Bronkhorst liquid water mass flow controller, a Bronkhorst controlled evaporation module, and Bronkhorst hydrogen mass flow controller. The Bronkhorst system controls the rate of steam and hydrogen delivery. The Bronkhorst evaporator exit temperature as well as the hydrogen and water flow rate setpoints are controlled by computer. Paths 2 and 3 use Hastings mass flow controllers to regulate the flow of a hydrogen / nitrogen mixture to a temperature-controlled humidifier. In this case, nitrogen is used as an inert carrier gas. The use of a carrier gas allows for independent variation of both the partial pressures and the flow rates of the steam and hydrogen gases while continuing to operate near atmospheric pressure.

The humidifier water temperature is maintained at a constant setpoint value using computerized feedback control. Since the vapor pressure of the water and the resulting partial pressure of the steam exiting the humidifier are determined by the water bath temperature, the water vapor mass flow rate is directly proportional to the carrier gas flow rate for a specified bath temperature. Hydrogen is included in all three paths as a reducing gas in order to prevent oxidation of the Nickel cermet electrode material. The air sweep gas to the furnace is supplied by the shop air system, after passing through a two-stage extractor / dryer unit and is controlled by a Hastings mass flow controller. 


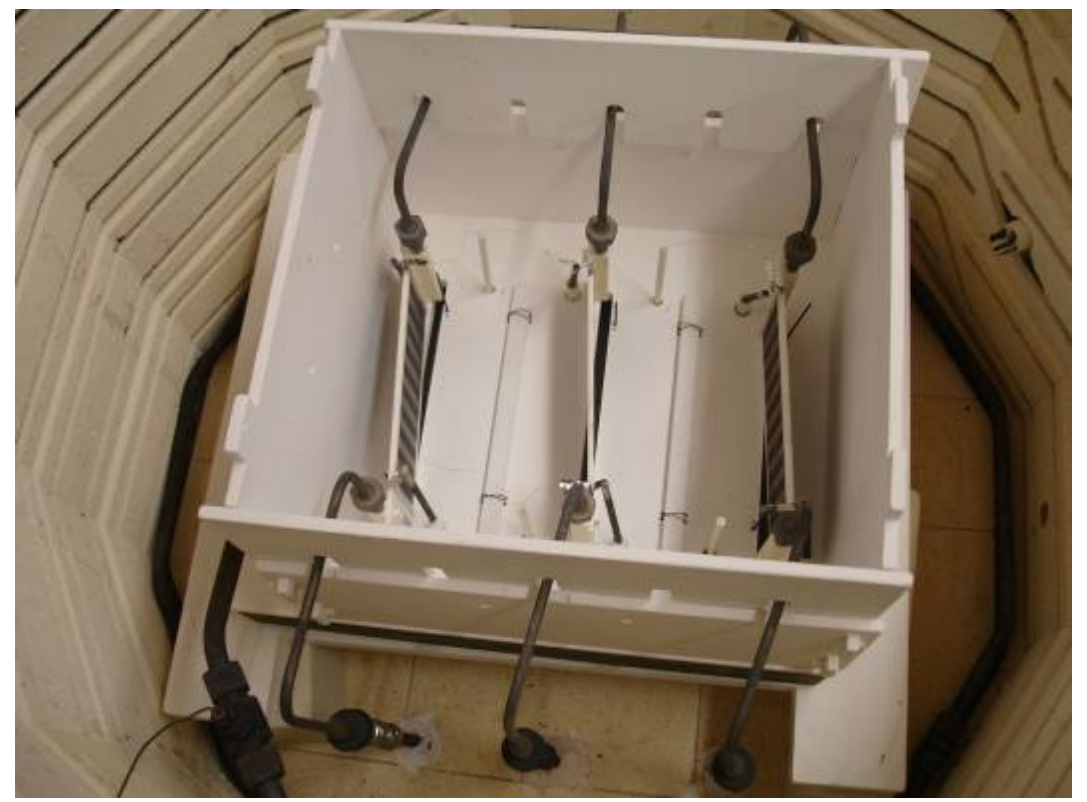

Figure 5.8. Pre-test photograph of triple tube installation inside test box in furnace.

The dewpoint temperatures for the inlet gas / steam mixtures are monitored continuously using precision dewpoint sensors. Pressure is also measured at the dewpoint measurement stations using absolute pressure transducers. Local stream pressure information is required to determine the mole fraction of steam in the gas mixture. Also, since the nitrogen and hydrogen flow rates are fixed by the mass flow controllers, and the steam partial pressure is fixed by the bath temperature, the complete inlet gas composition is precisely known at all times. All gas lines located downstream of the humidifier are heat-traced in order to prevent steam condensation. Gas line temperatures are monitored by thermocouples and controlled by means of computercontrolled SCRs.

The inlet gas mixture is then directed to the high temperature furnace. The electrolyzer is heated and maintained at an appropriate operating temperature $\left(800\right.$ to $\left.830^{\circ} \mathrm{C}\right)$ via computer-based feedback control. The furnace also serves to preheat the inlet gas mixture and the air sweep gas. Oxygen produced by electrolysis is captured by the sweep gas stream and expelled into the laboratory. The electrolysis product stream is directed towards a second dewpoint sensor upon exiting the furnace and then to a condenser through a heat-traced line. The condenser removes most of the residual steam from the exhaust. The final exhaust stream is vented outside the laboratory through the roof.

A photograph of three IP-SOFC tubes installed in the furnace prior to testing is provided in Figure 5.8. The tubes are positioned inside of a ceramic test box. The test box design is based on a design provided by RRFCS.

\subsection{REPRESENTATIVE RESULTS FROM FIRST BATCH OF IP-SOFCS}

Initial performance of the IP-SOFC tubes was characterized through a series of DC potential sweeps performed at several temperatures ranging from 800 to $950^{\circ} \mathrm{C}$. The IP-SOFC tubes are nominally designed to operate at $900^{\circ} \mathrm{C}$. This operating temperature is significantly higher than the $800^{\circ} \mathrm{C}$ operating temperature of the Ceramatec planar stacks. The Ceramatec stacks utilize 
metallic interconnects, so the operating temperature is limited by corrosion concerns. The IPSOFC tubes are nearly 100\% ceramic, so higher operating temperatures are allowed. Higher operating temperatures are desirable for high-temperature electrolysis from the standpoint of both thermodynamics and kinetics.

For testing of the IP-SOFC tubes, tube \#1 was supplied with an inlet flow of hydrogen and steam, using the Bronkhorst CEM system. No nitrogen carrier gas was required with this tube. The inlet mass flow rate of liquid water and hydrogen gas is specified and the resulting inlet dewpoint value was measured using the inlet dewpoint sensor.

Tubes \#2 and \#3 used a heated water bath/bubbler for steam supply. The inlet gas mixture of nitrogen and hydrogen is bubbled through the heated water bath, humidifying the gas mixture to the desired inlet dewpoint value. Nitrogen was used as an inert carrier gas for these tubes in order to increase the total quantity of steam flow. The inlet steam mass flow rates were calculated based on the measured inlet flow rates of hydrogen and nitrogen, and on the measured inlet dewpoint value. The matrix of polarization test conditions studied is presented in Table 5.3.

Tests were performed at temperatures ranging from 800 to $950 \mathrm{C}$ at various flow rates. Tests \#120 were performed with one batch of three tubes. Tests \#21-26 were performed with a second batch of three tubes. Sweeps were performed on only one of the three tubes in batch 2. Long duration tests were also performed. Some representative results will be presented here.

Table 5.3 Summary of Rolls-Royce polarization test conditions.

\begin{tabular}{|c|c|c|c|c|c|c|c|c|c|c|c|c|c|}
\hline \multirow[b]{2}{*}{$\begin{array}{l}\text { Test } \\
\#\end{array}$} & \multirow[b]{2}{*}{$\begin{array}{l}\text { Temp } \\
\text { (C) }\end{array}$} & \multicolumn{2}{|l|}{ Tube \#1 } & \multirow[b]{2}{*}{$\begin{array}{l}\text { Inlet } \\
\mathrm{T}_{\text {dew }} \\
\text { (C) }\end{array}$} & \multirow[b]{2}{*}{$\begin{array}{l}\text { ASR } \\
\left(\Omega \mathrm{cm}^{2}\right)\end{array}$} & \multicolumn{2}{|c|}{ Tube \#2 } & & \multicolumn{2}{|c|}{ Tube \#3 } & \\
\hline & & $\begin{array}{l}\mathrm{H}_{2} \\
(\mathrm{sccm})\end{array}$ & $\begin{array}{l}\mathrm{H}_{2} \mathrm{O} \\
(\mathrm{g} / \mathrm{hr})\end{array}$ & & & $\begin{array}{l}\mathrm{H}_{2} \\
(\mathrm{sccm})\end{array}$ & $\begin{array}{l}\mathrm{N}_{2} \\
(\mathrm{sccm})\end{array}$ & $\begin{array}{l}\text { Inlet } \\
\mathrm{T}_{\text {dew }} \\
\text { (C) } \\
\end{array}$ & $\begin{array}{l}\text { ASR } \\
\left(\Omega \mathrm{cm}^{2}\right)\end{array}$ & $\begin{array}{l}\mathrm{H}_{2} \\
(\mathrm{sccm})\end{array}$ & $\begin{array}{l}\mathrm{N}_{2} \\
(\mathrm{sccm})\end{array}$ & $\begin{array}{l}\text { Inlet } \\
\mathrm{T}_{\text {dew }} \\
\text { (C) } \\
\end{array}$ & $\begin{array}{l}\text { ASR } \\
\left(\Omega \mathrm{cm}^{2}\right)\end{array}$ \\
\hline 2 & 800 & 331.2 & 20.2 & 79.1 & 2.0 & 92.3 & 228.9 & 77.9 & 2.0 & 92.1 & 242.5 & 77.8 & 2.0 \\
\hline 3 & 800 & 631.3 & 13.2 & 64.3 & 2.2 & & & & & & & & \\
\hline 4 & 800 & 451.2 & 22.2 & 76.5 & 1.7 & & & & & & & & \\
\hline 7 & 850 & 331.2 & 20.2 & 79.3 & 1.6 & 92.1 & 228.6 & 77.5 & 1.8 & 92.0 & 242.7 & 77.5 & 2.0 \\
\hline 8 & 850 & 631.3 & 13.2 & 64.2 & Starved & 46.1 & 109.3 & 77.5 & Starved & 46.0 & 121.5 & 73.9 & Starved \\
\hline 9 & 850 & 451.2 & 22.2 & 77.1 & 1.5 & & & & & & & & \\
\hline 10 & 850 & 271.2 & 30.2 & 85.3 & 1.3 & & & & & & & & \\
\hline 11 & 850 & 201.0 & 87.4 & 92.5 & 1.3 & & & & & & & & \\
\hline 12 & 900 & 451.0 & 22.0 & 76.5 & 1.1 & 451.0 & 0.0 & 77.4 & 1.1 & 451.0 & 0.0 & 77.2 & 1.1 \\
\hline 17 & 950 & 202.9 & 22.4 & 84.8 & 1.2 & 92.2 & 231.3 & 80.9 & 1.6 & 92.0 & 242.5 & 80.0 & 1.5 \\
\hline 18 & 950 & 201.3 & 87.3 & 92.3 & 1.3 & & & & & & & & \\
\hline 19 & 800 & 701.3 & 20.0 & 68.7 & 4.8 & 92.2 & 389.7 & 72.0 & 4.2 & 92.1 & 400.6 & 71.9 & 4.1 \\
\hline 20 & 800 & 331.2 & 20.1 & 78.6 & 7.1 & 92.2 & 231.0 & 71.2 & 4.1 & 92.1 & 242.7 & 70.6 & 4.6 \\
\hline 21 & 925 & & & & & 92.0 & 242.0 & 77.8 & 1.3 & & & & \\
\hline 22 & 925 & & & & & 92.0 & 242.0 & 77.8 & 1.3 & & & & \\
\hline 23 & 925 & & & & & 92.0 & 242.0 & 77.8 & 1.3 & & & & \\
\hline 24 & 925 & & & & & 92.0 & 242.0 & 77.8 & 1.3 & & & & \\
\hline 25 & 925 & & & & & 92.0 & 242.0 & 77.8 & 4.0 & & & & \\
\hline 26 & 925 & & & & & 92.0 & 242.0 & 77.8 & 4.5 & & & & \\
\hline
\end{tabular}


Figure 5.9 presents typical polarization curves for the IP-SOFC cells. These curves were generated for a voltage range of 8 to 18 volts, step 0.02 volts. The polarization plots from the three tubes have similar slopes, with corresponding ASR values of approximately $2.1 \mathrm{Ohm} \mathrm{cm}^{2}$. The ASR is calculated from the slope of the polarization curve divided by the number of cells on one side of the tube (10) and multiplied by 2 times the active cell area $\left(\sim 4.3 \mathrm{~cm}^{2}\right)$ as measured by inspection of the tubes. Some evidence of steam starvation is observed at the higher current values for tubes 2 and 3 .

Figure 5.10 presents the polarization sweep results for Test \#8. In this test, the three tubes were intentionally starved, evident in the rapid change in ASR at higher current levels. Sweep test \#15 also exhibited starvation, as evident in Figure 5.11.
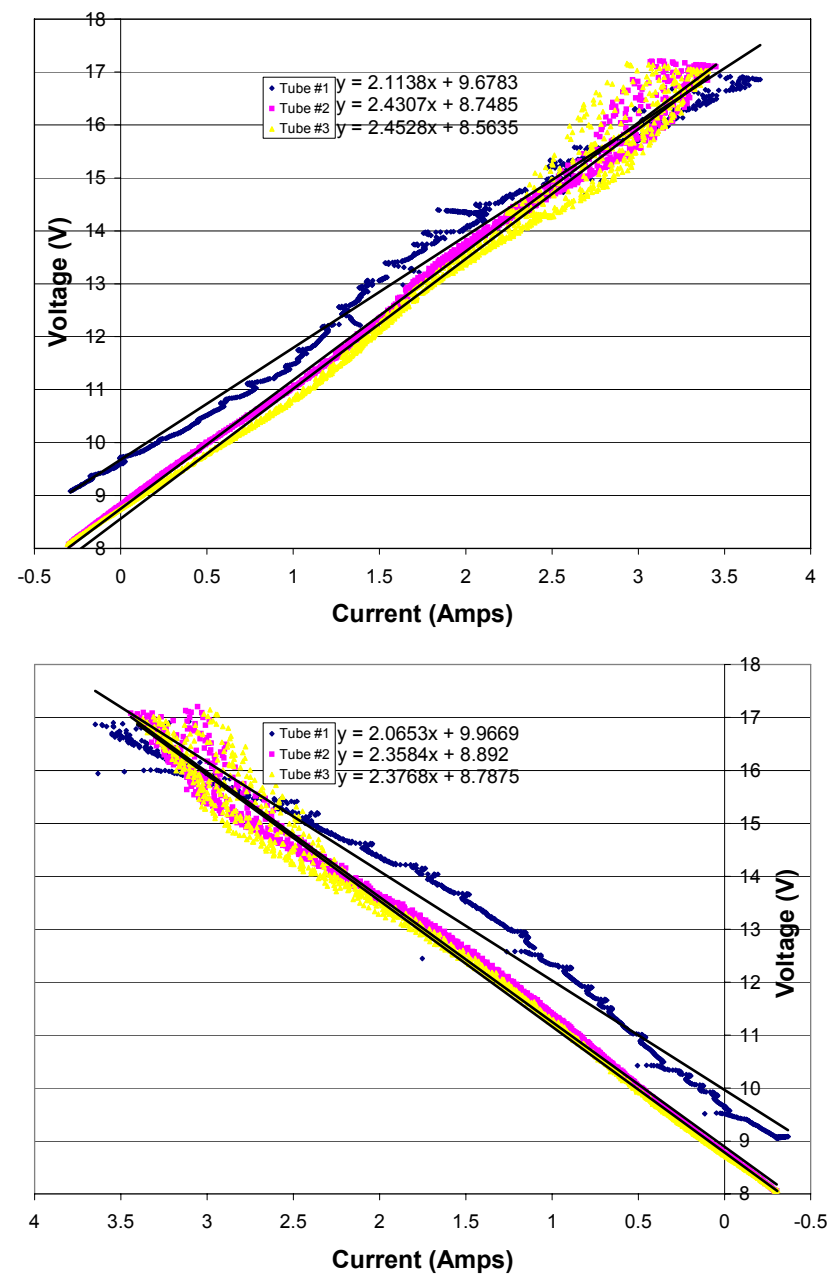

Figure 5.9. Polarization curves for Test $\# 1,800^{\circ} \mathrm{C}$, forward and reverse. 


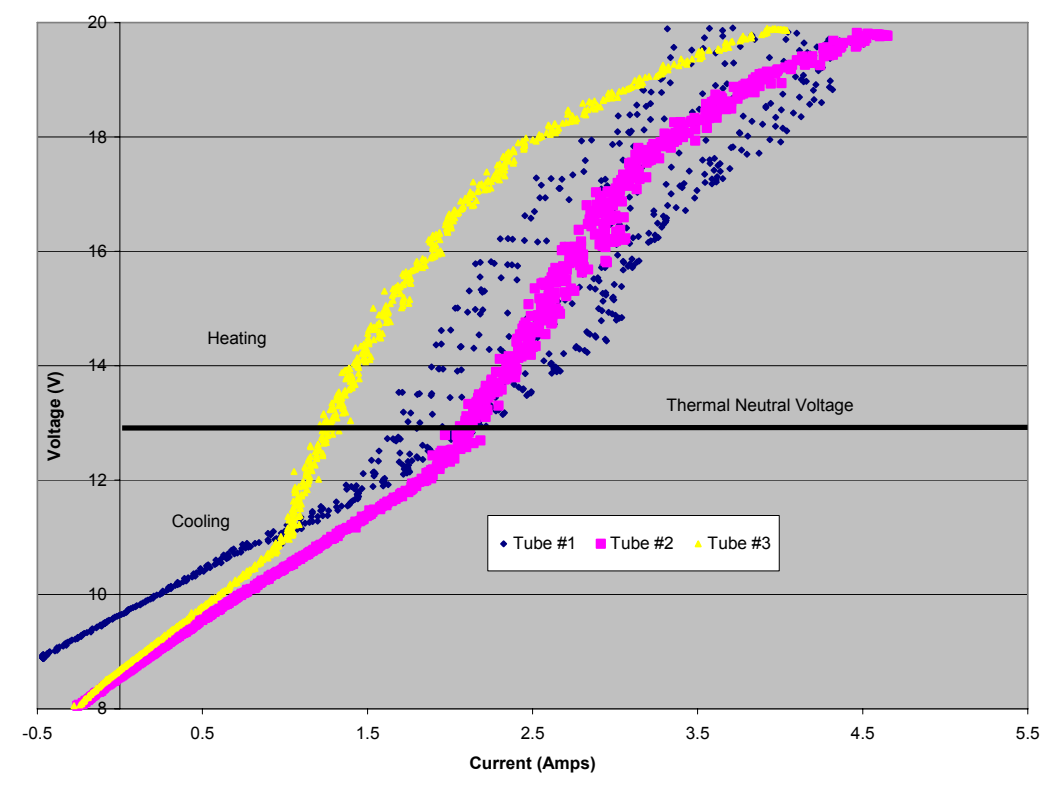

Figure 5.10. Polarization curves for sweep 8, tubes $1-3$, - intentional steam starvation at $850^{\circ} \mathrm{C}$.

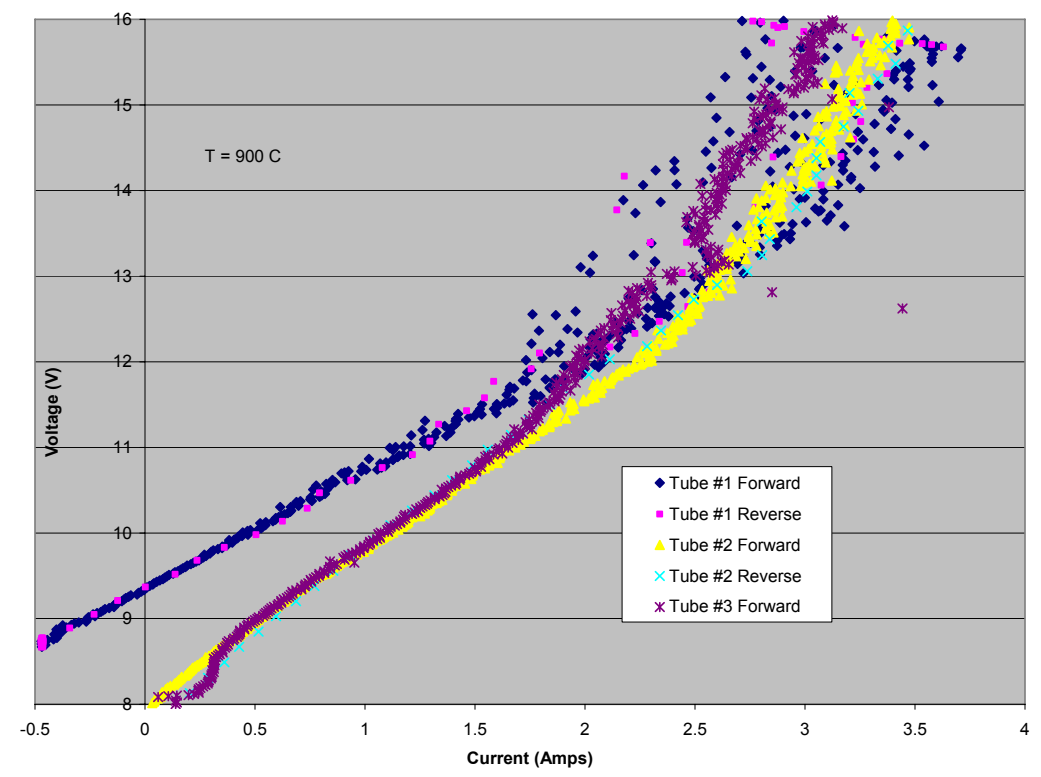

Figure 5.11. Polarization curves for sweep 15, tubes $1-3,900 \mathrm{C}$. Steam starvation is evident. 


\subsection{REPRESENTATIVE LONG DURATION TEST RESULTS FOR IP-SOFC CELLS}

Figure 5.12 shows the heat-up temperature profile for the second batch of IP-SOFC cells tested. The cells were brought up to $930 \mathrm{C}$ over the course of 12 hours.

Test conditions were set to $\mathrm{N}_{2}=242$ sccm, $\mathrm{H}_{2}=92 \mathrm{sccm}, \mathrm{T}_{\text {furnace }}=925^{\circ} \mathrm{C}$, $\mathrm{T}_{\text {bubbler }}=80^{\circ} \mathrm{C}$, Air $=5000 \mathrm{sccm}$, Inlet dew point $77.8^{\circ} \mathrm{C}$. Open-cell potential was $8.2 \mathrm{~V}$. Two forward and two reverse sweeps were performed (Figure 5.13). Typical ASR values were approximately $1.5 \mathrm{ohm} \mathrm{cm}^{2}$ per cell. All four sweeps showed similar results.

At this point, long duration testing was begun (Figure 5.14). The cell was operated in a constant current mode. The operating voltage climbed from $11 \mathrm{~V}$ to over $16 \mathrm{~V}$. At 22 hours, the tube OCV was measured to have fallen to $7.5 \mathrm{~V}$. This value was used to calculate ASR values. The change in OCV indicates that probably one cell was shorted.

A forward and reverse sweep test was conducted as well at the 22 hour point of the test (Figure 5.15). Note the large increase in ASR between the first and second sweeps.
Batch 2, Tubes \#1, \#2, \#3 Heatup

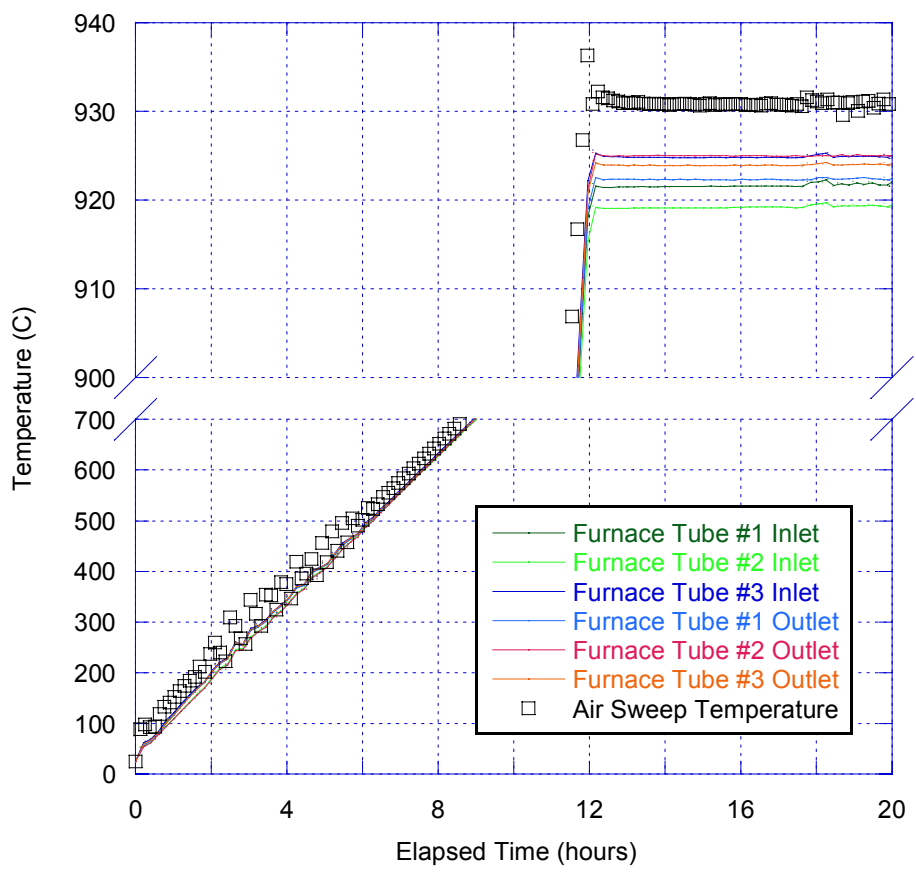

Figure 5.12. Heatup data, tubes 12 , and 3 of batch 2 .

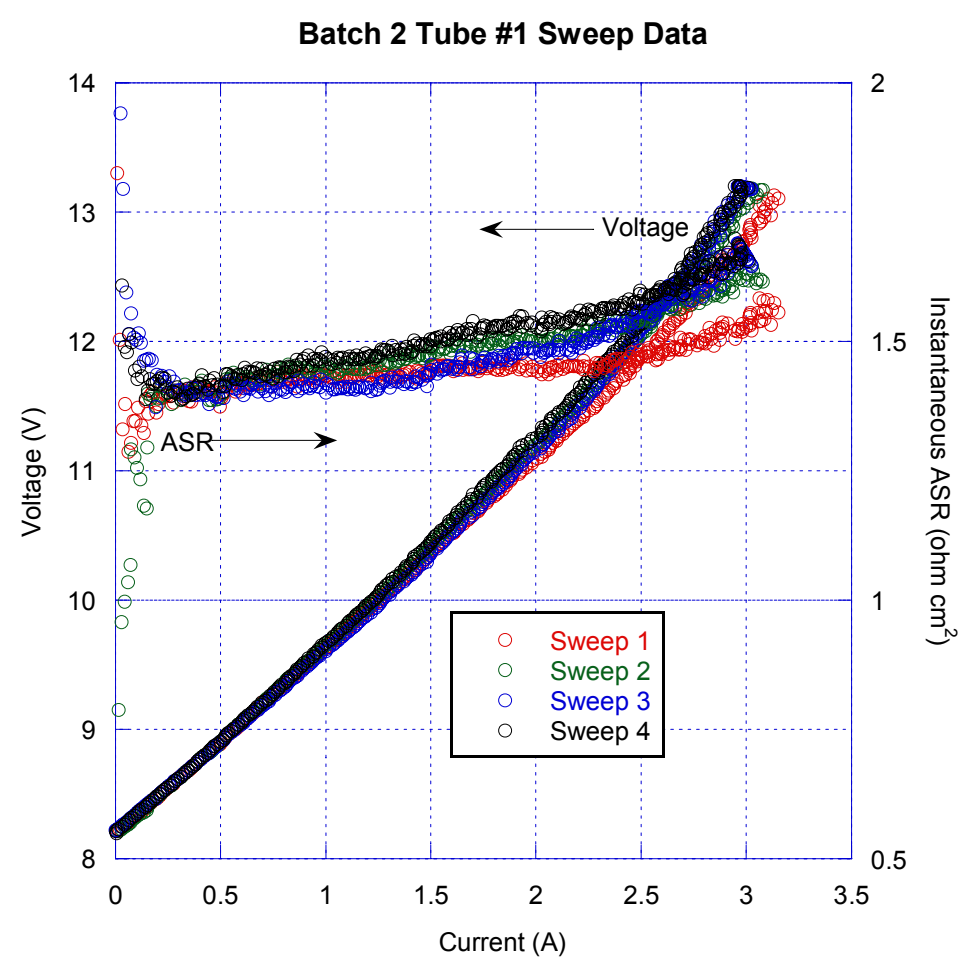

Figure 5.13. Polarization curves and ASR values for sweeps 1-4, tube \#1 of batch 2 . 


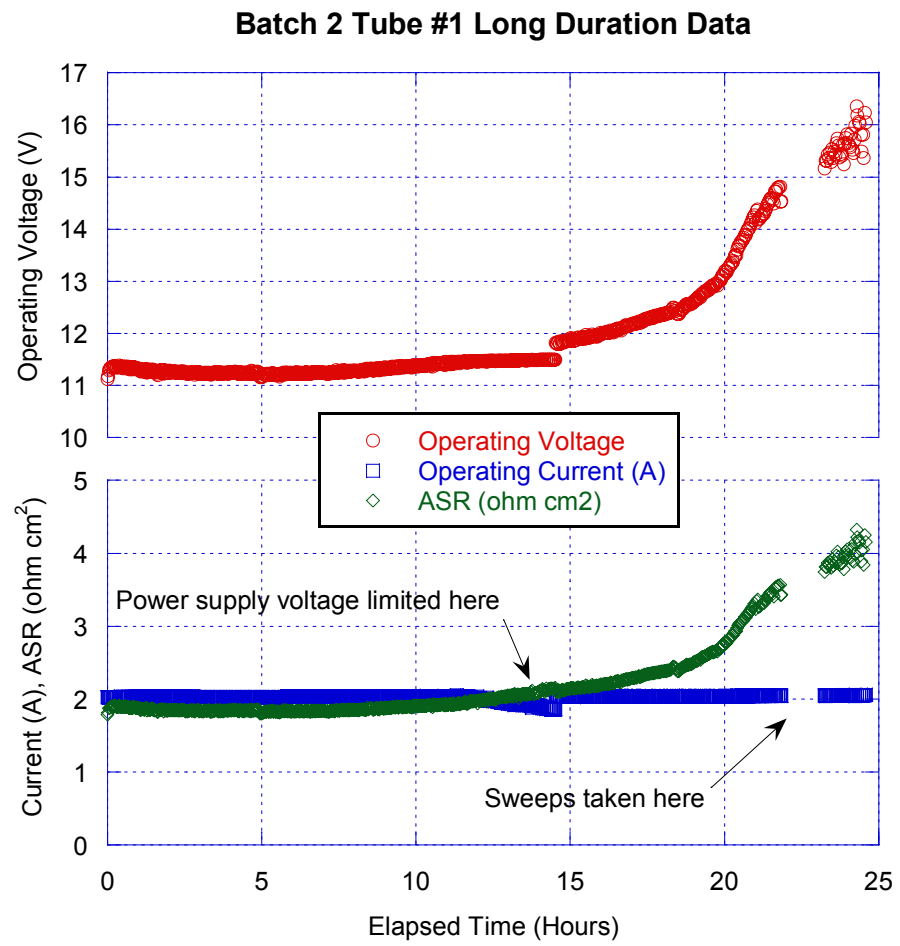

Figure 5.14. Long-duration test data for tube \#1 of batch 2 .

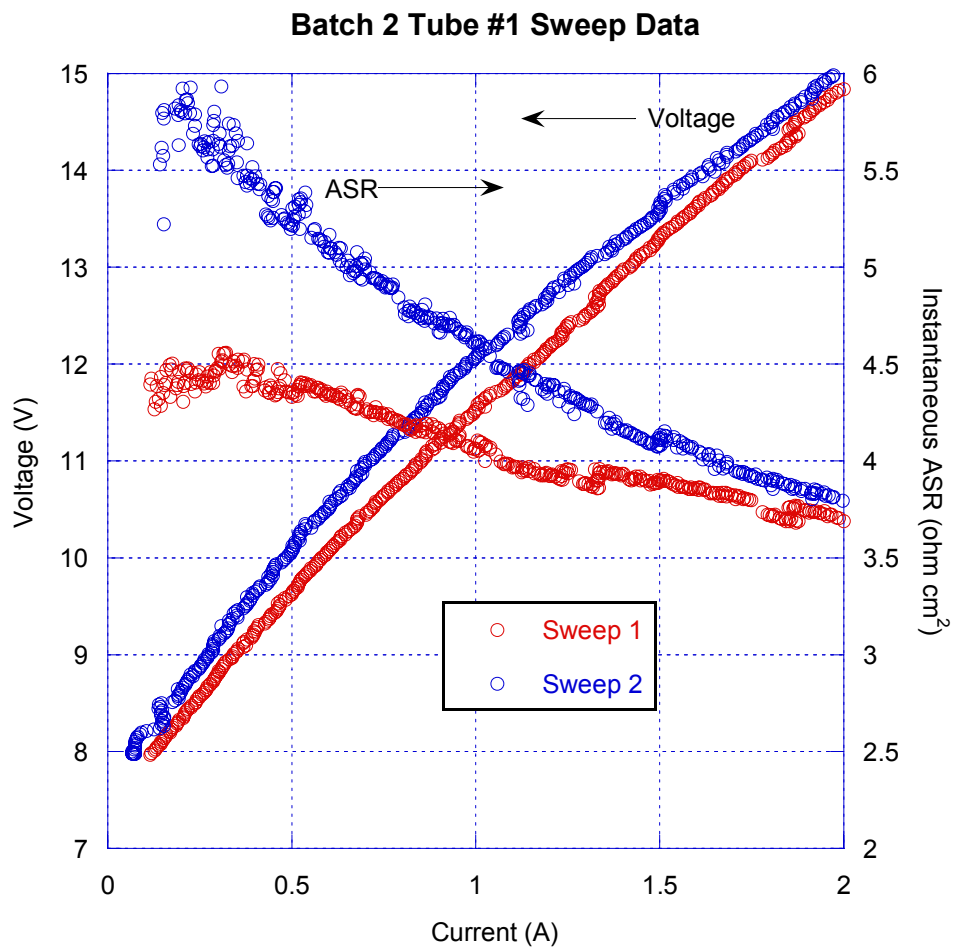

Figure 5.15. Sweeps conducted at 22 hours for tube $\# 1$, batch 2 . 
Below (Figure 5.16) is a "before vs. after" collage for tube \#1 of batch 2. It is of particular interest to note the blistering that has occurred at the leading edge of the first cells. Also evident was some delamination of the electrode material from the electrolyte.

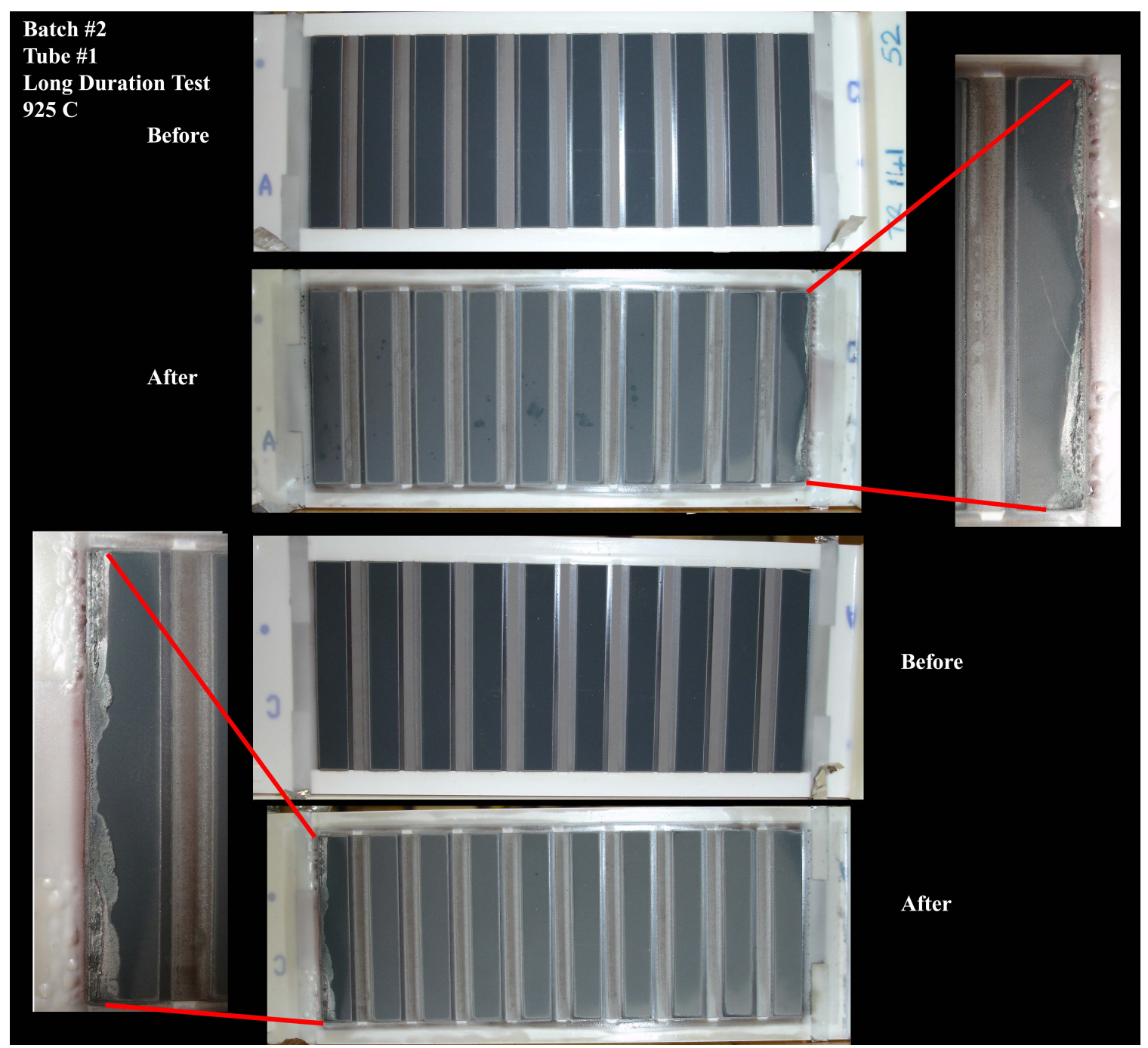

Figure 5.16. Before and after photographs of IP-SOFC tube \#1, long duration test. 


\section{SUMMARY}

This report documents the small-scale high-temperature electrolysis testing activites for FY07 performed at the Idaho National Laboratory and at Ceramatec, Inc under the DOE Nuclear Hydrogen Initiative, High-Temperature Electolysis Program. The activities discussed in this report include tests on single (button) cells, short planar stacks and tubular cells. The objectives of these small-scale tests are to evaluate advanced electrode, electrolyte, and interconnect materials, alternate modes of operation (e.g., coelectrolysis), and alternate cell geometries over a broad range of operating conditions, with the aim of identifying the most promising material set, cell and stack geometry, and operating conditions for the high-temperature electrolysis application. Some of the tests were run in the coelectrolysis mode. Research into coelectrolysis was funded by Laboratory Directed Research and Development (LDRD). A total of 65 single cells, 11 stacks, and 6 IP-SOFC units were tested.

\section{REFERENCES}

1) Forsberg, C. W., "The Hydrogen Economy is Coming. The Question is Where?" Chemical Engineering Progress, December, 2005, pp. 20-22.

2) O’Brien, J. E., Stoots, C. M., Herring, J. S., and Hartvigsen, J. J., "Performance of Planar High-Temperature Electrolysis Stacks for Hydrogen Production from Nuclear Energy," Nuclear Technology, Vol. 158, pp. 118 - 131, May, 2007.

3) Hawkes, G. L., O’Brien, J. E., Stoots, C. M., Herring, J. S., “CFD Model of a Planar Solid Oxide Electrolysis Cell from Hydrogen Production from Nuclear Energy," Nuclear Technology, Vol. 158, pp. 132 - 144, May, 2007.

4) Herring, J. S., O’Brien, J. E., Stoots, C. M., and Hawkes, G. L., "Progress in HighTemperature Electrolysis for Hydrogen Production using Planar SOFC Technology," International Journal of Hydrogen Energy, Vol. 32, Issue 4, pp. 440-450, March 2007.

5) O’Brien, J. E., McKellar, M. G., Hawkes, G. L., and Stoots, C. M., "Development and Validation of a One-Dimensional Model for Use in Large-Scale Process Modeling Analysis," Fifth International Fuel Cell Science, Engineering, and Technology Conference, New York, NY, June 18 - 20, 2007; paper submitted for consideration for the Journal of Fuel Cell Science and Technology.

6) Stoots, C.M., O’Brien, J.E., and Hartvigsen, J., "Test Results of High Temperature Steam/CO2 Coelectrolysis in a 10-Cell Stack," ANS Embedded Topical: International Topical Meeting on the Safety and Technology of Nuclear Hydrogen Production, Control, and Management, June 24 - 28, 2007, Boston, Massachusetts, USA.

7) Stoots, C.M., O’Brien, J.E., and Hartvigsen, J., “Syngas Production Via HighTemperature Coelectrolysis of Steam and Carbon Dioxide In A Solid-Oxide Stack," 
submitted, Fifth International Conference on Fuel Cell Science, Engineering \& Technology, June 18-20, 2007, New York, USA.

8) O’Brien, J. E., McKellar, M. G., Hawkes, G. L., and Stoots, C. M., “Development of a One-Dimensional Co-Electrolysis Model for Use in Large-Scale Process Modeling Analysis," submitted, Fifth International Conference on Fuel Cell Science, Engineering \& Technology, June 18-20, 2007, New York, USA.

9) McKellar, M. G., O’Brien, J. E., Stoots, C. M., and Hawkes, G. L., “A Process Model for the Production of Syngas Via High Temperature Co-Electrolysis," submitted for presentation at the 2007 ASME International Congress and Exposition, Seattle, Nov., 2007.

10) Jensen, S. H., and Mogensen, M., "Perspectives of High Temperature Electrolysis Using SOEC," $19^{\text {th }}$ World Energy Congress 2004, Sydney, Australia, September 5-9, 2004.

11) O’Brien, J. E., Stoots, C. M., Herring, J. S., and Hartvigsen, J. J.,"Hydrogen Production Performance of a 10-Cell Planar Solid-Oxide Electrolysis Stack," Journal of Fuel Cell Science and Technology, Vol. 3, pp. 213-219, May, 2006.

12) Hart, N.T., "Scale-Up Of The IP-SOFC To Multi-Kilowatt Levels", Rolls-Royce internal report F/01/00197/REP URN 04/556, 2004.

13) Private communication "Data transfer to Idaho National Laboratory (INL) for modeling of RRFCS Solid Oxide Cells in Electrolysis. Cell and tube modeling data", document number FDN000000168, 2007.

14) "Solid-Oxide Fuel Cell System For Stationary Power Generation”, Rolls-Royce Fact Sheet 